\title{
Antioxidants and their metabolites: some toxicological aspects
}

Citation for published version (APA):

Rezk, B. M. (2004). Antioxidants and their metabolites: some toxicological aspects. [Doctoral Thesis, Maastricht University]. Maastricht University. https://doi.org/10.26481/dis.20041215br

Document status and date:

Published: 01/01/2004

DOI:

10.26481/dis.20041215br

Document Version:

Publisher's PDF, also known as Version of record

\section{Please check the document version of this publication:}

- A submitted manuscript is the version of the article upon submission and before peer-review. There can be important differences between the submitted version and the official published version of record.

People interested in the research are advised to contact the author for the final version of the publication, or visit the DOI to the publisher's website.

- The final author version and the galley proof are versions of the publication after peer review.

- The final published version features the final layout of the paper including the volume, issue and page numbers.

Link to publication

\footnotetext{
General rights rights.

- You may freely distribute the URL identifying the publication in the public portal. please follow below link for the End User Agreement:

www.umlib.nl/taverne-license

Take down policy

If you believe that this document breaches copyright please contact us at:

repository@maastrichtuniversity.nl

providing details and we will investigate your claim.
}

Copyright and moral rights for the publications made accessible in the public portal are retained by the authors and/or other copyright owners and it is a condition of accessing publications that users recognise and abide by the legal requirements associated with these

- Users may download and print one copy of any publication from the public portal for the purpose of private study or research.

- You may not further distribute the material or use it for any profit-making activity or commercial gain

If the publication is distributed under the terms of Article $25 \mathrm{fa}$ of the Dutch Copyright Act, indicated by the "Taverne" license above, 
Antioxidants and their metabolites:

\section{Some toxicological aspects}

Bashir Mahmoud Rezk 


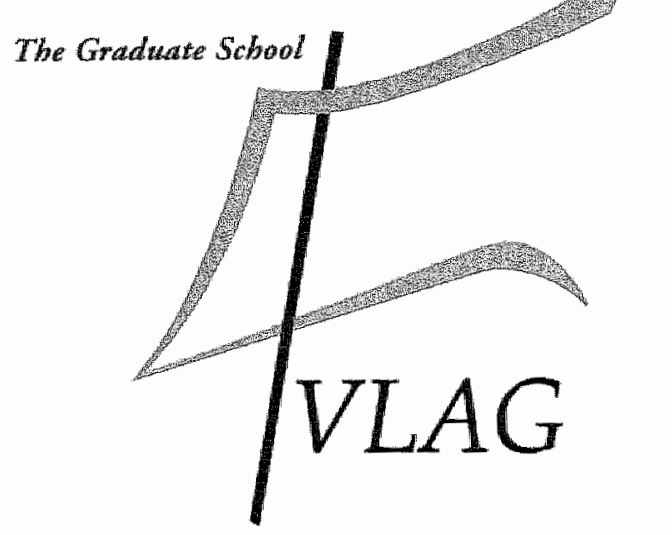

The study presented in this thasis was perfomed at the Nutrition and Toxicology Research lnstinte Mastricht (NUTRIM) which participates in the Gradtate School VLAG (Food Technology, Agrobiotechnology, Nutrition and Health Sciences), accredited by the Royal Netherlands Academy of Arts and Sciences.

ISBN 90-5278-439-6

Universitaire Pers Maastricht 


\title{
Antioxidants and their metabolites: Some toxicological aspects
}

\author{
PROEFSCHRIFT
}

ter verkrijging van de graad van doctor aan de Universiteit Maastricht, op gezag van de Rector Magnificus,

Prof. mr. G.P.M.F. Mols

volgens het besluit van het College van Decanen, in het openbaar te verdedigen op woensdag 15 december 2004 om 10.00 uur

door

Bashir Mahmoud Rezk

Geboren op 23 januari 1972 te El-Beheira, Egypte

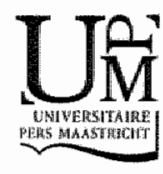




\section{Promotoren:}

Prof. dr. A. Bast

Prof. dr. W.J.F. van der Vijgh

\section{Co-promotor:}

Dr. G.R.M.M. Haenen

\section{Beoordelingscommissile :}

Prof. dr. M. Hofker (voorzitter)

Dr. H. van den Berg (Voedingscentrum, Den Haag)

Prof. dr. J.F.M. Smits

Prof. dr. C.D.A. Stehouwer

Prof. dr. W. Stahl (Heinrich-Heine Universität, Düsseldorf) 

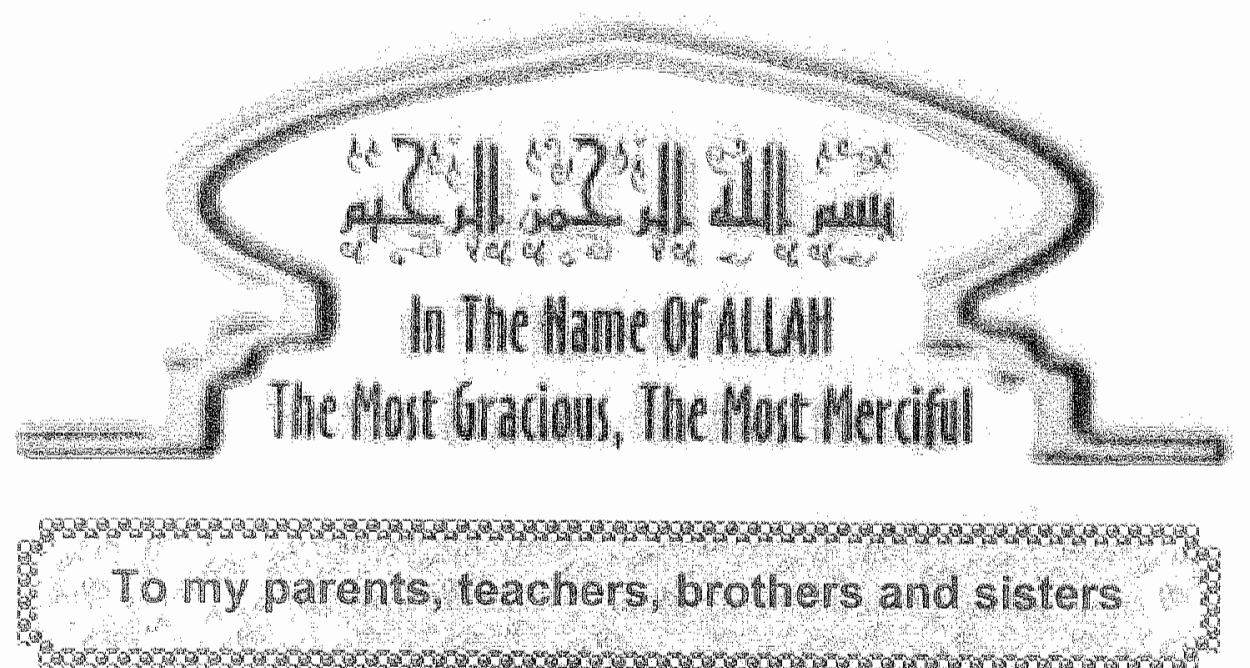



\section{Table of contents}

Preface

Chapter 1

Antioxidants and their metabolites:

Some toxicological aspects.

Chapter 2

The extraordinary antioxidant activity of

vitamin E phosphate. .55

Chapter 3

Vitamin E phosphate is a novel apoptotic agent 71

Chapter 4

The antioxidant activity of phloretin: the disclosure

of a new antioxidant pharmacophore in flavonoids

Chapter 5

Lipoic acid protects efficiently only against a specific form

of peroxynitrite induced damage

Chapter 6

Tetrahydrofolate and 5-methyltetrahydrofolate are

folates with high antioxidant activity.

Identification of the antioxidant pharmacophore

Chapter 7

Summary and conclusions

Samenvatting

Arabic summary

List of publications

Acknowledgements

Curriculum Vitae

Arabic Curriculum Vitae 



\section{Preface}




\section{Preface}

The fundament of toxicology is the risk-benefit analysis. This means that the positive as well as the duegative health effects of all compounds, including antioxidants, have to be assessed and related to each other. Only in this way the rational for the use of a compound can be evaluated.

The beneficial effects of antioxidants are due to their ability to protect against free radical damage. In the diseases and other pathological conditions where free radicals are implicated, the biochemistry may greatly vary, i.e. the radicals involved, their flux, the site where they are generated and the target they attack can differ. Thus for each type of radical damage specific criteria need to be fulfilled by an antioxidant in order to be aclive.

Regarding safety, in the $16^{\text {li }}$ century Paracelsus already stated that all compounds are toxic, provided the dose is high enough. There is no reason to assume that antioxidants should be an exception to this rule. On the contrary, the mega-dosages sometimes recommended make safety a very relevant issue for antioxidants. The biological origin of most antioxidants helps to increase the acceptance of antioxidant supplementation by the general public. The perception is that the biological origin guaranties that antioxidants are not harmful; biological and natural is incorrectly thought to be synonymous to safe.

The adage on the use of antioxidant supplementation seems to be: The more, the better. Iindeed, antioxidant supplements are taken frequently by a great part of the public at a relatively high dose despite our limited knowledge on their beneficial health effect and safety. From a toxicological point of view, the free radical processes as well as the profiles of antioxidants have to be elucidated to a greater extend to be able to further rationalize and optimize antioxidant therapy (1).

An important issue in the use of antioxidants is metabolism (2). Like other bioactive compounds, metabolites formed by phase 1 and phase 2 enzymes can contribute to the beneficial and toxic effect of an antioxidant. More importantly, during the actual antioxidant activity of a free radical scavenging antioxidant, it is converted into a metabolite. The effect of such a metabolite on a biological system is relevant since the metabolite usually contains some residual reactivity of the radical that has been scavenged. In the present thesis, antioxidants are studied from a toxicological point of view. Therefore, the general introduction reviews radicals and four antioxidants that were selected based on biological interest. Both the antioxidant and non-antioxidant effects of these antioxidants are discussed as well as the relative importance of the different chemical forms and metabolites of them. In the following chapters, original research on the four selected antioxidants is described. The focus is on the mechanism of action of these 
compounds. The part of the molecule responsible for the biological effect is studied. This will contribute to more accurate risk-benefit analysis of antioxidants

\section{References}

1 Haenen GRMM, Bast A. The use of vitamin supplements in self-medication. Therapie. 2002; 57 : 119-22.

2 Bast A, Haenen GRMM. The toxicity of the antioxidants and their metabolites. Emiron. Toxicol Pharmacol. 2002; 11:251-258 



\section{Chapter 1}

Antioxidants and their metabolites: Some toxicological aspects

Bashir M. Rezk, Wim J.F. van der Vijgh, Aalt Bast and Guido R.M.M. Haenen 


\section{Free radicals in biology}

A free radical is defined as an atom or molecule that contains one or more unpaired electron(s). The presence of an unpaired electron results in a relatively high reactivity of the free radical compared to the corresponding non-radical since the spin of the unpaired electron is not compensated by another one. In aerobic organisms free radicals appear to be formed sometimes intentionally. The phagocytes (neutrophils, eosinophils, macrophages, monocytes) that defend against e.g. bacteria, generate large amounts of reactive species such as superoxide, $\mathrm{O}_{2}{ }^{*}$. Also other reactive species such as hydrogen peroxide, $\mathrm{H}_{2} \mathrm{O}_{2}$ and hypochlorous acid, $\mathrm{HOCl}$ are generated. These reactive species are formed to kill bacteria (1-4), however, they also induce collateral damage to healthy tissue at the site of infection.

Another example of an intentionally generated radical is the nitric oxide radical, $\mathrm{NO}^{*}$. It is produced by nitric oxide synthases (NOS) and plays a key role in different physiological events such as vasodilatation and neurotransmission $(5,6)$. NO* readily reacts with $\mathrm{O}_{2}{ }^{*}$, and the product formed, i.e. peroxynitrite (ONOOH) is highly reactive (7). Peroxynitrite is also generated during the bactericidal action of phagocytes and again this reactive compound may induce collateral damage (8).

Free radicals are also generated accidentally in living cells as the result of numerous processes such as endogenous metabolic reactions. Exogenous triggers of radical formation include pollutants, xchobiotics, and radiation (9). Excessive free radical formation plays a role in the etiology of many pathological processes such as cancer, cardiovascular disease, neurological disease, rheumatoid arthritis, cataract, emphysema, diabetes, and Alzheimer's disease (10-12).

Free radicals of biological interest are often divided into oxygen centred and nitrogen centred radicals. Reactive oxygen species (ROS) is a collective term that includes both oxygen centred radicals and certain oxygen containing non-radicals that are oxidizing agents or easily converted into radicals. In the reactive nitrogen species (RNS) the reactivity of the species is located on or near a nitrogen atom. Typical physiological relevant ROS and RNS are given in Table 1 . The adjective "reactive" is not always appropriate; $\mathrm{H}_{2} \mathrm{O}_{2}, \mathrm{O}_{2}$ and $\mathrm{NO}^{*}$ quickly react only with very few molecules. $\mathrm{OH}$ reacts instantaneously with almost everything. $\mathrm{RO}_{2}{ }^{\circ}, \mathrm{RO}^{*}, \mathrm{HOCl}_{3} \mathrm{NO}_{2}{ }^{*}, \mathrm{ONOOH}$, and $\mathrm{O}_{3}$ have a reactivity that lies in between these extremes $(10-12)$.

$\mathrm{NO}^{*}$ and $\mathrm{O}_{2}^{*-}$ are probably the most studied free radicals in biology. In 1997 , the Journal of Nitric Oxide: Biology and Chemistry, a joumal on $\mathrm{NO}^{*}$ research, has been founded. This reflects the physiological, toxicological and medical appreciation of $\mathrm{NO}^{\circ}$, which has not yet appeared for $\mathrm{O}_{2}{ }^{*}$. Despite many similarities between both radicals, $\mathrm{NO}^{*}$ research, after a relatively short time span, has been awarded a Nobel Prize in 1998 
$(13,14)$, whereas research on $\mathrm{O}_{2}$ ", a radical with a much larger track recond in scienee, has not received swch an appreciation.

Table 1. Radical and non-radical ractive species

\begin{tabular}{|c|c|c|}
\hline Reactive species & Radicals & Non-radicals \\
\hline \multirow[t]{6}{*}{ ROS } & Superoxide, $\mathrm{O}_{2}{ }^{*-}$ & Hydrogen peroxide, $\mathrm{H}_{2} \mathrm{O}_{2}$ \\
\hline & Hydroxyl, $\mathrm{OH}^{\circ}$ & Hypochlorous acid, $\mathrm{HOCl}$ \\
\hline & Peroxyl, $\mathrm{RO}_{2}$ & Hypobromous acid, $\mathrm{HOBr}$ \\
\hline & Alkoxyl, $\mathrm{RO}^{*}$ & Hypoiodous acid, $\mathrm{HOL}$ \\
\hline & Hydroperoxyl, $\mathrm{HO}_{2}$ & Ozone, $\mathrm{O}_{3}$ \\
\hline & Trioxocarbonate, $\mathrm{CO}_{3}{ }^{\circ-}$ & Singlet oxygen, $\mathrm{O}_{2}$ \\
\hline \multirow[t]{12}{*}{ RNS } & Nitric axide, $\mathrm{NO}^{\circ}$ & Nitrous acid $\mathrm{HNO}_{2}$ \\
\hline & Nitrogen dioxide, $\mathrm{NO}_{2}{ }^{\circ}$ & Dinitrogen trioxide, $\mathrm{N}_{2} \mathrm{O}_{3}$ \\
\hline & & Dinitrogen tetroxide, $\mathrm{N}_{2} \mathrm{O}_{4}$ \\
\hline & & Nitryl chloride, $\mathrm{NO}_{2} \mathrm{Cl}$ \\
\hline & & Nitronium cation, $\mathrm{NO}_{2}$ \\
\hline & & Nitrosyl cation, $\mathrm{NO}$ \\
\hline & & Nitrosyl anion, $\mathrm{NO}^{\circ}$ \\
\hline & & Peroxynitrite, ONOO \\
\hline & & Peroxynitrous acid, ONOOH \\
\hline & & Nitrosoperoxycarbonate anion, $\mathrm{O}=\mathrm{N}-\mathrm{OOCO}_{2}{ }^{-}$ \\
\hline & & Nitrocarbonate anion, $\mathrm{O}_{2} \mathrm{~N}-\mathrm{OCO}_{2}^{\circ}$ \\
\hline & & Alkyl peroxynitrites, ROONO \\
\hline
\end{tabular}

This reflects the physiological, toxicological and medical appreciation of $\mathrm{NO}^{*}$, which has not yet appeared for $\mathrm{O}_{2}{ }^{*}$. Despite many similarities between both radicals. NO" research, after a relatively short time span, has been awarded a Nobel Prize in 1998 $(13,14)$, whereas research on $\mathrm{O}_{2}{ }^{\circ}$, a radical with a much larger track record in science, has not received such an appreciation.

As stated above, when $\mathrm{NO}^{\circ}$ and $\mathrm{O}_{2}{ }^{*-}$ meet, they react fast with each other and form the non-radical peroxynitrite $(\mathrm{ONOOH})$. In biollogical systems carbon dioxide $\left(\mathrm{CO}_{2}\right)$ is present in relatively high concentrations. The rate of the reaction of $\mathrm{CO}_{2}$ with $\mathrm{ONOOH}$ clearly exceeds the rate of reaction of $\mathrm{ONOOH}$ with most biological substrates (15). The reaction of $\mathrm{NOO}$ with $\mathrm{CO}_{2}$ generates an adduct, the nitrosoperoxycarbonate anion $\left(\mathrm{ONOOCO}_{2}\right)$. $\mathrm{ONOOCO}_{2}{ }^{-}$is, like $\mathrm{ONOOH}$, very reactive. In biological systems $\mathrm{ONOOCO}_{2}^{-}$is the species that is ultimately responsible for the toxicity that starts when $\mathrm{NO}^{\circ}$ and $\mathrm{O}_{2}{ }^{*}$ combine. $\mathrm{ONOOCO}_{2}$ fragments into the reactive free radicals $\mathrm{CO}_{3}{ }^{*}$ and $\mathrm{NO}_{2}{ }^{\circ}$. Alternatively, $\mathrm{ONOOCO}_{2}^{-}$can be rearranged into nitrocarbonate anion 
$\left(\mathrm{O}_{2} \mathrm{NOCO}_{2}\right)$ which, in thrn, undergoes hydrolysis by water to give the relatively nontoxic products nitrate $\left(\mathrm{NO}_{3}\right)$ and carbonate $\left(\mathrm{CO}_{3}{ }^{2-}\right)$.

Hydrogen peroxide $\left(\mathrm{H}_{2} \mathrm{O}_{2}\right)$ is from a toxicological point of view a very important nonradical ROS because of its ability to penetrate biological membranes. It is easily converted into more reactive species. Stimulated neutrophils generate $\mathrm{O}_{2}{ }^{*}$ and its dismutation product, $\mathrm{H}_{2} \mathrm{O}_{2}$, and release the heme enzyme myeloperoxidase. Myeloperoxidase catalyses the oxidation of halide ions $\left(\mathrm{Cl}^{\circ}, \mathrm{Br}^{\circ}, \mathrm{r}\right)$ to hypohalous acid at the expense of $\mathrm{H}_{2} \mathrm{O}_{2}$. It has been estimated that up to $80 \%$ of the $\mathrm{H}_{2} \mathrm{O}_{2}$ generated by activated neutrophils is used to form $\mathrm{HOCl}(1-4)$.

Hypochlorous acid (HOCl) is a highly reactive species and is a strong 2 electron oxidator but a weak 1 electron oxidator (16). It is capable of oxidizing many important biomolecules such as plasma membrane ATPases, collagen, $\alpha_{1}$-antiproteinase, nucleotides, RNA, DNA and DNA repair enzymes $(4,17)$. HOCl can react with nitrite $\left(\mathrm{NO}_{2}\right)$ to form nitryl chloride $\left(\mathrm{NO}_{2} \mathrm{Cl}\right)(18,19)$. $\mathrm{NO}_{2} \mathrm{Cl}$ is capable of nitrating, chlorinating, dimerising phenolic compounds such as tyrosine as well as protein modification $(18,19)$. The hydroxyl radical ( $\mathrm{OH}$ ) is extremely reactive, it is probably capable of doing more damage to biological systems than any other $\operatorname{ROS}(10,11,20)$. The radical is formed from $\mathrm{H}_{2} \mathrm{O}_{2}$ in a reaction catalysed by metal ions $\left(\mathrm{Fe}^{2+}\right.$ or $\left.\mathrm{Cu}^{+}\right)(21,22)$. $\mathrm{OH}$ can be also formed by the reaction of $\mathrm{HOCl}$ with $\mathrm{O}_{2}{ }^{*}$ (23).

Organic peroxyl radicals $\left(\mathrm{RO}_{2}{ }^{\circ}\right)$ also have been identified as important reactive species in physiology (24). They are generated throughout the body when organic molecules, e.g. polyunsaturated fatty acids, react with radicals. The presence of double bonds in a polyunsaturated fatty acid weakens the carbon-hydrogen bond of the carbon atom adjacent to a double bound. Reactive free radicals ( $\mathrm{R}^{*}$ ), e.g. "OH, have the capacity to abstract the hydrogen atom from the carbon-hydrogen bound, preferably located between two double bounds (Fig. 1). Because only the hydrogen atom is abstracted, an unpaired electron is left on the carbon. This lipid radical undergoes molecular rearrangement resulting in a conjugated diene (25). The conjugated diene radical rapidly reacts with oxygen to form a peroxyl radical. Subsequently, the lipid peroxyl radical abstracts a hydrogen atom from a second polyunsaturated fatty acid resulting in a lipid hydroperoxide and a new lipid radical. This new lipid radical, on its turn, rearranges into a conjugated diene and the chain reaction is continued by its reaction with oxygen and generation of a second lipid hydroperoxide and a third lipid radical. The formed carbon centred lipid radical continues the process. 

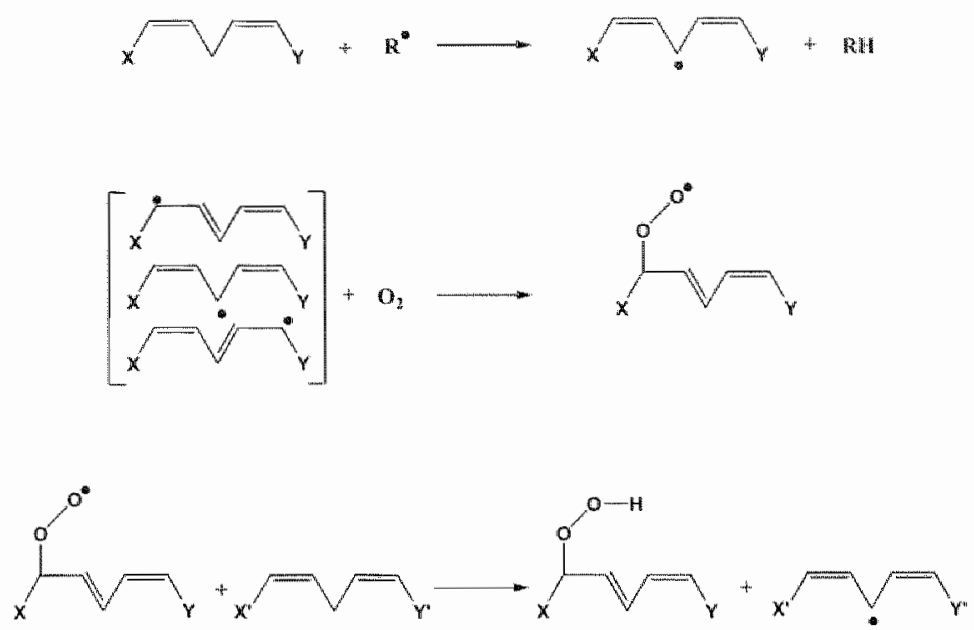

Fig. 1. Reactions taking place in the process of lipid peroxidation. $R^{*}$ is a radical that starts lipid peroxidation.

This chain reaction or propagation will stop when one of the substrates (the lipid or oxygen) is consumed or the reaction is terminated because two radicals combine. Under physiological conditions, peroxyl radicals can react with $\mathrm{NO}^{\circ}$, generating a non-radical that has been identified as alkyl peroxynitrite (ROONO) (26). If the ROONO simply rearranges to an organic nitrate, $\mathrm{NO}^{\circ}$ may serve as an antioxidant (27). Alternatively, ROONO can decompose to nitrogen dioxide $\left(\mathrm{NO}_{2}\right)$ and an oxyl radical $\left(\mathrm{RO}^{\circ}\right)(26)$. In this case, $\mathrm{NO}^{*}$ will induce a more reactive species and act as a prooxidant (26). The chain reaction can also be interrupted by antioxidants such as vitamin $\mathrm{E}$ (28).

\section{Antioxidant defence}

As described above, free radicals are continuously produced in the living cells and they may damage almost any cellular component. Fortunately, the cell is equipped with an elaborate antioxidant defence system, from either endogenous or exogenous origin, that protects cellular components from free radical induced damage. An antioxidant is defined as a compound which, in a relatively low concentration, prevents or delays the oxidation of another compound. Directly acting antioxidants do so by reacting with radicals or other reactive species. The directly acting antioxidants can be divided into enzymatic antioxidants and non-enzymatic antioxidants. 


\section{I Enzymatic antioxidants}

\subsubsection{Catalase}

Catalase consists of four protein subunits, each containing a heme group and NADPH (29). The enzyme catalyses the conversion of hydrogen peroxide to water and oxygen $(29,30)$. Catalase is largely located within cells in the peroxisomes, which also contain most of the enzymes capable of generating hydrogen peroxide. The amount of catalase in cytoplasm and subcellular compartments has not been established accurately, because peroxisomes are easily ruptured during manipulation. The highest activity is present in liver and erythrocytes but some catalase is found in all tissues. Glucose 6-phosphate dehydrogenase deficiency is a genetic disorder in which NADPH is lowered in mature erythrocytes. It has been suggested that the hemolysis observed in glucose 6-phosphate dehydrogenase deficiency is derived from inhibition of catalase rather than from less glutathione peroxidases or glutathione reductase activity (31).

\subsubsection{Gluthione peroxidase and glutahione reductase}

There are at least four different glutathione peroxidases (GPx) in mammals, all of them contain selenium at the active site. Deficiency might occur as a result of selenium deficiency $(32,33)$. The highest concentrations are found in the liver, although $\mathrm{GPx}$ is widely distributed in almost all tissues. GPx catalyses the reduction of hydrogen peroxide or other hydroperoxides such as a lipid hydroperoxide using reduced glutathione (GSF) as a cofactor (34). The catalytic mechanism for the reduction of hydroperoxides by GPx involves oxidation of the active site selenolate ( $\mathrm{Se}$ ) to selenenic acid ( $\mathrm{SeOH}$ ) In this reaction a hydroperoxide (ROOH) is converted into the corresponding, far less reactive alcohol ( $\mathrm{ROH}$ ). Upon addition of one molecule of $\mathrm{GSH}$, the SeOH is transformed to a selenenylsulfide adduct with GSH (Se-SG), which can be regenerated to the active Se" and glutathione disulfide (GSSG) by addition of a second molecule of GSH (34). Thus, in the reaction, two molecules of GSH are oxidized to GSSG. GSSG can be reduced by the NADPH-dependent flavoenzyme glutathione reductase (GR), the major mammalian GSSG-reducing enzyme which has a similar tissue distribution as GPX (3537). The activity of GPx is dependent on the constant availability of GSH and the ratio of GSH/GSSG is usually kept very high as a result of the activity of GR $(36,37)$.

\subsubsection{Superovide dismutase}

Superoxide dismutase (SOD) was the first antioxidant enzyme characterized to have a free radical as a substrate. It catalyses the dismutation of $\mathrm{O}_{2}{ }^{*}$ to $\mathrm{H}_{2} \mathrm{O}_{2}$ and $\mathrm{O}_{2}(38,39)$. 
There are three forms of superoxide dismutase in mammalian tissues, each with a specific subcellular location and different tissue distribution.

(1) Manganese superoxide dismutase (Mn-SOD), an 80-kDa tetrameric enzyme, is found in mitochondria of almost all cells in relatively high amounts. It forms a primary line of defence against $\mathrm{O}_{2}{ }^{*}$ that is formed due to the leakage of electrons from the respiratory chain $(40,41)$.

(II) Copper zinc superoxide dismutase (CuZn-SOD) is a cytosolic $32-\mathrm{kDa}$ dimeric enzyme $(38,42)$. Mice with deletion of the gene that codes for CuZn-SOD, develop normally but show enhanced susceptibility to central nervous system injury (43). A specific form of the lethal neurodegenerative disease amyotrophic lateral sclerosis (ALS) is caused by mutations in the gene for cytosolic CuZn-SOD (44).

(III) Extracellular superoxide dismutase (EC-SOD) has been identified by Marklund (45) and is a secretory copper and zinc containing SOD distinct from the CuZn-SOD described above. EC-SOD is highly synthesized in fibroblasts and endothelial cells and it is released into the circulation upon the injection of heparin (46). EC-SOD might play a role in the regulation of the vascular tone, because $\mathrm{NO}^{*}$ or another closely related endothelial derived relaxing factor is inactivated in the plasma by $\mathrm{O}_{2}{ }^{\circ}$ (47).

\subsection{Non-enzymatic antioxidants}

Directly acting, non enzymatic antioxidants usually act by directly scavenging free radicals. These antioxidants can receive an electron from a radical or donate an electron to a radical with the formation of relatively stable products. They can be divided into lipophilic and hydrophilic antioxidants.

\subsubsection{Vitamin $E$}

Lipophilic antioxidants scavenge radicals in membranes and lipoprotein compartments and are crucial in preventing lipid peroxidation. The most important lipophilic antioxidant is probably vitamin $\mathrm{E}$ (VE) (28). VE was discovered in 1922 by Evans and Bishop (48) and recognized as a dietary factor in animal nutrition which was needed for normal fertility. They found that in pregnant rats deprived of VE, the fetuses do not develop normally but are resorbed. Rat fetal resorption is still the bioassay for the determination of the vitamin E activity of a preparation. In 1936 the chemical diversity of VE was observed when two vitamers were isolated and characterized from wheat germ oil (49). These two vitamers were assigned as $\alpha$ - and $\beta$-tocopherol. The name was derived from Greek words 'tokos' (childbirth) and 'phorein' (to bring forth).

In the following years two additional tocopherols, $\gamma$ - and $\delta$-tocopherol $(50,51)$ as well as the tocotrienols (52) were isolated from edible plant oils. The tocopherols $(\alpha, \beta, \gamma$, and $\delta$ ) have a hydrocarbon tail and a chromanol head (with two rings: one phenolic and the 
other heterocyclic) in which the number and position of the methyl groups differ. The tocotrienols $(\alpha, \beta, \gamma$, and $\delta)$ are structurally similar to tocopherols but have an unsaturated hydrocarbon tail. In biomembranes, the hydrocarbon tail of VE intercalates with fatty acid residues of phospholipids, while the chroman head faces the cytosol, although it is still located in the lipophilic region.

The 4 tocopherols each have 3 independent asymmetrical carbon atoms giving rise to 8 different stereoisomers of each tocopherol. The 4 tocotrienols have one asymmetrical carbon atom, and thus two stereoisomers of each of these vitamers exist. This makes a total of 40 different vitamers of VE. The vitamer of VE that has the highest vitamin activity in vivo is RRR- $\alpha$-tocopherol.

\subsubsection{Bioavailability of vitamin $E$}

VE is a vitamin and thus it has to be provided by foods and supplements to maintain good health. Major dietary sources of VE are vegetable oils, nuts, foods such as grains and dairy products $(53,54)$. Because of its hydrophobicity, $V E$ requires special transport mechanisms in the aqueous enviromment of plasma, body fluids and cells.

The absorption of tocopherols and tocotrienols follows that of lipids and they are taken up in chylomicrons. The chylomicrons are transported via the lymph and they reach the blood stream in the ductus thoracicus (55). Only free tocopherols and tocotrienols appear in chylomicrons and in blood, VE esters are hydrolysed in the gastrointestinal tract e.g. by pancreatic esterases (56). The triacylglycenols present in chylomicrons are hydrolysed in the blood by the endothelial-bound lipoprotein lipase. The chylomicron remnant formed in this way still contains the VE. In hepatocytes, the $\alpha$-tocopherol transfer protein $(\alpha-T T P)$ specifically filters RRR- $\alpha$-tocopherol from all incoming tocopherols and transfers it into nascent very low-density lipoproteins (VLDL) (57).

About half of the resulting VLDL is transformed into low-density lipoproteins (LDL) by hepatic lipase. LDL is the major carrier for RRR-a-tocopherol in blood, supplying it to tissues in a transport process involving the $\mathrm{LDL}$ receptor. The intracellular transport of vitamin $\mathbb{E}$ is mediated by tocopherol-associnted proteins (TAPs). Again RRR- $\alpha-$ tocopherol is the vitamer with the highest affinity for these proteins. TAP protects tocopherol against oxidation and might be involved in VE cell signalling. As a consequence of its high affinity to these proteins, the half hife and the biological activity of RRR-a-tocopherol are much higher than those of the other stereoisomers which are more readily excreted from the plasma and secreted with the bile $(57,58)$.

\subsubsection{Antioxidant activity of vitamin $E$}

The best-known biochemical activity of $\mathrm{VE}$ is the protection of biomembranes against endogenous and exogenous oxidative stress. VE inhibits lipid peroxidation by scaveng- 
ing of lipid peroxyl radicals. In its tole as a chain-breaking antioxidant, the hydrogen atom from the aromatic hydroxyl group of VE is rapidly abstracted by the lipid peroxyl radicall resulting in formation of a lipid hydroperoxide and a VE radical (Fig. 2) (59). Beside lipid peroxyl radicals, VE is also able to efficiently scavenge a number of other reactive species such as singlet oxygen (60), peroxynitrite (61), nitrogen dioxide (62), ozone (63) and superoxide (64).

The VE radical produced during its antioxidant activity, is relatively stable due to delocalization of the unpaired electron over the chroman head (Fig 2). This makes the radical relatively un-reactive. The oxygen in the heterocyclic ring of the chroman head is fixed in such a way that there is a considerable overlap between the $2 \mathrm{p}$-type orbital of a lone pair of the oxygen and the aromatic $\pi$-system (59). This allows stabilization of the VE radical by interaction of the umpaired electron with a lone pair of that oxygen, and in this way the delocalisation is enhanced (59).

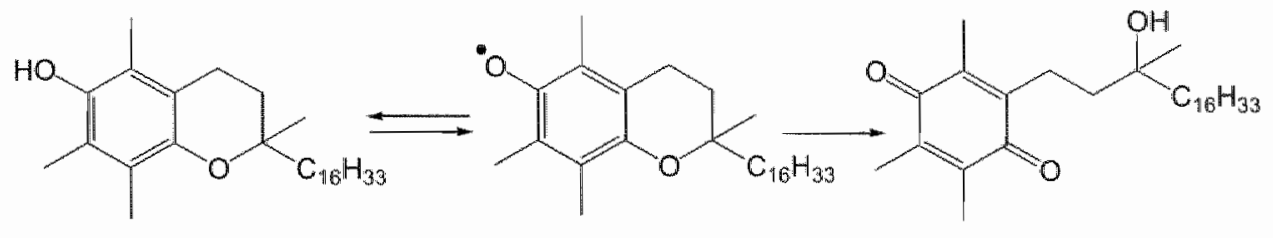

$\alpha$-Tacopherol a.-Tocopheroxyl radical $\alpha$-Tocopherol quinone
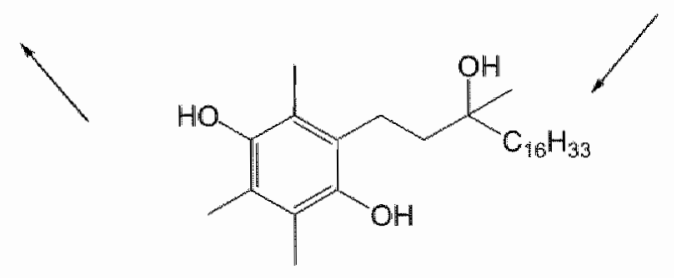

a.m Tocopherol hydroquinone

Fig. 2. Oxidation and regeneration of $\alpha$-tocopherol.

In the antioxidant network, it has been proposed that regeneration of VE from VE radicals can occur by interaction of the VE radical with vitamin $C(65)$, GSH or reduced Q10 (66). Alternatively, the VE radical can be further oxidized into a quinone (Fig. 2). In this oxidation reaction, the heterocyclic ring of the chroman head is opened $(67)$. Interestingly, in vivo, the quinone is readily reduced into the corresponding hydroquinone (67-69). The antioxidant activity of $\alpha$-tocopherol hydroquinone is superior to that of $\alpha$ tocopherol $(59,69,70)$. Kohar et al. (68) suggested that in vivo not VE itself but instead VE-hydroquinone displays the actual antioxidant activity ascribed to VE. VE-quinone administered to human volunteers is partly converted into VE (71).

Also prooxidant activities have been ascribed to VE. VE can reduce transition metals like iron and reduced iron might generate free radicals by reacting with lipid hydroper- 
oxides which are present in arterial plaques. This mechanism was put forward as an explanation for the rise in fatal myocardial infarctions observed in a clinical study on VE supplementation (72).

The VE radical that is formed during the antioxidant activity still has sufficient residual reactivity to promote radical damage. For example, the VE radical can react with a polyunsaturated fatty acid, thus starting the chain reaction again that was interrupted once VE scavenged the lipid peroxyl radical. As also mentioned above, elimination of the $V E$ radical can occur by interplay with other antioxidants present in the so-called antioxidant network; Vitamin C, GSH or reduced Q10 have the ability to regenerate VE from is VE radical.

VE quinone that is formed by the two-electron oxidation of VE (Fig. 2), is cytotoxic due to its ability to generate oxygen radicals and to form an adduct with thiols (59). Thornton et al. (73) has reported that $\gamma$-tocopherol quinone and $\delta$-tocopherol quinone are more toxic than $\alpha$-tocopherol quinone. This toxicity involves the formation of Michael adducts with cellular thiols (73).

\subsubsection{Non-antioxidant activity of $V E$}

Various non-antioxidant activities have been ascribed to VE. Some of them are summarized in Table 2.

Beside the protection of membranes against free radical damage, VE can also directly interact with membranes. Despite its low concentration, VE stabilizes membranes by forming complexes with products of membrane lipid hydrolysis, such as lysophospholipids and free fatty acids (85). Patel and Edwards (86) have reported that vitamin $\mathrm{E}$ affects membrane fluidity, at low concentration it increases membrane fluidity, whereas at high concentration it has the opposite effect.

Table 2. Some of the non-antioxidant effects of VE.

\begin{tabular}{lll}
\hline Compound & Activity & Reference(s) \\
\hline$\alpha$-Tocopherol & Inhibition of protein kinase C- $\alpha$ & $74-79$ \\
& Activation of protein phosphatase 2A & 80 \\
& Inhibition of platelet aggregation & 75 \\
& Reduction of the expression of CD36 scavenger \\
& receptor & 81 \\
& Activation of eNOS & 82 \\
& Inhibition of glutathione-transferase P1-1 & 83 \\
Tocotrienols & Inhibition of 3-hydroxy-3-methylglutaryl-CoA \\
& reductase & 84 \\
\hline \multirow{2}{*}{ All vitamers } & Stabilisation of lipid membranes & 85 \\
\hline
\end{tabular}


The inhibition of PKC activity by $\alpha$-tocopherol has gained much attention. This effect is perceived to occur at concentrations of $\alpha$-tocopherol close to those measured in healthy adults (77,78). $\beta$-Tocopherol does not inhibit PKC. "Tlus indicates that the mechantsm imvolved in the inhibition of $\mathrm{PKC}$ is not directly related to the antioxidant activity since both compounds have a similar direct antioxidant effect (79). Ricciarelli al (81) have demonstrated that treatment of rat aotic smooth-muscle cells with a-tocopherol resulted in a time- and dose-dependent inhibition of $\mathrm{PKC}-\alpha$, whereas the other isoforms, $\mathrm{PKC}-\beta, \mathrm{PKC}-\delta, \mathrm{PKC}-\mathrm{E}$, and $\mathrm{PKC}-\zeta$ are not affected by a-tocopherol The inhibition of PKC- $\alpha$ by $\alpha$-tocopherol has been found to be associated with its dephosphorylation (80). $\alpha$-Tocopheral activates proten phosphatase 2A (PP2A). This enzyme might mediate the observed dephosphorylation and subsequent deactivation of PKCO induced by a-tocopherol ( 80 ).

The antiproliferative effect of $\alpha$-tocopherol has been linked to the inhibition of $\mathrm{PKC}-\alpha$. $\beta$-Tocopherol has no antiproliferative activity $(80)$. The inhibition of cell proliferation by $\alpha$-tocopherol is blocked by addition of $\beta$-tocopherol ( 80 ). It has also been suggested that the tocopherol-binding protein TAP, that selectively binds $\alpha$-tocopherol, initiates a cascade of events once $\alpha$-tocopherol binds that leads to the inhibition of cell proliferation. (79)

Despite a long history of extensive research on the compound, new activities of VE still emerge. For example, in human aortic smooth muscle cells $\alpha$-tocopherol but not $\beta$ tocopherol interferes with the oxLDL uptake by reducing the expression of the CD36 scavenger receptor. This receptor mediates the uptake of oxLDL (81). Heller et al. (82) have demonstrated that $\alpha$-tocopherol primes eNOS by increasing the phosphorylation of its residue serine 1177 . VE can also directly interact with membranes. In our opinion, the complete picture on the role of VE in nutrition, physiology, pathology, biochemistry and toxicology still has to be revealed.

\subsubsection{Ester derivatives of $V E$}

Because of the oxidizability of VE, supplementation with VE often occurs by adding more stable VE esters to VE formulations. The phenolic hydroxyl group is essential for" the antioxidant activity and esterfication of this group improves the stability of the compound. Various esters have been prepared (Fig 3). The esters themselves do not display a free radical scavenging activity (87). The ester of $V E$ most commonly used in foods and cosmetic products is vitamin $\mathrm{E}$ acetate (VEA). Cheeseman ef al. (88) found that in humans the availability of VE from VEA is higher than that of other VE esters such as vitamin E succinate (VES). In lambs, the concentrations of VE were significantly higher after supplementation with VEA compared to that after supplementation with VES (89). The bioavalability of vitamin $\mathrm{E}$ nicotinate (VEN) was lower than that of VES (89). VES is taken up more readily than free VE in neuroblastoma cells (90). As also stated 
above, after oral administration the esters are hydrolysed in the intestime and the released VE is absorbed (91).

As shown in Table 3, the rank order of the antioxidant activity of VE and its esters is variable. The differences in potency of VE and its derivatives in the reported studies are probably due to differences in the assay and the experimental conditions.

In contrasi to its antioxidant effect, VES also induces apoptosis and promotes cell death. Allready in 1982 (98), it was noted that treatment of murine B-16 mellanoma cells with VES induced a more potent morphological differentiation and growth inhibition in comparison to treatment of these cells with VE, VEA, and VEN.

Table 3. The reported rank order of the antioxidant activity of VE and its ester derivatives.

\begin{tabular}{|c|c|c|}
\hline Rank order & Assay & Reference(s) \\
\hline$V E A>V E$ & Rat fetal resorption & 92 \\
\hline$V E A>V E$ & Rat fetal resorption & 93 \\
\hline$V E A>V E$ & Rat fetal resorption & 94 \\
\hline $\mathrm{VES}>\mathrm{VE}$ & Microsomal lipid peroxidation & 95 \\
\hline $\begin{array}{l}\text { Trolox }>V E \gg \text { VEA and } \\
\text { VES }\end{array}$ & $\begin{array}{l}\text { Lipid peroxidation in cultured endo- } \\
\text { thelial cells }\end{array}$ & 96 \\
\hline $\mathrm{VES}>\mathrm{VE} \approx \mathrm{VEA}$ & Lipid peroxidation in hepatocytes & 97 \\
\hline Trolo $x>V E>V E A>V E S$ & Microsomal lipid peroxidation & 87 \\
\hline
\end{tabular}

One year later, Rama and Prasad (99) reported that VES inhibited growth and caused morphological changes in mouse melanoma (B-16), mouse neuroblastoma (NBP2), and rat glioma (C-6) cells in culture. In 1986, it was established that VES enhanced the growth inhibitory effects of adriamycin on a variety of cancer cells in vitro $(100)$. In 1989, Slack and Proulx (90) reported that VES can inhibit the growth of neuroblastoma NIE 115 cells. Recently, several studies have shown that VES induces growth inhibition and apoptotic activity on a variety of human and rodent cancer cell lines without affecting the proliferation of normal cells in vitro (101-108) and in vivo (109-112).

The mechanism by which VES induces apoptosis is not fully understood. It might involve a combination of membrane destabilising activity and dysregulation of signalling pathways. Destabilisation of the membrane can occur due to the detergent-like action of VES, since VES has a hydrophobic tail, essential for membrane docking of the compound, and a hydrophilic succinyl moiety, in membranes located in the water-membrane interface (105).

VES can exist as a deprotonated, charged species, or the protonated, uncharged counterpart (105). The ratio of these two forms depends on the pH. Almost $99 \%$ of the total VES is charged at neutral $\mathrm{pH}$. The part that is uncharged will increase to $25 \%$ at $\mathrm{pH} 6.2$ 
(105). Of the two, only the uncharged species will enter cells by passive diffusion. This might contribute to the apparent selective toxicity of VES towards malignant versus normal cells $(104,110)$, since the $\mathrm{pH}$ of the interstitim in most tumours is $6.2-6.5$, whereas the pH of most nomal tissues is 7.0-7.4 (113). Interestingly, the cytotoxic ef fect of VES in Jurkat and MCF-7 cell lines was greater at acidic pH, which might also be due to the high diffusion rate of VES over cell membranes at acidic pH (I05).

Birringer et al. (106) found that neither trolox succinate nor phytyl succinate caused apoptosis. This indicates that all parts of the molecule (i.e. the succinate group, the chroman head and the phytyl tail) are essential for the induction of apoptosis by VES. Vitamin $\mathrm{E}$ glutarate has a very poor apoptotic activity compared to that of VES, vitamin E maleate and vitamin $\mathrm{E}$ fumarate (Fig 3). Apoptotic potency also differs between vitamin $E$ oxalate, vitamin $E$ malonate and VES. The relative potency of these VE esters correlates with the flexibility of the terminal carboxyl containing moiety (108); the longer the terminal dicarboxylic moiety, the more flexible this moiety and the lower the apoptotic effect. Non-apoptotic and apoptotic VE analogues are shown in Figure 3.

The signalling pathways that have been suggested to play a role in the VES-induced apoptosis are diverse. One of the mechanisms that has been proposed is that VES can activate the caspase cascade and in this way modulates the mitochondral membrane function which finally leads to apoptosis (103).

\subsubsection{Vitamin E phosphate}

Only recently, it has been discovered that vitamin $E$ phosphate (VEP) is present in plant and animal tissues, including human. The concentrations of VEP are in general similar to those of VE. In rat and pig liver VEP levels were substantially higher (114). In food-

Table 4. Some physiological effects of VEP. Compound Activity

Vitamin E phosphate Reduction of the intensive rate of metabolism in rabbit muscles

Activation of cAMP phosphodiesterase

Increasing the rate of phenylalanine hydroxylase

Protection against irradiation in rat intestine and cultured mouse skin

Increase in sperm survival

Improvement of acetylcholine-dependent relaxation

in the aged aortic strips exposed to oxidative stress

Protection against LPO in non-heated and heated

rat liver microsomes 
stuffs such as chocolate and cheese the concentrations of VEP are 10 to 30 times thigher than those of VE (114). Interestingly, supplementation of VEP ( $30 \mathrm{mg} / \mathrm{kg} /$ day) in rats for 32 days significantly increased the levels of VEP $(62 \%)$ as well as of VE $(40 \%)$ in liver indicating the possible absorption of this VE-ester and conversion of VEP into VE $(87,114,115)$. Table 4 summarizes some of the physiological effects of VEP.

The research on VEP started some six decades ago. In 1942, Houchin and Mattill (116) have shown that the administration of VEP to a dystrophic rabbit lowers the excessive metabolic rate of the muscle tissue to a normal level within 4 hours. The level of creatine in the liver was not affected (119). Furthermore, VEP increased the maximum velocity of phenylalanine hydroxylase about 25 -fold in the presence of tetrahydrobiopterin $\left(\mathrm{BH}_{4}\right)$, while the increase by VES was only 3-fold (121). It was stated that VEP is intimately connected with complicated and unknown enzyme systems that maintain the physiological integrity of muscle tissue (116).

During the last ten years, VEP has been promoted as a radioprotector. Felemovicius et al. (122) reported that a chronic oral supplementation of VEP $(5 \mathrm{mg} / \mathrm{ml})$ significantly protected against acute irradiation in rat intestine. This protection was slightly superior to that of VEA $(5 \mathrm{mg} / \mathrm{ml})$ (122). Pre-treatment of cultured mouse skin with $0.5 \%$ of VEP (9.4 mM) substantially protected against UV-B triggered skin damage in comparison to that of VEA $(9.4 \mathrm{mM})(115)$. The radioprotective effect of VEP has been ascribed to its ability to protect against lipid peroxidation, cell damage due to sunburn and DNA degradation (115). This protection was suggested to be due to the conversion of VEP to VE in mouse skin by alkaline phosphatase (115).

Another remarkable function of VEP was reported by Pérez-Pé et al. (123). They found a significant beneficial effect of VEP in combination with semen plasma protein on sperm survival. There was no protective effect with VEA (123). They suggested that this difference might be due to a more potent inhibition of lipid peroxidation by VEP compared to VEA (123). Recently, we have shown that - in contrast to VEA - VEP had a potent antioxidant activity of its own, without conversion into VE (Chapter 2) (87). VEP was not consumed during its protection against lipid peroxidlation. VEP also induced a potent hemolysis in erythrocytes and reduced membrane fluidity (87). Our results indicated that VEP might act as a detergent and forms a barrier in biomembranes and in this way inhibits the transfer of radicals from one polyunsaturated fatty acid to another (87).

We have also found that VEP has a very potent apoptotic activity (Chapter 3) (125). VEP potentially induced DNA fragmentation and nuclear condensation in osteosarcoma celis (125). As stated above, in a series of dicarboxylic esters of VE, the ester with the least flexible dicarboxylic moiety displayed the highest apoptotic effect $(106,108)$. The 
phosphate group is not flexible and, based on analogy with the VE ssters, this migh be an important feature for the apoptotic activity of VEP.

Recently, Munteanu et al. (126) reported that a mixture of VEP (VEPm) containing VEP $(55.3 \%)$, di-VEP $(30.6 \%)$, VE (5\%), inorganic phosphate $(2.6 \%)$, water (1.9\%), oleic acid (1\%) and some unidentified products (3.5\%) modulated cell proliferation and gene expression in rat aortic smooth muscle cells (RASMC) at a relatively low concentration. At higher concentrations, VEPm induced apoptosis in human THP-1 monocytic leukaemia cells. Munteamu et al. (126) focussed on a beneficial nole of VEPm in atherosclerosis and inflammation. In our opinion, the apoptotic effect of VEP on monocytic leukaemia cells might also be of interest.

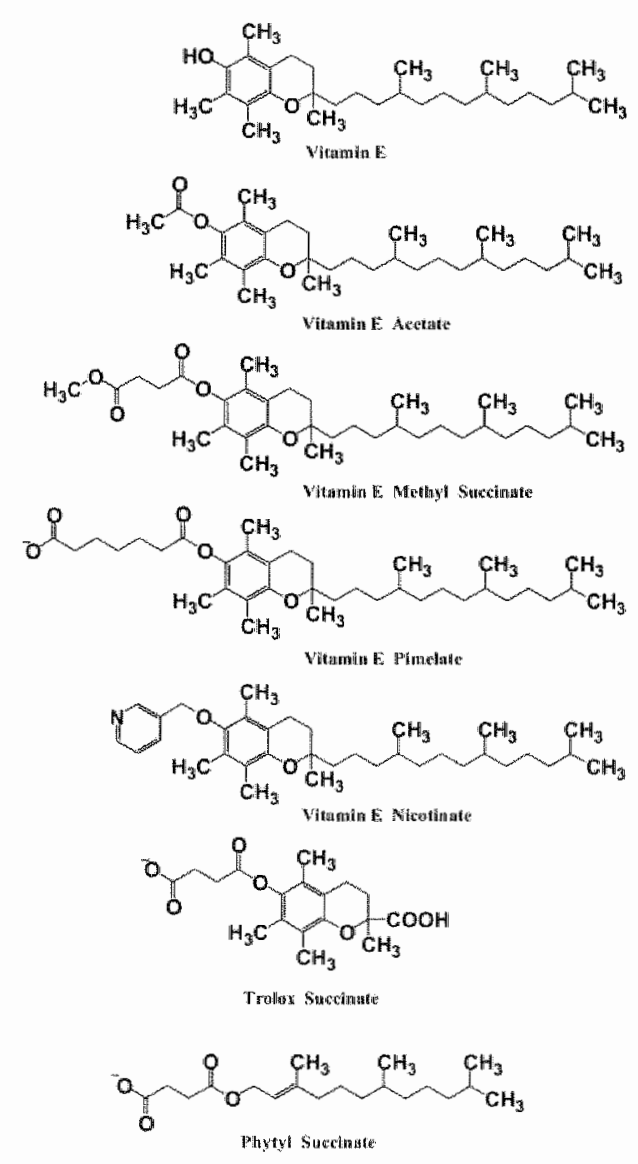

A

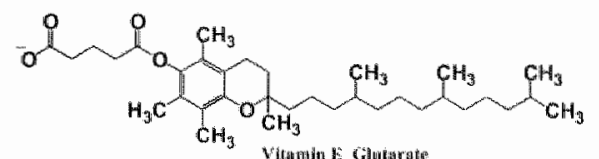<smiles>CC1=C(C)C2OC(C)(CCCC(C)CCCC(C)CCCC(C)C)CCC2C(C)=C1OC(=O)CCC(=O)O</smiles><smiles>CC(C)CCCC(C)CCCC(C)CCCC1(C)CCC2C(C)C(OC(=O)CC(=O)[O-])C(C)C(C)C2O1</smiles><smiles>CC1=C(C)C2OC(C)(CCCC(C)CCCC(C)CCCC(C)C)CCC2=C(C)C1OC(=O)/C=C\C(=O)[O-]</smiles><smiles>CC1=C(OC(=O)C(=O)[O-])C(C)C2CCC(C)(CCCC(C)CCCC(C)CCCC(C)C)OC2C1C</smiles><smiles>CC1=C(OC(=O)/C=C/C(=O)[O-])C(C)C2CCC(C)(CCCC(C)CCCC(C)CCCC(C)C)OC2=C1C</smiles><smiles>CC1=C(OP(=O)([O-])O)C(C)C2CCC(C)(CCCC(C)CCCC(C)CCCC(C)C)OC2C1C</smiles>

B

Fig. 3. Chemical structures of non-apoptotic (A) and apoptotic (B) analogues of VE and its ester derivatives. 


\subsubsection{Flavonoids}

Several plant pigments have been idenbified as flavonoids during the last century. Also other polyphenolic compounds which are widely distributed in foods of plant origin belong to this group. Over 5000 different naturally occurring flavonoids have been described and the list is still growing. Flavonoids are divided into eight main groups based on the degree of saturation of the C-ring, the hydroxylation pattern of the compound and the substitution in the 3-position (Fig. 4). These groups include flavanols (e.g., epicatechin), flavonols (o.g., quercetin), flavones (e.g., luteolin), flavanones (e.g., naringenin), isoflavones (e.g., genistein), anthocyanidins (e.g., cyanidin), chalcones (e.g., chalcone naringenin) and dihydrochalcones (e.g., phloretin) (Table 5).

Humans have consumed flavonoids and other dietary phenols ever since the emergence of human life on earth. They are present in fruits, vegetables, nuts, plant-derived beverages such as tea and wine, as well as in some traditional herbal-containing medicines. Much attention is given to the potential health-beneficial properties of flavonoids. They are reported to be powerfil antioxidants in vitro $(127-133)$ and in vivo $(134,135)$. Furthermore, flavonoids interfere in several of the steps that lead to the development of different types of cancer, including protection of DNA from oxidative damage, inhibition of carcinogen activation and activation of carcinogen-detoxifying systems (136-138). Understanding the mechanisms of action of flavonoids, either as antioxidants (127-135) or as modulators of cell signalling (139), and the influence of absorption and metabolism $(140-142)$ on these properties are fundamental to determine the effect of these compounds on health.

Dietary flavonoids have been shown to act as pro-oxidants in systems containing redoxactive metals. In the presence of $\mathrm{O}_{2}$, transition metals such as copper and iron catalyze the redox cycling of some llavonoids leading to the formation of ROS and phenoxyl radicals that can damage DNA, lipids, and other biological molecules (143-145). Quercerin, the most ubiquitous of the dietary flavonoids, contains a catechol ring and is oxidized readily to a quinone/quimone methide. This oxidation product readily reacts with GSH resulting in quercetin glutathionyl adducts (146). Boots et al. (147) have shown that the oxidation product also readily reacts with protein thiols and this is a key event in quercetin toxicity. Consumption of large amounts of flavonoids present in various supplements night be harmful due to the reaction of flavonoid oxidation products with cellular constituents. 


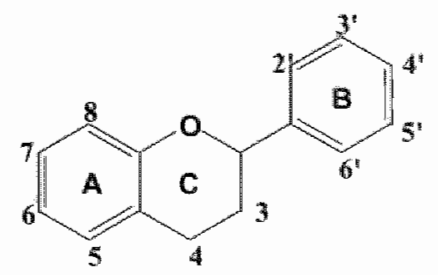

Flavonoid basic structure<smiles>O=C1CC(c2ccccc2)Oc2ccccc21</smiles>

Flavanone<smiles>O=c1c(O)c(-c2ccccc2)oc2ccccc12</smiles>

Flavon-3-0l<smiles>O=c1cc(-c2ccccc2)oc2ccccc12</smiles>

Flavome<smiles>O=C(/C=C/c1ccccc1)c1ccccc1O</smiles>

Chalcone<smiles>O=c1c(-c2ccccc2)coc2ccccc12</smiles>

Isoflavone<smiles>OC1Cc2ccccc2OC1c1ccccc1</smiles>

Flavan-3-0|<smiles></smiles>

Anthocynaidin<smiles>O=C(CCc1ccccc1)c1ccccc1O</smiles>

Dihydrochalcome

Fig. 4. Basic structure of flavonoids. 
Table 5. Subclases of glavonoids with some examples of each class.

\begin{tabular}{llllllll}
\hline Class & Compound & \multicolumn{7}{c}{ Substituents } \\
& & 3 & 5 & 7 & $3^{\prime}$ & $4^{\prime}$ & $5^{r}$ \\
\hline Flavonol & Quercetin & $\mathrm{OH}$ & $\mathrm{OH}$ & $\mathrm{OH}$ & $\mathrm{OH}$ & $\mathrm{OH}$ & $\mathrm{H}$ \\
& Kaempferol & $\mathrm{OH}$ & $\mathrm{OH}$ & $\mathrm{OH}$ & $\mathrm{H}$ & $\mathrm{OH}$ & $\mathrm{H}$ \\
Flavanone & Naringenin & $\mathrm{H}$ & $\mathrm{OH}$ & $\mathrm{OH}$ & $\mathrm{H}$ & $\mathrm{OH}$ & $\mathrm{H}$ \\
& Naringin & $\mathrm{H}$ & $\mathrm{OH}$ & $\mathrm{ORu}$ & $\mathrm{H}$ & $\mathrm{OH}$ & $\mathrm{H}$ \\
Flavone & Apigenin & $\mathrm{H}$ & $\mathrm{OH}$ & $\mathrm{OH}$ & $\mathrm{H}$ & $\mathrm{OH}$ & $\mathrm{H}$ \\
& Diosmin & $\mathrm{H}$ & $\mathrm{OH}$ & $\mathrm{ORu}$ & $\mathrm{OH}$ & $\mathrm{OMe}$ & $\mathrm{H}$ \\
\multirow{5}{*}{ Isoflavone } & Genistein & $\mathrm{H}(2)$ & $\mathrm{OH}$ & $\mathrm{OH}$ & $\mathrm{H}$ & $\mathrm{OH}$ & $\mathrm{H}$ \\
& Biochanin A & $\mathrm{H}(2)$ & $\mathrm{OH}$ & $\mathrm{OH}$ & $\mathrm{H}$ & $\mathrm{OM}$ & $\mathrm{H}$ \\
Flavanol & Catechin & $\mathrm{OH}$ & $\mathrm{OH}$ & $\mathrm{OH}$ & $\mathrm{OH}$ & $\mathrm{OH}$ & $\mathrm{H}$ \\
& $3^{\prime}$-O-methyl & $\mathrm{OH}$ & $\mathrm{OH}$ & $\mathrm{OH}$ & $\mathrm{OMe}$ & $\mathrm{OH}$ & $\mathrm{H}$ \\
& epicatechin & & & & & & \\
Anthocyanidin & Cyanidin & $\mathrm{OH}$ & $\mathrm{OH}$ & $\mathrm{OH}$ & $\mathrm{OH}$ & $\mathrm{OH}$ & $\mathrm{H}$ \\
& Pelargonidin & $\mathrm{OH}$ & $\mathrm{OH}$ & $\mathrm{OH}$ & $\mathrm{OH}$ & $\mathrm{H}$ & $\mathrm{H}$ \\
Chalcone & Chalcone & $\mathrm{OH}(2)$ & $\mathrm{OH}(4)$ & $\mathrm{OH}(6)$ & $\mathrm{H}$ & $\mathrm{OH}$ & $\mathrm{H}$ \\
& naringenin & & & & & & \\
Dilhydrochalcone & Phloretin & $\mathrm{OH}(2)$ & $\mathrm{OH}(4)$ & $\mathrm{OH}(6)$ & $\mathrm{H}$ & $\mathrm{OH}$ & $\mathrm{H}$ \\
& Phloridzin & $\mathrm{OGl}(2)$ & $\mathrm{OH}(4)$ & $\mathrm{OH}(6)$ & $\mathrm{H}$ & $\mathrm{OH}$ & $\mathrm{H}$ \\
\hline
\end{tabular}

$\mathrm{Ru}=$ Rutinose ( $=\mathrm{Glu}-\mathrm{Rha}), \mathrm{Me}=\mathrm{CH}_{3}, \mathrm{Gl}=$ Glucose

\subsubsection{Phloretin}

An apple a day keeps the doctor away! This saying might be related to the presence of the dihydrochalcones, phloretin and phloridzin, in apples. These compounds are present predominantly in the peel of apples but they are also found in the pulp (148). Significant quantitative differences between the apple varieties have been found. The Golden Delicious variety has the lowest content of dilhydrochalcones and the Green Reineta variety the highest (148). Generally, apples contain as much as $2 \mathrm{~g}$ of polyphenols per kilogram wet weight. 


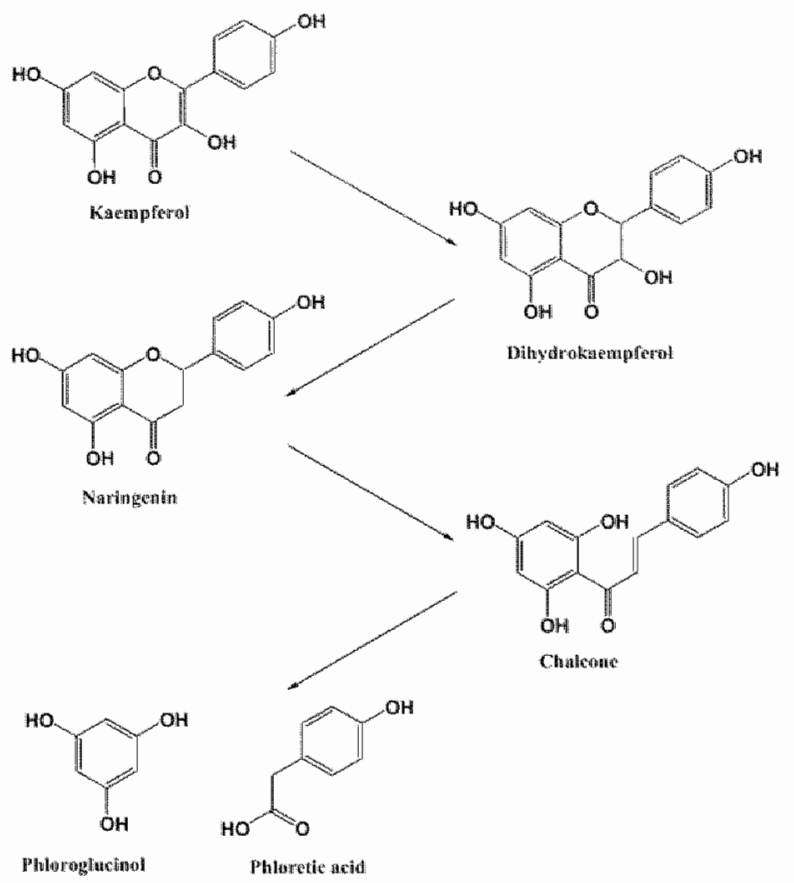

Fig. 5. Scheme of the metabolic degradation of the flavonoid kaempferol, showing chalcone as a metabolic product.

\subsubsection{Bioavailability and metabolism of phloretin}

Due to the large chemical heterogeneity of flavonoids, bioavailability and metabolism of flavonoids is diverse. In Figure 5, the metabolic pathway of the flavonoid kaempferol, showing chalcone as a metabolic product, is depicted. For phloridzin, Malathi and Crane (149) reported that in the brush border of the hamster small intestime, the enzyme $\beta$-glucosidase hydrolysed phloridzin into phloretin and glucose. This enzyme was identified in the study of Kraml et al. (150) as lactase-phloridzin hydrolase (LPH).

The degradative metabolism of dihydrochalcones aglycons involves splinting of the molecule, giving products that only contain the A- or B-ring (Fig. 5) (151). Monge et al. found that in rat about half of the administered phloretin was excreted in the urine within two days (152). Most of the metabolites were degradation products, including phloroglucinol and, in larger amounts, phloretic acid and related metabolites formed by dehydrogenation, betamoxidation and glycine conjugation. Phloroglucinol, administered in a similar experiment, was rapidly ( $90 \%$ within 24 h) excreted in the urine, either unchanged or as conjugates (glucuronide/sulphate) (152). Crespy et al. (153) reported that the same compounds are found in 24-h urine of the rat fed either phloretin or phloridzin. This is in line with the conversion of phloridzin into phloretin in the intestine before absorption. The time needed for this conversion explains why phloretin appeared more 
rapidly in plasma after phloretin administration compared to phloridzin acministration. These results are in good agreement with a previous study of the same group (154), showing that phloretin was absorbed efficiently in an in sitw intestinal perfusion nodel. Clearance of the conjugated metabolites of phloretin was higher than that of unconjugated phloretin (153).

\subsubsection{Antroxidant activity of phloretin}

The antioxidant activity of phloretin has been demonstrated in different assays with different reactive spiecies, such as $\mathrm{OH}^{*}(155-157)$, ONOOH (157) and the 1,1-diphenyl-2picrylhydrazyl radical $(158-160)$. Various activities e.g. the radioprotective effect of phloretin in mice, has been attributed to its scavenging potency (156). The position of hydroxyl groups in phloretin plays an important role in its antioxidant activity (155160). Formation of intramolecular hydrogen bonds is of great importance for the antioxidant activity (160). In Chapter 4 (157), it is shown that the activity of phloretin does not reside only in the three hydroxyl groups of ring $A$. The carbonyl group plays a key role in the potent antioxidant activity of phloretin (157). Phloretin also possesses some prooxidant activity since it can oxidize human erythrocyte oxyhemoglobin and cause erythrocyte hemolysis (144).

\subsubsection{Non-amtioxidant activity of phloretin}

The reported non-antioxidant activities of phloretin and phloridzin are summarized in Table 6 . The effect of phloretin or phloridzin on glucose uptake suggests the use of both compounds as an antidiabetic agent $(161,162)$. Interestingly, the phloretin induced apoptosis in mellanoma cells was suggested to proceed through the inhibition of glucose transmembrane transport and inhibition of PKC activity (163).

Table 6. Non-antioxidant activity of phloridzin and phloretin.

\begin{tabular}{lll}
\hline Compound & \multicolumn{1}{c}{ Activity } & Reference(s) \\
\hline Phloridzin & Competitive inhibition of intestinal glucose uptake & 164 \\
Phloretin & Insulin-like activity on glucose transport & 165 \\
& Antagonist of the prostaglandin F 20 receptor & 166 \\
& Anti-inflammatory activity & 167 \\
& lnhibition of tyrosine kinase and protein kinase C & 163,168 \\
& Induction of apoptotosis in melanoma cells & 163 \\
\hline
\end{tabular}

\subsubsection{Lipoic acid}

Lipoic acid (LA), a naturally occurring dithiol, is present in the cells of most prokaryotes and eukaryotes. In foodsturf, LA is present in a relatively high amount in meat and 
liver and to a lesser extent in fruits and vegetables. In lwumans, LA is present in all parts of the body as a cofactor for several mitochondrial enzymes which are required for anergy metabolism. In the late 1940's, LA was identified as a growth factor and as a protein-bound cofactor to activate acyl-molety transfer reactions. Based on this biological activity, LA has been named "acetate-replacing factor", "pyruvate oxidation factor" and "protogen A". In 1951, $30 \mathrm{mg}$ of LA was purified as a yellow crystalline substance from $100 \mathrm{~kg}$ liver by Reed et al. (169). The chemical structure was elucidated (170,171) and the substance was identified as 1,2-dithiolane-3-pentanoic acid (Fig. 6). Because of its lipophilicity and acidity, LA obtained its name. The non-official name 6,8-thioctic acid emphasizes the presence of the two sulfur atoms in the molecule. Other names of lipoic acid are $\alpha$-lipoic acid, 5-(1,2-dithiolane-3-yl)-valeric acid and 5-3-(1,2-dithiolanyl)pentanoic acid.

LA is not a vitamin because its biosynthesis occurs in man. In E. colt, LA is synthesized from octanoic acid by the addition of two sulfur atoms to an octanoyl group bound to the acyl carnier protein ( $A C P$ ) in mitochondria. Miller et al. (172) showed that this reaction is catalyzed by an enzyme, lipoic acid synthase. The actual source(s) for the two sulfhydryl moieties in the biosynthesis of $L A$ is currently unknown. In mammals LA is synthesized in mitochondria by lipoic acid synthase, but it can also be absorbed from the diet (173).

\subsubsection{Bioavailabily and metabolism of lipoic acid}

Several bioavailability studies have shown that LA is well absorbed from the gastrointestinal tract after oral administration. This rapid uptake is followed by an equally rapid clearance, suggesting both transport into tissues as well as glomerular filltration and renal excretion (174). Biewenga et al. (175) revealed that after oral administration of $1 \mathrm{~g}$ of LA to a human volunteer, LA appeared in the blood plasma after 30 min and its elimination showed first order kinetics with a half life of 56 min. In a comparable study, Teichert et al. reported that LA was absorbed rapidly with peak plasma concentrations at 10 to 45 min after administration. It was eliminated rapidly, with a mean plasma elimination half-life of 0.56 hours (176). Similarly, Smith et $a 1$. (177) also found a rapid uptake and clearance in human subjects following oral LA administration.

Besides LA, its reduced form, dihydrolipoic acid (DHLA), as well as several metabolites could be detected in plasma after oral administration of $1 \mathrm{~g}$ of L A to human volunteers. The maximum concentration of $\mathrm{LA}$ (1154 $\mathrm{ng} / \mathrm{ml})$, 3-ketolipoic acid (2092 $\mathrm{ng} / \mathrm{ml})$, and bisnorlipoic acid $(704 \mathrm{ng} / \mathrm{ml})$ were observed after $92 \mathrm{~min}, 119 \mathrm{~min}$, and 189 min respectively (175). Bisnorlipoic acid, $\beta$-hydroxy-bisnorlipoic acid, and tetranorlipoic acid were the first discovered metabolites of $L A$ in rats $(174,178)$. 4,6Bismethylthio-hexanoic acid was found as the main metabolite in urine samples of healthy volunteers after oral administration of $\mathrm{LA}$, whereas both 6,8 -bismethylthio- 
octanoic acid and 2,4-bismethylthio-butanoic acid were minor metabolites $(179,180)$. It was suggested that 3 -ketolipoic acid has a major contribution to the antioxidant activity and therapeutic effect of LA (175). Most metabolites are produced via $\beta$-oxidation of the LA pentanoic side chain (175). Harrison and McCormick (174) found that $25 \%$ of the radioactivity of $\mathrm{LA},{ }^{14} \mathrm{C}$ labelled on the 1 and 6 position, was exhaled as ${ }^{14} \mathrm{CO}_{2}$ within $2 \mathrm{~h}$ after administration, reaching a total amount of $30 \%$ after $24 \mathrm{~h}$. This indicates that $L A$ is metabolised via $\beta$-oxidation. Some of the metabolites which are generated via this process are depicted in Figure 6.

The $L D_{50}$ after oral administration in rats and mice is 1130 and $502 \mathrm{mg} / \mathrm{kg}$, respectively, and after intraperitoneal administration this is 200 and $160 \mathrm{mg} / \mathrm{kg}$, respectively (175). This indicates that LA is relatively non toxic (175). The therapeutic dose of LA in the treatment of diabetic polyneuropathy is three times $600 \mathrm{mg}$ per day (175).

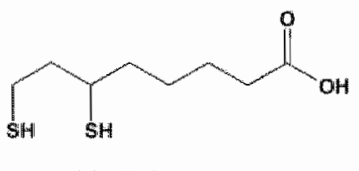

Délygdrolligole acid

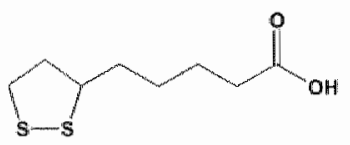

H.jpote acid
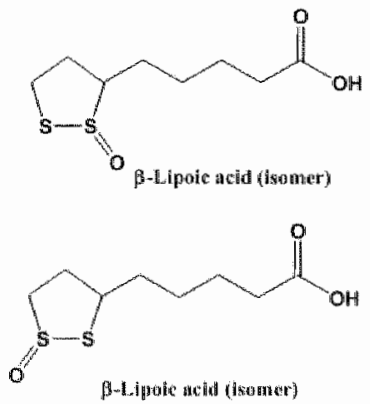

d
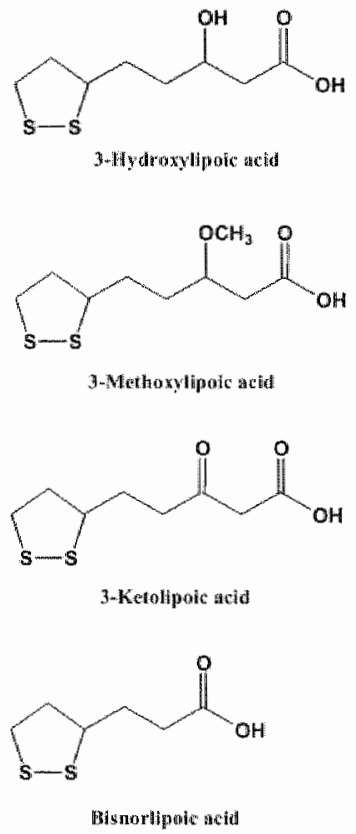

B

Fig. 6. Lipoic acid, dihydrolipoic acid, isomers of $\beta$-lipoic acid (A) and $\beta$-oxidation products of lipoic acid (B).

\subsubsection{Antioxidant activity of lipoic acid}

The successful therapeutic application of LA as antioxidant has boosted scientific research on LA, especially directed to understand the beneficial effect of LA on pathophysiological processes. LA and DHLA were found to be highly reactive against several ROS and RNS in the different in vitro (181-188) and in vivo (189-192) assays. During 
this scavenging activity, LA is oxidized to $\beta$-lipoic acd ( $9-\mathrm{LA})$ (Fig. 6) (175,185, 188 ). LA efficiently protected against hypochlorous acid (182) and peroxymitrite $(185,186)$ induced $\alpha 1$-antiproteinase inhibition, while another disulfide such as GSSG has no effect.

The explanation for the relatively potent scavenging activity of the disulfide LA can be found in the dihedral angle of C-S-S-C moiety $(\varphi)$. In the open chain disulfide GSSG, $\varphi$ approximates $90^{\circ}(182,193)$. At this angle, the energetically unfavourable interaction between the sulfur lone pairs is kept at a minimum and an interchange of these electrons with the free d-levels of the neighbouring sulfur atoms is possible to give the $\mathrm{S}-\mathrm{S}$ bond a partial double bond character. Indeed, GSSG is a poor scavenger. The disulfide group in LA is located in a dithiolane, a strained, five membered ring in which $\varphi$ is $35^{\circ}$. This results in an energetically unfavourable interaction of the orbital of the lone pz electron pairs of the sulfur atoms $(182,1.93)$. The relatively high energy content of the disulfide group in LA is responsible for the relatively high antioxidant activity.

In addition to direct scavenging activity of $L A$, the LA/DHLA redox couple appears to be favourable to regenerate other antioxidants in the antioxidant network such as $\mathrm{VE}$, VC and GSH (193-195). Considering a redox potential of $-0.32 \mathrm{~V}$ for the LADHLA redox couple compared to that of the GSH/GSSG couple $(-0.24 \mathrm{~V})$, DHLA is able to reduce GSSG to GSH (193-195). Increasing of the intracellular availability of cysteine was proposed to be the underlying mechanism of LA to increase GSH synthesis (196). Cysteine is a major building block for the synthesis of GSH.

Various studies have shown an antioxidant effect of LA in vivo. LA supplementation (600 $\mathrm{mg} /$ day, 2 months) to healthy volunteers decreases urinary F2-isoprostane levels, a biomarker of lipid peroxidation, and increased the lag time of LDL oxidation (189). Intragastric LA administration (150 $\mathrm{mg} / \mathrm{kg} / \mathrm{day}, 2$ months) to rats protects against cxercise-induced oxidative lipid damage in heart, liver, and skeletal muscle, increased total GSH levels in liver and blood and also prevented the exercise-induced decline in heart GST activity (190). Cardiac myocytes from old, LA-supplemented rats $(0.2 \% \mathrm{w} / \mathrm{w})$ exhibited a markedly lower rate of oxidant production that was no longer significantly different from that in cells from control, young rats (191). LA supplementation also rew stored myocardial ascorbic acid levels and reduced oxidative DNA damage (191). Intraperitoneal administration of LA (100 mg/kg body weight/day for 7 and 14 days) attenuated cerebral lipid peroxidation and prevented age-associated decrease in the levels of VC, VE, and GSH (192). Dietary supplementation of LA for 2 weeks completely reversed the age-related decline in hepatocellular GSH levels and the increased susceptibility to tert-butylhydroperoxide.

Interestingly, in an animal model of Wilson's disease, which results in hepatic copper overload and chronic necroinflammatory disease, LA lowered the mitochondrial copper content with no effect on the cytosolic levels (197). Despite the potential benefits of LA 
and DHLA to amelorate metalcatalysed oxidative stress, DHLA accelerated irondependent bydroxyl radical generation and lipid peroxidation in liposomes, probably by reducing ferric to ferrous ions $(181,198)$. Under certain circumstances, DHLA accelerated the loss of activity of alpha-antiproteinase exposed to ionising radiation under a $\mathrm{N}_{2} \mathrm{O} / \mathrm{O}_{2}$ atmosphere and also the loss of creatine kinase activity in human plasma exposed to gas-phase cigarette smoke $(198,199)$.

\subsubsection{Non-anvioridant activity of lipoic acid}

LA is successfully used in the treatment of type II diabetes induced polyneuropathy (200). In experimental animal models of diabetes, LA treatment improved neural blood flow, endoneural glucose uptake and metabolism as well as nerve conduction (201). Mechanistic studies conducted in insulin-responsive cells in culture demonstrate that LA $(2.5 \mathrm{mM})$ rapidly stimulates glucose uptake by activating the insulin-signalling pathway (202). The increase in glucose uptake has also been explained by a stimulatory affect of LA on the glucose transport by GLUT-4 $(193,203)$. Since the increased glucose transport is not accompanied by an increase in GLUT-4 mRNA, it is supposed that the degradation of GLUT-4 is decreased by LA $(193,203)$.

LA reduced the expression of adhesion molecules of Jurkat $T$ cells and of vascular endothelial cells stimulated by TNF- $\alpha$ or phorbol myristate acetate $(204,205)$. LA also attenuated the $N F_{h} B$-induced expression of TNF- $\alpha$ in macrophages treated with lipopolysaccharide (206). Kim al, (207) showed that LA exerted anti-obesity effects by suppressing hypothalamic AMP-activated protein kinase activity.

\subsubsection{Folic acid}

Folic acid (FA), a water soluble $B$ vitamin, is the most oxidised and stable form of folate. FA consists of an aromatic pteridine ring linked through a methylene bridge to $p$ aminobenzolc acid and then to one L-glutamic acid residne. In the plant folate-synthesis pathway, the pteridine moiety, hydroxymethyldihydropterin, is formed from guanosine5 -triphosphate (GTP), whereas the $p$-aminobenzoic acid is formed from chorismate. Folates present in body tissues and foods are mainly 5,6,7,8-tetrahydropteroylpolyglutamates, which contain a fully-reduced pteridine ring together with additional glutamic acid molecules linked by $\gamma$-peptide bonds. The vitamin activity of these reduced polyglutamates is present as long as the essential subunit structure of folic acid remains largely intact. Folates are usually carbon substituted at the N-5 (e.g. 5methyltetrahydrofolate) or $\mathrm{N}-10$ (e.g. 10-formyltetrahydrofolate) positions, or have a single carbon bridge spanning these positions (e.g. 5,10-methylenetetrahydofolate). Apparently, there are many chemical forms of folic acid that exhibit vitamin activity (as folates) $(208,209)$. 
Plants, fungi, and many microorganisms synthesize folates de novo, but hunans and other higher animals do not and therefore require a dietary supply (210,211). The B vitamin was first isolated from spinach leaves. Therefore, the name folate, derived from the Latin word folwm, meaning leaf, was given to this compound. Folate deficiency has been implicated in cardiovascular and hematological diseases, $(212,213)$ neurological and neuropsychiatric disorders, (214,215) neural tube defects (NTD) (216) and cancer including cervical, lung, brain, pancreatic, colorectal and breast cancer $(217,218)$.

\subsubsection{Bioavailability and metabolism of folic acid}

The metabolism of folates is schematically depicted in Figure 7. Plant folates have a short $\gamma$-linked chain of glutamyl residues attached to the first glutamate, and most folate-requiring enzymes prefer such polyglutamylated forms (210). Before absorption in the intestine can take place, dietary folates need to be hydrolysed to the folate monoglutamate in the gut lumen by a brush-border $\gamma$-glutamyl hydrolase or conjugase (folylpolyglutamate carboxypeptidase) (219). Human brush-border folate conjugase is a $\mathrm{Zn}$ dependent exopeptidase that catalyses the stepwise hydrolysis of folate polyglutamates (220). The mucosal cells of the proximal small intestine (jejunum) then take up these monoglutamates by a saturable, active process at "normal" concentrations, and also by passive diffusion at higher concentrations (221). Many foods contain inhibitors of the intestinal brush-border folate conjugase enzyme or the folate transport system, which can reduce the efficiency of absorption (222). Some foods, such as milk and other dairy products, contain folate-binding proteins that also reduce folate absorption (223). The efficiency of deconjugation and absorption in the gut lumen can vary considerably with the folate form, the composition of the diet and various physiological factors. Absorption is not affected by ageing (224) but it is markedly influenced by pH. Maximum ab. sorption is at $\mathrm{pH} 6.3$ and sharply declines from $\mathrm{pH} 6.3$ to 7.6 (225). Small amounts of folate may also be synthesised by the intestinal flora in the body, but in man (unlike the rat) this source of absorbable folate is of minor importance. Absorbed folate monoglutamates are converted into 5-methyltetrahydrofolic acid (5-MTHF) during transit through the intestinal nucosa. The only follate form normally entering the human circulation from intestinal cells is 5-MTHF. The liver removes a sizeable proportion of the absorbed dose (226). 


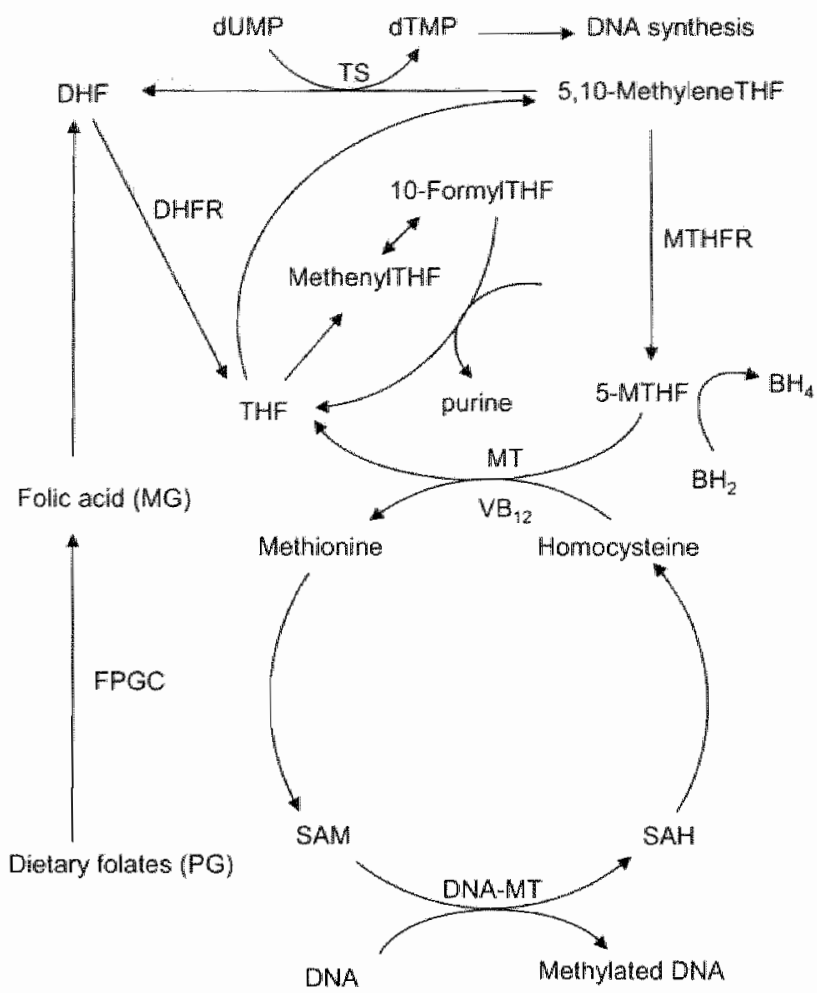

Fig. 7. Metabolism of folate and homocysteine. $\mathrm{PG}$, polyglutamate; $\mathrm{MG}$, monoglutamate; FPGC, folylpolyglutamate carboxypeptidase; DHF, dihydrofolate; DHFR, diliydrofolate reductase; THF, tetrahydrofolate; TS, thymidylate synthetase; dUMP, deoxyuridylate; dTMP, thymidylate; MTHFR, methylenetetrahydrofolate reductase; 5-MTHF, 5-methyltetrahydrofolate; MT, methionine synthetase; $\mathrm{VB}_{12}$, vitamin $\mathrm{B}_{12}$; SAM, Sadenosylmethionine; SAH, S-adenosylhomocysteine; DNA-MT, DNA methyltransferase; $\mathrm{BH}_{2}$, dihydrobiopterin; $\mathrm{BH}_{4}$, tetrahydrobiopterin.

\subsubsection{Antioxidant activity of folic acid}

Stupplementation with FA improves endothelial dysfunction in patients with established coronary heart disease independent on the levels of homocysteine $(212,227)$. It has been suggested that the reduction of oxidative stress by folic acid might be involved in this effect $(212,228)$. S-MTHF when given intra-arterially, abolished the homocysteine-induced increase in intracellular $\mathrm{O}_{2}{ }^{*}$ generation. $\mathrm{FA}$ and $\mathrm{H}_{4} \mathrm{~B}$ also abolished the homocysteine-induced intracellular $\mathrm{O}_{2}{ }^{*-}$ production in cultured cells (227). This suggests that FA, 5 -MTHF, and $\mathrm{H}_{4} \mathrm{~B}$ (a cofactor essential of $\mathrm{NO}^{*}$ formation by NOS) restore endothelial function by suppressing $\mathrm{O}_{2}{ }^{*}$ production and increasing $\mathrm{NO}$ " half-life. This is supported by the observation that 5-MTHF has no direct effect on in vitro $\mathrm{NO}^{\circ}$ 
production by eNOS but induces a dose-dependent reduction in eNOS- and xanthine oxidase-mediated $\mathrm{O}_{2}$ " generation. The reduced $\mathrm{O}_{2}{ }_{2}^{-}$production might be responsible for the impaired endothelium-dependent vasodillation in patients with familial hypercholesterolemia (228). Additionally, it has been reported that 5-MTHF has a direct stimulatory effect on the enzymatic activity of NOS in recombinant eNOS and cultured endothelial cells (229). It is also interesting to note that oral FA supplementation (10 $\mathrm{mg} / \mathrm{d})$ to healthy human volunteers not only enhances NOS activity but also prevents nitrate tolerance to continuous treatment with nitroglycerin, possibly by restoring or stimulating endogenous regeneration of $\mathrm{H}_{4} \mathrm{~B}(230)$. In vitro, 5-MTHF and THF inhibit lipid peroxidation and scavenge ONOOH (Chapter 6) (231). Also the ability of FA to scavenge and repair of thiyl radicals makes it possible to consider this vitamin as a physiologically relevant antioxidant (232).

\subsubsection{Non-antioxidant activity of folic acid}

The non-antioxidant effect of FA has gained more attention than its potential antioxidant effect. A too high homocysteine level has been implicated in the development of cardiovascular diseases. Hyperhomocysteimemia involves both genetic and mutritional causes (233) and has been found in patients with coronary arterial disease, (234) cerebrovascular (235) and peripheral vascular diseases and thrombosis (236).

The metabolism of FA and homocysteine are interrelated (Fig. 7). Folic acid catalyses methylation of homocysteine, leading to a reduction of plasma total homocysteine (233). Conversion of homocysteine into methionine can occur in a reaction catalyzed by methionine synthetase, which uses 5-MTHF as a methyl donor and cobalamin (vitamin $\mathrm{B}_{12}$ ) as an essential cofactor (237). Several studies have shown a protective role of periconceptional intake of folic acid in reducing both the occurrence and recurrence of neural tube defects. Goldenbergh, et al.(238) showed that folle acid improves the outcome of pregnancy not only by decreasing NTD but by decreasing growth retardation and increasing binth weight. In 1992, the U.S. Public Health Service issued a recommendation that all women of childbearing age capable of becoming pregnant should consume $400 \mu \mathrm{g}$ of folic acid each day. Homocysteine might directly be involved in NTD by causing vasculopathy leading to an inadequate maternal-fetal circulation. This is based on the observed relationship between high levels of total homocysteine and defective chorionic villous vascularisation in mothers with recurrent early pregnancy loss $(239)$.

Currently, it is believed that the beneficial effect of folate is due to its ability to maintain DNA stability (240-245). One of the mechanisms suggested is through DNA methylation. Folate, in the form of 5-MTHF enhances the formation of methionine, which can be converted into $S$-adenosylmethionine (SAM). SAM methylates specific cytosines in DNA, and this regulates gene transcription. As a consequence of folate deficiency, cel- 
lular SAM is depleted, which potentially induces proto-oncogene expression leading to cancer $(217,246)$.

Another mechanism through which folate might enhance DNA stability has received less attention. Folate, as 5,10 methylene THF, donates a methyl group to uracil converting it into thymine, which is used for DNA synthesis and repar (Fig. 7). When folate is lacking, uraci misincorporation into DNA may occur which may lead to double strand breaks and chromosomal damage (247).

\section{Conclusilion}

Free radicals are impilicated in various pathophysiological processes. Protection is provided by both enzymatic and non-enzymatic antioxidants.

The biological effects of antioxidants are diverse. First of all, an antioxidant is often not a clear defined compound, consists of various chemical forms and in the body it is converted into various metabolites. Each of these different forms of the antioxidant displays a different biological effect. Additionally, antioxidants do not only display various antioxidant activities, they often possess some prominent non-antioxidant effect. The free radical processes in the body as well as the biological effects of antioxidants have to be elucidated to a greater extent in order to further rationalise and optimise antioxidant therapy.

\section{Outline and scope of the thesis}

As indicated in the Introduction a more accurate risk-benefit analysis of antioxidants is needed. Therefore, the mechanism of action of vitamin $\mathrm{E}$ phosphate, phloretin, lipoic acid and folic acid was studied. These antioxidants were chosen because they represent different chemical classes and are widely used as food constituents, food supplements or as a medicament. Moreover, the studied compounds are of interest from a toxicological point of vilew.

Vitamin E phosphate (VEP) is of interest because very recently it has been discovered that its levels in the human body are equal to or higher than those of vitamin $\mathrm{E}$ (VE). The question is whether VEP has its own intrinsic activities or has to be converted into VE to display a prominent biological effect. Therefore we investigated the antioxidant activity of VEP (Chapter 2) and its apoptotic properties (Chapter 3 ).

Phloretin is representative for the compounds in the group of dihydrochalcones, i.e. flavonoids without a heterocyclic $\mathrm{C}$ ring. It is abundantly present in apples. Therefore it is likely that phloretin might contribute to the positive health effect associated with a high intake of fruit and vegetables. To understand its antioxidant activity, the part of the molecule responsible for this activity was identified (Chapter 4 ). 
Lipoic acid (LA) is a naturally occurring dithol and present in all parts of the human body. Additionally, it is the only antioxidant that has been registered as such. In Germany LA is widely used in the treatment of polyneuropathy in diabetics. LA appears to be a very potent protector against one type of $\mathrm{ONOOH}$ - mediated damage as well as a wery poor protector against another type of damage mediated by the same reactive species. This controversy was further investigated by examining the antioxidant activity of LA and other sulfur-containing compounds in the presence of different detectors and different oxidants (Chapter 5).

Folic acid (FA) supplementation can significantly reduce the etiological risk of a number of diseases. In these pathologies the production of reactive oxygen species plays a role. The antioxidative potential of FA itself and of its physiological metabolites was assessed and the part of the molecule which is important for this activity was determined(Chapter 6).

Finally, the results and impact of our findings are summarised in Chapter 7 .

\section{References}

1 Foote CS, Goyne TE, Leltrer RI. Assessment of chlorination by human neutrophils. Nature. 1983; 301: $715-6$.

2 Hampton MB, Kettle AJ, Winterbourn CC. Inside the neutrophil phagosome: oxidants, myeloperoxidase, and bacterial killing. Blood. 1998; 92:3007-17.

3 Kenle AJ, Clark BM, Winterbourn CC. Superoxide converts indigo carmine to isatin sulfonic acid: implications for the hypothesis that neutrophils produce ozone, $J$ Biol Chem. 2004; 279: 18521-5.

4 Babior BM. Phagocytes and oxidative stress. Am. J. Med. 2000 109:33-34

5 Moncada S, Palmer RM, Higgs EA.. Nitric oxide: physiology, pathophysiology, and pharmacology. Pharmacol Rev. 1991; 43: 109-42.

6 Stamler JS, Singel DJ, Loscatizo J. Biochemistry of nitric oxide and its redox-aclivated forms. Science. 1992; 258: $1898-902$.

7 Huie RE, Padmaja S. The reaction of NO" with superoxide. Free Radic Res Commmn, 1993;18: 1959.

8 Pryor WA, Squadrito GL. The chemistry of peroxynitrite: a product from the reaction of nitric oxide with superoxide. Am J Physiol. 1995; 268: L699-722.

9 Young LS, Woodside JV. Antioxidants in health and disease. J Clin Pahiol. 2001; 54 : 176-86.

10 Halliwell B. Free radicals, antioxidants, and human disease: curiosity, cause, or consequence? Lamcet. 1994; 344: $721-4$.

1) Sies H. Oxidative stress: oxidants and antioxidants. Exp Physiol. 1997; 82: 291 -5.

12 Hallwell B. Antioxidants in human health and disease. Anmu Rev Nutr. 1996:16:33-50.

13 Frohlich ED, Navar LG, Re RN. Nobel laureates honored by the council for high blood pressure research. Hypertension. 1999; $34: 1025$.

14 Raju TN. The Nobel chronicles. 1998: Robert Francis Furchgott (b 1911), Louls J Ignarro (b 1941), and Ferid Murad (b 1936). Lancet. 2000; 356: 346 
15 Uppu RM, squadrito GL, Iryor WA. Acceleration of peroxynilinte oxidations by carbon doxida Arch Brochem Biophy. 1996; 327:335-43.

16 Koppenol WH. Thermodyamic considerations on the formation of reactwe spacies from hypochlorite, superoxide and nitrogen monoxide. Could thitrosyl chloride be produced by neutrophils and macrophages? FLES Leti. 1994; 347:5-8.

17 Pullar JM, Vissers MC, Winterboum CC. Living with a killer the effects of hypottlorous acid on martmalian cells IUBMB Lifo, 2000; $50: 259-66$.

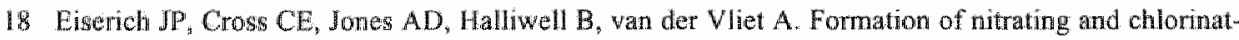
ing spectes by teaction of nitrite with hypochlorous acid. A novel mechanism for nitric oxidemediated photein modification. I Biol Chew. 1996; 271:19199-208.

19 Eiserich IP, Hristova M, Cross CE, Jones AD, Freeman BA, Halliwell B, van der Vliet A. Formation of nitric oxide-derived inflammatory oxidants by myeloperoxidase in neutrophils. Narme. 1998; 391: 393.7

20 Betteridge DJ. What is oxidative stress? Merabolism. 2000; 49:3-8.

21 Nordberg J, Armer ES. Reactive oxygen species, antioxidants, and the mammalian thioredoxin system. Free fradic Biol Med. 2001; 31: 1287-312.

22 Halliwall B. Antioxidant defence mechanissms: from the beginning to the end (of the beginning). Free Radic Res. 1999, 31:261.72.

23 Candeias LP, Patel KB, Stratford MR, Wardman P. Free hydroxyl radicals are formed on reaction between the neutrophit-derived species superoxide anion and hypochlorous acid. FEBS Letr. 1993; $333: 151-3$

24 Spiteller G. Lipid peroxidation in aging and age-dependert diseases. Exp Gerontol. 2001; 36: 142557

25 Gutteridge $\mathrm{JM}$. Lipid peroxidation and antioxidants as biomarkers of tissue damage. Chn Chem. $1995 ; 41: 1819-28$.

26 Padmaja S, Huie RE. The reaction of nitric oxide with organic peroxyl radicals. Biochem Biophys Res Commus. 1993:195:539-44.

27 Kirsch $\mathrm{M}_{\text {, Lehnig }}$, Konth $\mathrm{HO}$, Sustmann $\mathbb{R}$, de Groot H. Inhbition of peroxynitrite induced nifras tion of yrosine by glutathone in the presence of carbon dioxide through both radical tepair and peroxynutate fomation. Chempisy. 2001:7:3313-20.

28 Wang $X$, Quinn $P J$ Vitamin E and its Lunction in membranes. Prog Lipid Res. 1999; 38: $309-36$

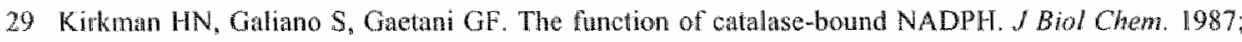
262: $600-6$.

30 Zamoky M, Koller F. Understanding the structure and function of catalases: ches from molecular evolution and in vitro mutagenesis. Progr Biophys Mol Biol. 1999; 72: 19-66.

3 Kirkman HN, Rolfo M, Ferraris AM, Gatani GF. Mechanisms of protection of catalase by NADPH. Kinetios and stoich iometry. J Biol Chen. 1999; 274: 13908-14.

32 Nakane T, Asayama K, Kodera K, Hayashibe H, Uchida N, Nakazawa S. Effect of selenium deficiency on cetlular and extracellutar glutathone peroxidases: immunochenucal detection and mRNA analysis in rat kidney and serum. Free Radic BHol Med. 1998; 25: 504-11.

33 Ursini $F$, Maiorino M, Brigehus-Flohe R, A unamn KD, Roveri A, Schomburg D, Flohe L. Diversity of glutathionta peroxidases. Mathods Enzymol. 1995;252:38-53.

34 Takahash $\mathrm{K}$. Cohen HJ. Selenum-dependent glutathione peroxidase protein and activify: immunological investigations on cellular and plasma enzymes. Bload $1986 ; 68: 640-5$. 


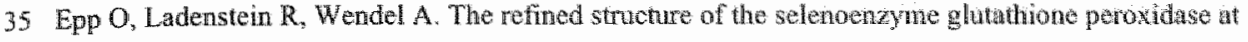
0.2-nm resolution. Eur J Bhochem. 1983:133: $51-69$

36 Holben DH, Smith AM. The diverse role of selenim withri selenoprotains a neview. Am Diet AsS01. 1999:99:836-43.

37 Gibson DD, Hawrylko J, McCay PB. GSH-dependen inhibition of lipid peroxidwtion: propenties of a patent cytosolic system which protects cell membranis. Lipids. 1985; 20: 704-11.

38 MeCord MM, Fridovich 1. Superoxide dismutase. An enzymic function for erythocuprem (hemocuprein). J Biol Chem. 1969; 244: 6049-55.

39 McCord JM, Fridovich L. The utility of superoxide dismutase in studying free madical renctions 1 . Radicals generated by the interaction of sulfite, dimethyl sultoxide, and oxygen. $J$ Bhol Chewn. 1969; 244: $6056-63$

40 Weisiger RA, Fridovich I. Mitochondrial superoxide simutase. Site of synthesis and intrannitochondrial localization. J Brol Chem. 1973; 248: 4793-6.

41 Tyler DD. Polarographic assay and intracellular distribution of superoxide dismutase in pat liver. Biochem J 1975; 147: 493-504.

42 Lion W, Chang LY, Geuze HJ, Strous GJ, Crapo JD, Slot JW. Distribution of CuZn superoxide dis mutase in rat liver. Free Radic Biol Med. 1993; 14: 201-7.

43 Ohlemiller KK, McFadden SL, Ding DL, Flood DG, Reanme AG, Hofiman EK, Scott RW. Wright JS, Putcha GV, Salvi RJ. Targeted deletion of the cytosolic Cu/Zn $\mathrm{muperoxide}$ dismutase gene (SODI) increases susceptibility to noise-unduced hearing loss. Audiol Neuroorol. 1999; 4: 237 -46.

44. Rosen DR, Siddique T, Patterson D, Figlewicz DA, Sapp P, Hentati A, Donallson D, Goto J, O'Re gran JP, Deng $\mathbb{H X}_{\text {y }}$ at al. Mutations in CuZn superoxide dismulase gene are associated with hamilial anyotrophic lateral sclerosis. Norate. $1993 ; 362: 59-62$

45 Marklund SL. Human copper-containing superoxide dismutase of bigh molecular weight. Proc Natl Acad Sci US A. 1982; 79:7634-8.

46 Karlsson K, Sandstrom J, Edhund A, Edlund T, Marklund SL. Phamacokinetics of extracellularsuperoxide dismutase in the vascular system. Free Radic Biol Med. 1993; 14: 185-90.

47 Mclntye M, Bohr DF, Dominiczak AF. Endothelial function in hypertension: the role of shporotide anion. Hypertension. 1999; $34: 539-45$.

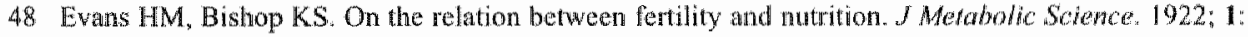
319-356.

49. Evans HM, Emerson OH, Emerson GA. The isolation from wheat-germ oil of an alcohol. alphatocopherol, having the properties of vitamin E. I. Biol Chent. 1936;113:319-332.

50 Enerson $O H$, Emerson GA, Mohammad $A$, and Evans HM. The chemistry of vitamin B. Tocopherols from various sources. $d$. Biol. Chem. 1937; 122:99-107.

51 Stem MH, Robeson CD, Weisler L, Baxter JG. G-Tocophenol. I. Isolation from Soybean Oil and Properties. J. Am Chem Sor. 1947;69:869-874.

52 Pennock JF, Hemming FW, Ken JD. A reassessment of tocopherol in chemistry. Biochesh Brophys Res Commun. 1964; 17: 542-8.

53 C. Jane Wyatt, S. Perez Carballido, and R. O. Méndez o- and \%-Tocopherol Content of Selected Foods in the Mexican Diet: Erfect of Cooking Losses. A. Agric. Food Chem, 1998; 46: 4657-61.

54 Heinonen $M$, Pironen $V$. The tocopherol, tocotrianol, and vitamin $E$ content of the average Finnish diet Int J Vitom NutP Res. 1991; 61:27-32.

55 Brigelius-Flohe R, Traber MG. Vitamin E: function and metabolism. FASEB /. 1999:13: 1145-55. 
56 Muller DP, Maninng MA, Mathas PM. Hamies IT. Studies on the intestinal hydrolysis of tocopheryl esters. Jnt J Wown Nutr Res. 1976; 46: 207-10.

57 Hosomi $A_{*}$ Arita $M$, sato $Y$, Kiyose $C$, Ueda $T$, Jgarashi $O$, Arai $H$, Inowe $K$. Affinity for alphatocopherol transfer protein as a determinant of the biological activities of witamin $E$ analogs. FEBS Letr. 1997; 409:105-8.

58 Traber $M \mathrm{M}$, Kayden $\mathbb{H}$. Alpha-tocoplerol as compared with gamma-tocopherol is preferentially secreted in buman lipoproteins. Ann N Y ACad Scr. 1989; 570: 95-108.

59 Bast A, Haenen GRMM. The toxicity of the antioxidants and their metabolites. Environ. Toxicol Pyamacol. $2002 ; 11: 251.258$

60 Fukuzawa $\mathrm{K}$, Inokami $\mathrm{Y}$, Tokumura A, Terao J, Suzuki A. Singlet oxygen scavenging by alphatocopherol and beta-carotene: kinetic studies in phospholipid membrames and ethanol solution. Biofactors. 1998: 7: $31-40$.

61 Botti H, Bathyany $C$, Trostchansky $A$, Radi R, Freeman BA, Rubbo $\mathbb{H}$. Peroxynitrite-mediated alpha-tocopherol oxidation in low-density lipoprotein: a mechanistic approach. Free Radic Biof Med. $2004 ; 36: 152-62$

62 Cooney RV, Franke AA, Harwood PJ, Hatch-Pigott V, Custer LJ, Mordan LJ. Gamma-tocopherol detoxification of nitrogen dioxicle: superionity to alpha-tocopherol. Proc Narl Acad Sci U S A. 1993; 90: $1771-5$.

63 Thiele JI, Traber MO, Tsang K, Cross CE, Packer L. In vivo exposure to ozone depletes vitamins C and $E$ and induces lipid peroxidation in epidermal layers of murine skin. Free Radic Biol Med. 1997; 23: $385-91$.

64 Csallany AS, Hee-Lee J, Shoeman DW. Protection of superoxide-induced cholesterol oxidation by antioxidants in protic conditions. Int J Food Sci Nutr, 2002;53:403-9.

65 Paker L, Slater TF, Wilson RL. Direct observation of a free radical interaction between vitamin $\mathrm{E}$ and vitamin C. Nature. 1979; 278: 737-8.

66 Haenen GRMM, Bast A. Protection against lipid peroxidation by a microsomal glutathionedependent laloile factor. FEBS Lert. 1983; 159:24-8.

67 Kamal-Eldin A. Appelqvist LA. The chemistry and antioxidant properties of tocopherols and tocotrienols. Lipids. 1996; 31 : 671-701.

68 Kohar I, Baca M, Suama C, Stocker R, Southwell-Keely PT. Is alpha-tocopherol a reservoir for alpha-tocopheryl hydroquinone? Free Radic Biol Med. 1995; 19: 197.207.

69 Bindoli A, Valente M, Cavalimi L. Inhibition of lipid peroxidation by alpha-tocopherolquinone and alpha-tocopherolhydroquinone. Biochem Int 1985; 10" 753-61

70 Neuzil 1 , Witting PK, Stocker R. Alpha-tocopheryl hydroquinone is an effucient multifunctional inhibitor of radical-initiated oxidation of low density lipoprotein lipids. Proc Nall Acad Sci USA. 1997; $94: 7885-90$.

71 Moore AN, Ingold KU. alpha-Tocopheryl quinone is converted into vitamin E in man. Free Radic: Biol Med. 1997; 22: 931-4.

72 Sitephens NG, Parsons A, Schoficld PM, Kelly F, Cheeseman K, Mitchinson MI. Randomised controlled trial of vitmin $\mathrm{E}$ in patients with coronary disease: Cambridge Heart Antioxidant Study (CHAOS). Lancet 1996; 347: 781-6.

73 Thomton DE, Jones KF, Jiang Z, Zhang H, Liu G, Cornwell DG. Antioxidant and cytotoxic tocoplleryl quinones in normal and cancer cells. Free Radic Biol Med. 1995; 18: 963-76 
74 Chatelain E, Boscoboinik DO, Bartoli GM, Kagan VE, Gey FK. Packer L, Azzi A. Inhbition of smooth muscle cell proliferation and protein kinase $C$ activity by hocoherols and tocotrienols. Bochim Biophys Acta. 1993; 1176:83i9

75 Freedman $\mathrm{JE}$, Farhat $\mathrm{JH}$, Loscalzo $J$, Keaney JF Jr: alpha-tocopherol inhbits aggregation of human platelets by a protein kimase C-dependent mechanism. Circulahion. 1996:94:2434-40.

76 Sirikci O, Ozer MK, Azzi A. Diatary cholesterol-induced changes of protain kintse $C$ and the effect of vitamin $E$ in rabbit aortic smooth muscle cells. Aherosclerosin. $1996,126,253-63$

77 Schutz M, Leist M. Petrika M. Gassmann B, Brigelius-Flohe RNovel wrinary metabolite of alphatocopherol, 2,5,7,8-tetramediyl-2(2'-carboxy ethyl)-6-hydroxychroman, as an indicaton of an adequate vitamin $\mathbb{E}$ supply?. Am J Clin Nutr. 1995; 62:15275-1534S

78 Traber MG, Ramakrishnan R, Kayden HJ. Human plasma viamin E kinetics demonstrate rapud racycling of plasma RRR-alpha-tocopherol. Proc Nat Acad Sci US A. 1994; $91: 10005-8$

79) Azri A, Stocker A. Vitamin E: non-antioxidant roles. Prog Lipid Res. 2000:39:23 $1-55$

80 Azzi A, Boscoboinik D, Marilley D, Ozer NK, Stable B, Tasinato A. Vitamin E: a sensor and an information transducen of the cell oxidation state. Am J Clin Nutr. $1995 ; 62 ; 13375-13465$

81 Riceiarelli $R$, Zingg JM, Azzi A. Vitamin E reduces the uptake of oxidized LDL by inhibiting CD36 scawenger receptor expression in cultured aotic smooth muscle cells. Crrowarion. 2000; 102: 82-7.

82 Heller R. Hecker M, Stahmann N, Thieie Jd, Wemer-Fehmayer G, Werner ER. alpla-Tocopherol Amplifies Phosphorylation of Endothelial Nitric Oxide Synthase at Serine 1177 and its Short-Cham Derivative Trolox Stabilizes Tetrahydrobiopterin. Free Radic Biol Med 2004: 37: 620-31.

83 Van Haaften RI, Evelo CT, Pendets J, Eijnwachter MP, Haenen GR, Bast A. Inhibition of humatn glutathione S-transferase P1-1 by tocopherols and alphantocopherol derivatives. Biachin Biophys Acto. $2001 ; 1548: 23-8$.

84 Khor HT, Ng TT. Effects of administration of alpha-tocopherol and tocotrienols on serum lipids and liver HMG COA reductase activity. Int I Food Sci Nutr. 2000; 51: $\$ 3.11$.

85 Wang $X$, Quim P. The location and function of vitamin $\mathbb{E}$ in membranes (revicw). Mol Membr Biot. $2000 ; 17: 143-56$.

86 Patel JM, Edwards DA. Vitamin E, membrane ordex, and antioxidant bohavior in lung morosomes and reonstituted lipid vesicles. Toxical App/ pharmacol. 1988; 96:101 14.

87 Rezk BM, Haenen GRMM, van der Vigh WJF, Bast A. The extatidinary antioxidant atetivity of vitamin E phosphate. Biochim Biophys Acha. 2004; 1683: 16-21.

88 Cheeseman KH, Holley AE, Kelly FJ, Wasil M, Hughes L, Burton O. Biokinetios in humans of RRR-alpha-tocopherol: the free phenol, acetate ester, and succinate ester forms of vitamin E. Free Radic Biol Med 1995; 19:591.8

89 Hidingglou N, McDowell LR, Papas AM, Antaph M, Wilkinson NS. Bloatwailaibility of witamin E compounds in lambs. Inim Sci. 1992; 70:2556m-61.

90 Slack R, Proulx P. Studies on the effects of vitamin E on neuroblastoma N1E 115 . Non Camcer. $1989 ; 12: 75-82$.

9]. Muller DP, Manning JA, Mathias PM, Harties JT. Studies on the intestinal hydrolysis of tocopheryd esters. In J Wilam Nuth Res. 1976; 46:207-10.

92 Harris PL, Hudwig M1. Vitamin E potancy of a-tocoplherol and a-tocopherol esters. J. Biol. Chem. $1949 ; 180: 611-15$

93 Leth T, Sondergaard H. Biological activity of all-rac-at-tocopherol and RRR-ib-tocopherol determined by three different rat bioassays. In J Wiram Narr Res. $1983,53: 297-311$ 
94 Weiser H, vechi M, Shtachter M. Stereoisomers of alpha-tocopheryl acetate. IV. USP wnits and alphu-tocopherol equivalems of all-tac-, 2-ambow and RRR-alplin-tocopherol evaluated by simultane-

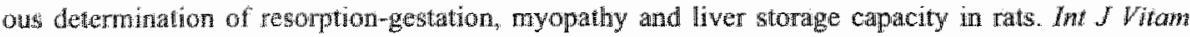
Nutr Res. 1986; $56: 45 \% 56$.

95 Carini $\mathrm{R}$, Poli $\mathrm{G}$, Ditnzani MU, Maddix SP, Slater TF, Cheeseman KH Comparative evaluation of the antioxidant activity of alpha-tocopherol, alpha-tocopherol polyethylene glycol 1000 succinate and alphamocopherol suceinate in isolated hepatocytes and diver microsomal suspensions. Biochem Phorkacal. 1990; 39:1597-601.

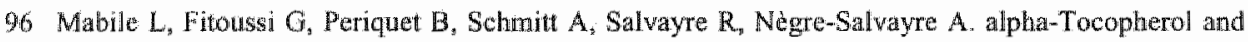
trolox block the early intracellalar events (TBARS and calcium nises) elicited by oxidized low density lipoproteins in cultured endothetial cells. Free Radic Biol Med 1995; 19: 177-87.

97 Fariss MW, Nicholls-Grzemsk FA, Tirmenstem MA, Zhang JG. Enhanced antioxidant and cyloprotective abilities of vitamin $\mathrm{E}$ succinate is associatled with a rapid uptake advantage in rat hepatocytes and mitochondria. Free Radic Biol Med. $2001 ; 31: 530-41$.

98 Prasad KN, Edwatds-Prasad J. Effects of tocopherol (vitamin E) acid succinate on morphological alterations and growth inhbition in melanoma cells in culture Cancer Res. 1982; 42:550-5.

99 Rant BN, Prasad $K N$. Study on the specificity of alpha-tocopheryl (vitamin E) acid succinate effects on molanoma, glioma and neuroblastoma cells in culture. Proc Soc Exp Biol Med, 1983; 174: 302-7.

100 Ripoll EA, Rama BN, Webber MM. Vitamin E enhances the chemotherapeutic effects of adriamyein on human prostatic carcinoma cells in vitro. J Urot. 1986; 136: 529-31.

10. Kline $\mathrm{K}$, Cochun $\mathrm{GS}$, Sanders $\mathrm{BG}$. Growth-inhibitory effects of vitamin $\mathrm{E}$ succinate on retrovinustransformed tumor cells in vitro. Nutr Cancer. 1990;14:27 41.

102 Turley JM, Ruscetti FW, Kim SJ, Fu T, Gou FW, Birchenall-Roberts MC. Vitamin E succinate inhibits proliferation of BT-20 human breast cancer cells: increased binding of cyclin A megatively regulates E2F transactivation activity. Cancer Res. 1997; 57: 2668-75.

103 Yamamoto S, Tamai H, Ishisaka R, Kanno $T$, Arita $K$, Kobuchi $H$, Utsumi K. Mechanism of alphatocopheryl succinate-induced apoptosis of promyelocytic lenkemia cells. Free Radic Res. 2000; 33 : $407-18$

104 Nauzil J, Wober T, Gellen N, Weber C. Selective cancer cell killirg by alpha-iocopheryl succinate. Br.J Comcer. $2001 ; 84: 87-9$.

105 Neuzil J, Zhao M, Ostemann G, Sticha M, Gellert N, Weber C, Eaton IW, Brunk. UT. Alphatocopheryl succinate, an agent with in vivo anti-tumour activity, induces apoptosis by calusing lysosomal instability. Biochern. $y, 2002 ; 362 ; 709-15$.

106 Birmgar M, EyTina JH. Salvatore BA, Neuzil I. Vitamin E analogues as inducers of apoptosis: structure-function relation. $B r \cdot J$ Cancer. 2003; 88: 1948-55

107 Wh $K_{*}$ Zho Y, Li GC, Yu WP. c-Jan N-teminal kinase is nequired for vitamin E succinate-induced. apoptosis in human gastric cancer cells. Words Gastroenterol. 2004; 10: 1110-4.

108 Kogure K, Hama S, Kisaki M, Takemasa H, Toknmura A, Suzuki I, Fukuzawa K. Structurä characteristic of terminal dicturboxylic moiety required for apoptogenic activity of alplan-tocopheryl esters. Biochim Biophys Acta. 2004: 1672: 93-9.

109 Neuzill J, Weber T, Schroder A, Lu M, Ostermann G, Gellert N, Mayne GC, Olejucka B, NegreSalvayte A, Sticha M, Coffey RJ. Weber C. Induction of cancer cell apoptosis by alpha-tocopheryl succinate: molecular pathways and structural requiremerts. FASEB $\& .2001 ; 15 ; 403-15$. 
110 Webet T, Lu M, Andera L, Lahm M, Gellet N, Faris MW, Kannek V, Sather W, Ucker DS, Tonman A, Schroder A, ErI W, Brunk UT, Cotfey R, Weber C. Newzil I. Vitumin E succinate is a potent novel antineoplastic agent with high selectivity and cooperativity with nmon necrosis factorebled apoptosis-inducing ligand (Apo2 ligand) in viwo. Chin Cahcer Res. 2002; 8 : $83-9$.

111 Bamett KT, Fokm FD, Malafa MP. Vitamin E suchate inhibis colon cancer liver metastases. Surg Res. 2002; 106: 292-8.

112 Tonasett M, Gellert N, Procopio A, Neuzil I. A vitamin E analogue suppresses malignant mesothelioma in a preclinical moded: a future drug against a fatal neoplastic disease? /n . Camcer. 2004; 109 : $61-2$.

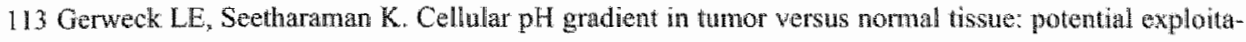
fion for the treatment of cameer. Cancem Res. 1996; 56: 1194-8.

114 Ogna E, Gianello R, Libinaki R, Smallridge A, Bak R, Geytenbeck S, Kannar D, West S. (Eds.), Vitamin E phosphate: An endogenous fom of vitamin E. Medimond S.r.l, 2003.

115 Nakayama S, Katoh EM, Tsuzuki T, Kobayashi S. Protective effect of alpha-tocopherol-6 0 . phosphate against ultraviotet B-induced damage in cuttured mouse skin. Imest Dermatol. 2003; 121: $406-11$.

116 Houchin OB, Matrill HA. The influence of parenteral administration of a-tocopherol phosphate on the metabolic process in dystrophic muscle. J Biol. Chaw $1942 ; 146: 309-12$.

117 Houchin OB, the invito effect of $\alpha$-tocopherol and its phosphate derivative on oxidation in muscle lissue. J. Biol. Chem 1942; 146:313-21.

118 Spaulding ME, Graham WD. The enzymatic degradation of cozymase and the inhibitory action of $\alpha$ tocopherol phosphate. J. Biol. Chem, 1947; 170: 711-18.

119 Heinrich MR, Mattill HA. The creatine content of the liver in the muscular dystrophy of vitamin $\mathbf{E}$ deficiency. J. Biol. Chem. 1949; 178:9 $11-17$.

120 Sakai $T$, Okano $T$, Makino $H$, Tsudzuki $T$. Activation of cyclic AMP phosphodiesterase by a new vitamin E derivative. Golic Nucleotide Res. 1976;2: 163-70.

121. Abita IP, Parniak M, Kaufman S. The activation of rat liver phenylalanine hydroxylase by limited proteolysis, lysolecithn, and tocopherol phosphate. Changes im confommation and catalytio properties. SBol Chen. 1984; 259: 14560\%6.

122 Felemovichus 1, Bonsack ME, Baptista ML, Delaney JP. Intestinal radioprotection by vitamin $\mathrm{E}$ (alpha-tocopherol). Ann Swg. 1995; 222:504-8; discussion 508-10.

123 Pérez-Pé R, Cebrián-Pérez JA, Muino-Blanco Tí, Semen plasma proteins preveni cold- shock mem brane damage to ram spermatozoa. Theriogenology. 2001; 56:425-34.

124 Gumieri C, Giordano E, Muscari C Grossi L, Caldarera CM. Alpha tocophorol pretreament imm proves endothelium-dependent vasodilation in aortic strips of young and aging rats exposed to oxidiative stress. Mol Cell Biochem. 1996; 157: 223-8.

125 Rexk BM, Haenen GRMM, van dev Vijgh WJP, Bast A. Vilmmin E phosphate in a novel apoptotic agent (Chapter 3)

126 Munteamu A, Zingg JM, Ogru E, Libinaki R, Griandllo R, West S, Negiss Y, Azzi A. Modulation of cell proliferation and gene expressiom by alpha-tocopheryl phosphates: relevance to aherosclerosis and inflammation. Biochem Biophys Res Commwn. 2004: 318:311-6.

127 Hejnen CG, Haenen GRMM, var Acker FA, wan der Vijgh WJF, Bast A. Flawonoids as peroxymtrite scavengers: the role of the hydnoxy groups. Toxicol In Vimo. 200 $1 ; 15: 3-6$. 
128 Hejnen CO, Haten GRMM, Oontveen RM, Stalpers EM, Bagl A. Protection of navonouds against

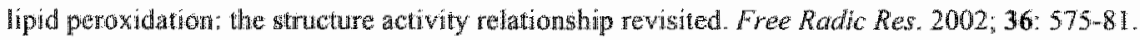

129 Heinan CG, Haenen GRMM, Vekmans IAM, Bast A. Peroxyntrite scavenging of Lavonoids: structure activity relationship. Emirom. Toxicol. Phormacol. 2001; 10: 199-206.

130 wan A wher SA, Tromp MN, Hatenen CRMM, wan der Vigh WJF, Bast A. Flavonoids as scawengers of nithic oxide radical. Biochem Brophys Res Comman. 1995; 214:755.9.

131 Hacnen CWMM, Paquay JB, Korthouwer RE, Bast A. Peroxymitrite scavenging by llavonoids. Biow chem Brophys Rex Comwnum. 1997:236:59:-3.

132 Maenen GRMM, Bast A. Nitrie oxide radical scavenging of Davonoids. Methods Enzynot. 1999 ; 301: $490-503$.

133 wan Acker FA, Schouten O, Haenen GRMM, wan der Vijgh WJF, Bast A. Favonoids can replace alpha-hocopherol as an antioxidant. fEBS Let. 2000; 473: 145-8.

134. Yousef MI, Kamel KI, Esmail AM, Baghdadi HH. Antioxidant activities and lipid lowering effects of lisollavone in malle rabits. Food Chom Toxicol. $2004 ; 42: 1497-503$.

$135 \mathrm{~K}$ iziltepe U, Turan $\mathbb{N N}$, Han U, Uhs AT, Akar F. Resveratrol, a red wine polyphenol, protects spinal cord from ischemia-reperfusion injury. $J / \mathrm{rac}$ Surg. $2004 ; 40: 138-45$.

136 Galat $\mathrm{G}$, Teng $\mathrm{S}$, Moridani MY, Chan TS, O'Brien PJ. Cancer chemoprevention and apoptosis mechanisms induced by dietary polyphenolics. Drug Metabo/ Drag theract 2000; 17:311-49.

137 Ren W, Qiao Z, Wang H, Zhu L, Zhang L. Flavonoids: promising anticancer agents. Med Res Rev. $2003 ; 23: 519-34$

138 Kitada S, Leone M, Sareth S, Zhai D, Reed JC, Pallechia M. Discovery, characterization, and structure-âctivity relationships studies of proApoptogenic polyphenols targeting B-cell lympliocyteleukernia-2 proteins. I Afed Cham. 2003; 46:4259-64.

139 Williams RJ. Spencer JP, Rice-Evans C. Flavonoids: antioxidants or signalling molecules? Free Radic Bial Med. 2004; 36: 838-49.

140 Schneider $H$, Schwierty A, Collins MD, Blat M. Anaerobic transformation of quercetin-3-glucoside by bacteria from the human intestinal tract. Arch Mricrobiol. 1999; 171: 81-91.

141 Walle T. Absorption and metabolism of flavonoids. Fine Radic Biol Med. 2004; 36: 829-37.

142 DuPon MS, Dny AJ, Bemett RN, Mellon FA, Kroon PA. Absorption of kaempferol from endive, a

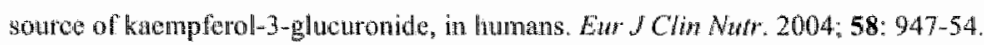

143 Decker EA. Phenolics: prooxidants or antioxidarts? Nutr Rev. $1997 ; 55: 396-8$.

144 Sakihama $\mathcal{Y}$, Coher MF, Grace SC, Yamasaki H. Plant phonolic antioxidant and prooxidant activitien: phenolics-induced oxidative dange mediated by netals in plants. Toxicology. 2002; 177: 6780.

145 Galati $\mathrm{G}$, Sabzevari $\mathrm{O}$, Witson JX, O'Brien PJ. Prooxidant activity and cellular effects of the phesnoxyl radicats of dietary flavonoids and other polyphendics. Toxicology 2002; 177: 91-104.

146. Awad HM, Boersma MG, Boeren S, Van Bladeren PJ, Verwoort J, Rietjens IM. Quenching of quercetin quinone/quinone methides by different tholate scavengers: stability and reversibility of conjugate formation. Chem Res Toxical 2003; 16:822-31.

147 Boots AW, Koblen N, Haenen ORMM, Bast A. Oxidized quercetin meacts with thiols rather than with ascorbate: implication for quercatin supplementation. Biochem Biophys Res Cammun. 2003; 308: 560$)-5$ 
148. Eserpa A, Gonzalez MC. High-pertormance liquid chomatography with diode-amy detedion for the detemmation of phenolic compounds in peel and pulp from differen apple varieties. J Chroma togr A. $1998 ; 823: 331-7$.

149 Malathi P, Cane RK. Phlorizin hydrolase: a betanglucosidase of hamster intestina brush border membrane. Biochim Biophys Acfa. 1969;173:245-56.

150 Kraml J, Kolinska J, Eddederova D. Hirsowa D. B-Glucosidase (phlorizin hydrolase) activity of the lactase fraction isolated from the small intestingl mucosa of infant rats, and the relationship betwesn B-glucosidases and Bugalactosidases. Biochim Biophys Acta 1972; 258: 520 - 30 .

151 Skjevalk 1, Solheim E, Scheline RR. Dihydrochalcone metabolism in the rat: trihydroxylated derivatives related to phloretin. Xenobiotica. $1986 ; 16: 35-45$.

152 Monge P, Solheim E, Scheline RR. Dihydrochalcone metabolism in the rat: phloretin. Xenobiatica. $1984: 14: 917-24$

153 Crespy V, Aprikian O, Morand C, Besson C. Manach C. Demigne $C$, Remesy C. Bioavailability of phloretin and phloridzin in rats. J Nutr. $2001 ; 131: 3227-30$.

154 Crespy V, Morand C, Besson C, Manach C, Demigne C, Remesy C. Comparison of the intestinal absorption of quercetin, phloretin and their glucosides in rats. $N$ Nor. 2001; 131:2109-14.

155 Bors $W$, Heller $W$, Michell $C$, Saran M. Flavonoids as antioxidants: detemination of radicalscavenging efficiencies. Methods Enzymol. 1990; 186:343-55.

156 Shimoi K, Masuda S, Furugori M, Esaki S, Kinae N. Radioprotective effect of antioxidativo flavonoids in gamma-ray iradiated mice. Carcinogenesis. 1994; 15:2669-72.

157 Rezk BM, Haenen GRMM, van der Vijgh WJF, Bast A. The antioxidant activity of phloretin: the disclosure of a new antioxidant phamacophore in flavonoids. Biochen Biophys Res Commwn.2002; 295: $9-13$.

158 Calliste CA, Le Bail JC, Trouillas P, Pouget C, Habrioux G, Chulia AJ, Duroux Jls. Chalcones: structural requirements for antioxidant, estrogenic and antiproliferative activities. Anticancer Res. $2001: 21: 3949.56$.

159 Nakamura $\mathrm{Y}$, Watanabe $\mathrm{S}$, Miyake $\mathrm{N}$, Kolmo $\mathrm{H}$, Osawa $\mathrm{T}$. Dihydrochalcones: evaluation as novel radical scavenging antioxidants. J Agric Food Chem. 2003; $51: 3309 \mathrm{~m} 12$.

160 Mathesen $L$, Mallerud KE, Sund RB. Hydrogen bond formation as basis for radical scavenging activity: a structure-activity study of C-methylated dihydrochalcones from Myrica gale and structurally related acetophenones. Firee Radic Biol Med. 1997; 22: 307-11.

161. Csaky TZ. Membrane-tmansport of sugats in diabetes nellitus. Prog Cho Biol Res. 1988; 258: $37-42$.

162 Dimitrakoudis D, Vranic M, Klip A. Effects of hyperglycemia on glucose tramsporters of the inuscle use of the renal glucose reabsomption inhibitor phlorizin to control glycemia. $J$ Am Soc Nephrol. 1992: $3: 1078-91$

163 Kobori M, Shinmoto H, Tsushida T, Shinohara K. Phloretin-induced apoptosis in B16 melanoma 4 A5 cells by inhibition of glucose transmembrane transport. Concer Lent. 1997; 119:207-12.

164 Alvarado F, Crane RK. Studies on the mechanism of intestinal absorption of sugars. VII. Phenylglycosides transpont and its possible retation to phloridzin inhibition of the active ranspott of sugars by the small intestine. Biochim Biophys Acta. 1964:93: 116-35.

165 Illiano $\mathrm{G}$, Cuatrecasas $\mathrm{P}$. Glucose transport in fat cell membranes. $/$ Bio/ Chem. 1971; 246:2472*9.

166 Kitanaka J, Ishibashi T, Baba A. Phloretin as an antagonist of prostaglandin $F 2$ alpha receptor in cultured rat astrocytes. I Netrochem. 1993; 60: 704-8. 
167 Blazso G. Gabor M. Elfects of prostaglandin antagonist phloretin deriwatives on mollse ear edema induced with different shin irtarts. Prostaglandins 1995; 50: 161-8.

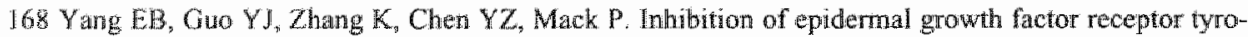
sine Kinase by chalcone derivatives. Brochm Bhoptys Acta. 2001; 1550: 144-52.

169 Reed LJ, De Dusk BC, Gunsalus IC, Schnakenberg GHF. Crystalline alpha-lipoic acid, a catalytic agemt associated whith pyruvate dehydrogenase. Schence. $1951,114: 93-4$.

170 Bullock MW, Buckmarn JA, Paterson EL, Piece JV, won Saltza MH, Sanders F, Stokstad ELR. Symthesis in the throctic acid series. J. Am. Chem. Soc. 1954; 76: 1828-32.

171 Brockmann JA, Stokstad ELR, Patterson EL, Pierce JV, Macchi ME, Proposed structures for protogen-A and protogenw B. J. Am. Chew. Soc. 1954; 76: 1827-28

172 Miller IR, Busby RW, Jordan SW, Cheek J, Henshaw TE, Ashley GW, Broderick JB, Cronan JE Jr, Marlefta MA. Escherichia coll LipA is a lipoyl synthase: in vitro biosynthesis of lipoylated pyruwate dehydrogenase complex from octanoyl-acyl cartier proten. Biochemisiry, 2000; 39: 15166-78.

173 Morikawa $T$, Yasuno R, Wada H. Do mammalian cells synthesize lipoic acid? Identification of a mouse cDNA encoding a lipoic acid sym thase located in mitochondria. FEBS Letr. 2001; 498: 16-21.

174 Harrison 1tH, McCormick DB. The metroolism of dl-(1,6-14C)lipoic acid in the rat. Arch Brochem Bhophys. 1974: 160:514-22.

175 Biewenge GP, Haenen GRMM, Bast A. The phamacology of the antioxidant lipoic acid. Gen Photmacal. $1997: 29: 315-31$

176 Teichert $\mathrm{J}$, Hermann $\mathrm{R}$, Ruus $\mathrm{P}$, Preiss $\mathrm{R}$. Plasma kinetics, metabolism, and uninary excretion of alpha-lipoic acid following orall administration in healthy volunteers. I Clin Pharmocol. 2003; 43. $1257-67$.

177 Smih AR, Shanvi SV, Widlansky M, Suh JH, Hagen TM. Lipoic acid as a potential therapy for chronic diseases enssociated with oxidative stress. Cur Med Chem. 2004; 11: 1135-46.

179. Spence JT", McComick DB. Lipoic acid metabolism in the tat. Arch Biochem Brophys. 1976; 174: $13 \times 9$

179 Preiss R, Teichert $f:$ Studies on the metabolism of a-lipotc acid in humans. Naumyn Schmiedebergs Arch Phammacol. $1997 ; 355: \mathrm{R} 121$.

180 Locher M, Busker E, Bowbe 10 O Metabolism of a-lipoic acid in human volunteers. Namym Schmiedebergs Arch Pramacol 1995; 351 : R52.

181 Bast A, Haenen GRMM. Regulation of lipid peroxidation by glutethione and lipoic acid: inwolvement of liver microsomal vitamin E free radical reductase. Adw Exp Med Biol. $1990 ; 264: 111-6$.

182 Haenen CoMM, Bast A. Scawenging of hypochlorous acid by lipoic acid. Brochent Phomacol. $1991: 42: 2244-6$.

183 van Haaten RHM, den Hartog GM, Evelo CT, Haenen GRMM, Bast A. Hypochlorous acid is a potent inhibitor of GST P1- Chew Biol Inrenact 2001:138:77-83

184 den Hantog GI, Vegt E, wan der Vigh WJF, Haenen GRMM, Bast A. Hypochlorous acid is a potent inhibitor of acetylaholunestense. Toxicol App Pharwacol 2002;181:228-32

185 Rezk BM, Haenen ORMM, van der Vijgh WJF, Bast A. Lipoic acid protects efficiently only aganst specific lon of peroxynitritem induced damage. J Biol Chem. 2004; 279:9693-7.

186 Whiteman $M$, Trischler $H$, Hallwell B. Protection against peroxynitrite-dependent tyrosime nitration and a lpha 1 -antiprotemase inacivation by oxidized and neduced lipoic acid. FEBS Leit. 1996; 379 : $74-6$ 


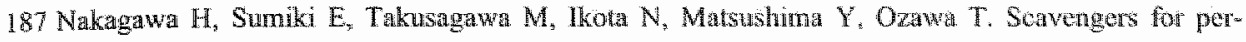

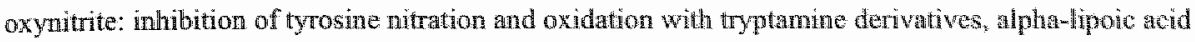
and synthetic compounds. Cheny Pham Bul. (Tokyo) 2000; $48: 261-5$.

188 Trujllo $M$. Radi $R$. Peroxynituite reaction with the reduced and the oxidized forms of lipoto acid: new insights into the reaction of peroxynitrite with thiols. Arch Biochem Blophys. 2002; 397: 91-8

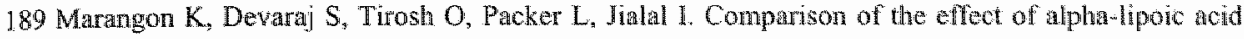
and alplua-focopherol supplementation on measures of oxidative stress. Free Radic Biol Med. 1999; 27: $1114-21$.

190 Khama S, Atalay M, Laaksonen DE, Gul M, Roy S, Sen CK. Alpha-lipoic acid supplememtalion: tissue glutathione homeostasis at rest and after exercise. I App/ Physiol 1999; 86: 1191-6.

191. Suh JH, Shigeno ET, Morrow JD, Cox B, Rocha AE, Frei B. Hagen TM. Oxidative stress in the aging rat heart is reversed by dietary supplementation with (R)-(alpha)-Hipotc acid. FASER $2.2001 ; 15$ : $700-6$.

192 Ariwazhagan P. Panneerselvam C. Effect of DL-alpha-lipoic acid on neural antioxidants in aged rats. Pharmacol Res. $2000 ; 42: 219-22$.

193 Bast A, Haenen GRMM. Lipoic acid: a multifunctional antioxidant. Biofactors. 2003; 17:207-13.

194 Jocelyn PC. The standard redox potential of cysteine-cystine from the thiol-disulphide exchange reaction with glutathione and lipoic acid. Ew J Biochen. 1967;2:327-31.

195 Packer L. alpha-Lipoic acid: a metabolic amtioxidant which regulates NI-kappa B signall tansduction and protects against oxidative injury. Drug Metab Rev. 1998; 30:245.75.

196 Han D, Handelnan G, Marcocci L, Sen CK, Roy S, Kobuchi H, Tritschler HJ, Flohe L, Packer L. Lipoic acid increases de novo synthesis of cellular glutathione by improving cystine ntilization. Biofactors. $1997 ; 6: 321 \cdot 38$.

197 Yanamoto H, Watanabe T, Mizmo H, Endo K, Fukushige I, Hosokawa T, Kazusaka A, Fujita $\mathrm{S}$. The antioxidant effect of DL-alpha-lipoic acid on copper-induced acute hepatitis in Long-Evans Cinnamon (LEC) rats. Free Radic Res. $2001 ; 34: 69-80$.

198 Scott BC, Armoma OI, Evans PJ, ONeill C, Van der Vhet A, Cross CE, Tritschler H, Halliwell B. Lipoic and dinydrolipoic acids as antioxidanis. A critical evaluation. Fores Radro Rex. 1994: 20: 11933.

199 Moini H, Packer L, Saris NE. Antioxidant and proox dant activities of apha-lipoic acid and dilydrolipoie acid Toxicol Appl Pharmacol. 2002; 182: 84-90.

200 Packer L, Kramer $K$, Rimbach G. Molecular aspects of lipoic acid in the prevention of diabetes complications. Nutrition. 2001; 17:888-95

201 Kishi Y, Schmelzer JD, Yao JK, Zollman PJ, Nickander KK, Tritschler HI, Low PA. Alpha-lipouc acid: effect on glucose uptake, sorbitol pathway, and energy metabolism in experimental diatbetic neuropatliy. Diaberes. 1999; 48:2045-51

202 Yaworsky K, Somwar R, Ramlal T, Ttitschler HJ, Klip A. Engagement of the insulin-sensitive pathway in the stimulation of glticose transpont by alpha-lipoic acid in 3T3-LI adipocyles. Diabetologia. 2000:43:294-303.

203 Biewenga G, Halenen GRMM, Bast A. The role of lipoic acid in the treatment of diabetie polynetropathy. Drug Metah Rev. 1997; 29: $\| 025-54$.

204. Roy S, Sen CK, Kobuchi H, Packer L. Antioxidant regulation of phorbol ester-indued adhesion of hurnan Jurkat T-cells to endothelial cells. Free Radic Biol Med. 1998; 25:229-41. 
205 2hang W/, Frei B. Apha-lipoic acid inwibits TNF-alphe-induced NF-kappab actuation and adhesion molecule expression in human aoric endothelial cells. FASEB J.2001, 15:2423,32.

206. Kiemer AK. Muller $C_{\text {, Volmar } A M}$ Inhibiton of LPS-induced nite oxide and TNE-apha producGon by alphamlipoic acid in rat Kuptfer cells and in RAW 264.7 murine macrophages. Imwtol Cell Biol. $2002 ; 80: 59-7$.

207 Kim MS, Park JY, Namkoong C, Jang PG; Ryu JW, Song HS, Wun IY, Namgoong IS, Ha J, Park IS,

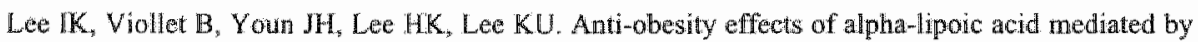
suppression of hypothatamic AMPmactivated protein kinase. Nar Med. 2004; 10: 727-33.

208 Wagner C. Symposium on the subcellular compantmentation of folate metabolism. $/ \mathrm{Natr}$ 1996; 126: $1.2285 \cdot 345$

209 Scot JM. Folate and vitamin B12. Proc Nut Soc. 1999; 58: 441-8.

210 Hanson AD, Gregory JF 3nd. Synthesis and turnover of folates in plants. Cur Opin Plom Biol. 2002; 5. 2449

211 Basset Gl, Quinlivan EP, Ravanel $S$, Rebeille $F$, Nichols BP, Shinozaki $K$, Seki M, Adamushillips LC, Giovannoni $\mathrm{J}$, Gregory JF $3 \mathrm{rd}$, Hanson AD. Folate synthesis in plants: the p-aminobenzoate branch is initiated by a bifunctional PabA-PabB protein that is targeted to plastids. Proc Nan Acad Sci USA. 2004; 101: 1496-501.

212 Vorhar MC, Stroes E, Rabelink TJ. Folates and cardiovascular disease Arterioscler Thromb Vasc Biol. 2002; 22:6-13.

213 Limdenbaum J, Nath BI. Megaloblastic anamia and neutrophil hypersegmentation. Br J Haematol. $1980 ; 44: 511-3$

214 Manzoor M, Runcie J. Folate-responsive meuropathy: repont of 10 cases. Br Med J. 1976; 1: 1176-8.

215 Alpert JE, Pava M. Nutrition and depression: the role of folate. Nutr Rev. 1997; 55: $145-9$.

216 Daly LE, Kirke PN, Molloy A, Weir DG, Scoti JM. Folate levels and neural tube defects. Implicathons for prevention. IAMA. 1995; 274: 1698-702

217 Duthie SJ, Natayanan S, Brand GM, Pirie L, Grant G. Impact of folate deficiency on DNA stability. J Nuti: 2002; 132:2444S-2449S.

218 Akoglu B, Faust D, Milovio V. Stem J. Folate and chemoprevention of colorectal cancer: Is 5 methyl-fetrahydtofolate an active antiprohiferative agent in folate-treated colonmancer cels? Nutrim niont. $2001 ; 17: 652-3$.

219 Halsted CH. Intestinal absorption and malabsorption of folates. Anmu Rev Med 1980; 31:79-87.

220 Reisenatuer $A M$, Krumalieck CL, Hasted GH. Folate conjugase: rwo separate activities in truman jejunum. Schence. 1977; 198:196-7.

221 Solhub $I$, Dhat G., Rosenberg IH. Gastrointestinal absorption of folates and antifolates. Phowracol Ther. $11983: 20: 397-418$.

222 Tamua T. Stokgtad EL. The avallability of food folate in man. Br. Haematol. 1973, 25:513-32.

223 Said HM, Home DW, Wagner C. Effect of human mik folate binding protein on folate intestinal transport. Aroh Biochen Biophys. 1986;251:114.20.

224 Bailey LB, Gregry JF 3rd. Follate metabolism and tequirements. W Nwt 1999; 129:779-82.

225 Russel RM, Dhar GJ, Dutta SK, Rosenberg IIL. Infuence of intraluminal pH on folate absomption: studies in control subjects and in patients with pancreatic insufficiency. $J$ Lab $C / W n$ Med. 1979; 93: $428-36$

226 Steinberg SE; Camplodl CL. Hillman RS. Kinetics of the normal folate enterohepatic cycle. of Chn Invest. $1979 ; 64: 83-8$ 
227 Dosli SN, McDowell IF, Mont SJ, Lang D, Wewcombe RG, Kedan MB, Lewis MU, Goodfllow J. Folate improves endothelial function in coronary artery disease: an effeot medinted by reducturn of intracellular superoxide? Amerioscler Thromb Vaxc Biol 2001; 21: 1196-202.

228 vehaar MC, Wever RM, Kastelein JI, van Dam T, Koomans HA, Rabelnk T. 5 . methyltetrabydrotolate, the active form of folic acid, restores endothelal function in famthal hypercholesterolemia. Circturion. 1998; 97: $237-41$.

229 Stroes ES, van Faassen EE, Yo M, Martasek P. Boer P. Govers R. Rabelink TJ. Folic acid revorts dysfunction of endothelial nitric oxide synthase. Ciro Res. 2000; 86:1129-34.

230 Gori T, Burstein JM, Ahmed S, Miner SE, Al-Hesayen A. Kelly S, Parker ID. Folio acid prevents nitroglycerin-induced nituic oxide synthase dysfunction aitd nitrate tolerance: a human in wivo study. Circularion. 2001; 104:1119-23.

231 Rezk BM, Haenen GRMM, wan der Vight WJ., Bast A. Tetralnydrofolate and 5methyltetrahydrofolate are folates with high antioxidant activity. Identification of the antioxidant pharmacophore. FEBS Letr. 2003; 555: 601-5.

232 Joshi $R$, Adhikari $S$, Patro $B S$, Chatopadhyay $S$, Mukherjee $T$. Free radical scavenging behavior of folic acid: evidence for possible antioxidant activity. Free Radic Biol Med. 2001; 30; 1390-9

233 Refsum H, Ueland PM. Nygard O, Vollset SE. Homocysteine and cardiovascular disease. Amm Rev Med. $1998 ; 49: 31-62$.

234 Pancharuniti $N$, Lewis, CA, Sauberlich HE, Perkins LL, Go RC, Alvarez IO, Macaluso M, Acton RT, Copeland RB, Cousins AL, et all. Plasma homocyst(e)ine, folate, and vitamin B-12 concentrations and risk for earlymonset coronary artery disease. Am $J$ Clm Nur $1994 ; 59: 940-8$.

235 Selhub J, Jacques PE, Bostom AG, D'Agostino RB, Wilson PW, Belanger AJ, O'Leary DH, Wolf PA. Schaefer EI, Rosenberg IH. Association between plisma homocysteine concentrations and extractanial carotid-artery stenosis. N Engl J Med. 1995; 332:286-91.

236 den Heijer M, Koster T, Blom HI, Bos GM, Briet E, Reitsma PM, Vandenbroucke JP, Rosendaal FR. Hyperhomocysteinemia as a risk factor for deep-vein thrombosis. N Engl J Med. 1996; 334: 759-62.

237 Finkelstein JD. The metabolism of homocysteine: pathways and regulation. Eur J Pediatr. $1998 ; 157$ $5,50 \times 4$.

238 Goldenberg RL, Tamura T, Cliver SP, Cutter GR, Hofmen H. Copper RL. Serum folathe and fotal growth retardation: a matter of compliance? Obstes Gyocol 1992; 79; $719-22$.

239 Nelen WL, Bulten J, Steogers EA, Blom HJ, Hanselar AG, Eskes TK, Matemal homocysteine and chotionic vascularization in recurent early pregnancy loss. Hum Reprod $2000 ; 15: 95460$.

240 Shikany IM, Heimburger DC, Piyathilake CI, Desmond RA. Greene PG. Effect of folic acid fortill. cation of foods on folate intake in female smokers with cerwical dysplasia. Nutrition. 2004; 20:409. 14.

241 Martinez ME, Henning SM, Aberts DS. Folate and colormetal neoplasia: relation between plasma and dietary markers of follate and adenoma recurrence. Am d Clim Nutr. 2004; 79:691-7.

242 Sellers TA, Grabrick DM, Vierkant RA, Hamack L, Olson JE, Vachon CM, Cerhan JR. Does folate intake decrease risk of postmenopausal breast cancer among women with a family bistory? Capce Causes Control 2004: 15:113-20.

243 Kim Y. Role of folate in colon carcer development and progression. I Natr. 2003; $133: 37315$ 37395 .

244 Shen H, We: Q. Pillow PC. Amos CI, Hong WK, Spitz MR. Dietary folate intake and Iung cancer risk in tormer smokers: a case - control analysis. Cancer Epratemiol Biomarkers Prew. 2003; 12:980-6. 
245 French AE, Grath R, Weitzman S, Ray JG, Vermeulen MIJ, Sung L, Greenberg M, Koren G. Folic acid food lortification is associated with a decline in neuroblastoma. Chin Pharmacol Ther. 2003; 74 : $288-94$.

246 Fang JY, Xiao SD, Zhu SS, Yuan JM, Qiu DK, Jiang SJ. Relationship of plasma folic acid and status of DNA mathylation in human gastric cancer. I Gastroenterol. 1997; 32:171-5.

247 Reidy IA. Role of deoxyuridine incorporation and DNA repair in the expression of human chromosomal fragile siture. Muar Res. 1988; 200:215-20. 


\section{Chapter 2}

\section{The extraordinary antioxidant activity of vitamin $\mathrm{E}$}

phosphate

Bashir M. Rezk, Guido R.M.M. Haenen, Wim J.F. van der Vijgh, and Aalt Bast

Biochim Biophys Acta. 2004; 1683: 16-21 


\begin{abstract}
The antioxidant activity of RRR-vitamin $\mathrm{E}$ (VE), all-rac-vitamin $\mathrm{E}$ (all-rac-VE), trolox, RRR-vitamin $E$ acetate (VEA), all-rac-vitamin E phosphate (VEP) and RRR-vitamin E succinate (VES) were compared. In this study, the rank order in the inhibition of lipid peroxidation of VE and its derivatives was trolox $>V E \approx$ all-rac-VE $>V E A>V E S$. VE and trolox inhibited lipid peroxidation in non-heated and heated rat liver microsomes. It has generally been accepted that this is due to scavenging of free radicals by these antioxidants, and during this protection the antioxidants are oxidized. VEA and VES have to be converted into VE by esterases to obtain antioxidant activity against lipid peroxidation. VEP, however, had a potent antioxidant effect of its own without conversion to VE. In contrast to VE, VEP is not consumed during this protection. Of the compounds tested, VEP is the most potent in induction of hemolysis of erythrocytes. EPR experiments using the spin label 16-doxylstearic acid showed that VEP reduces membrane fluidity, in contrast to VE. This indicates that VEP acts as a detergent and forms a barrier that might inhibit the transfer of radicals from one polyunsaturated faty acid to another. This new mechanism may form the basis for a new class of antioxidant.
\end{abstract}




\section{Introduction}

Free radicais are continuously produced within living cells as a result of metabolic reactions. In addition, numerous exogenous sources, inchding xenobiotics and radiation can induce free radicals. Although cells have an elaborate defense system that provides protection against these free radicals, the development of cancer, cardiovascular and neurological diseases, and other oxidative stress mediated dysfunctions occur $(1-3)$. Vitamin $\mathbb{E}(\mathrm{VE})$ is one of the most important lipid-soluble primary defense antioxidants. Vitamin $\mathbb{E}$ is a generic term used for several naturally occurring tocopherols and tocotrienols. The vitamin $E$ molecule can be divided into two parts, a hydroxyl-bearing aromatic system (one phenolic and one heterocyclic ring, called the chroman head) that is responsible for its antioxidant properties, and either a saturated (tocopherols) or polyunsaturated (tocotrienols) hydrocarbon tail for the orientation of VE in the lipid membrane (4).

In its function as a chain-breaking antioxidant, VE rapidly transfers its phenolic $\mathrm{H}=\mathrm{atom}$ to a lipid peroxyl radical, converting it into a lipid hydroperoxide and a VE radical (5, 6). The VE radical can be reduced to $\mathrm{VE}$ by vitamin $\mathrm{C}$ or reduced glutathione or alternatively it is further oxidized to VE quinone (6). VE is often supplemented as a chemically stable ester derivatiwe such as RRR-vitamin $E$ acetate (VEA), all-rac-vitamin E phosphate (VEP) or RRR-vitanin E succinate (VES). These esters are expected to possess no antioxidant effect due to the shielding of the phenolic active antioxidant group by acetate, phosphate or succinate, respectively (Fig. 1).

The aim of this study is to compare the intrinsic antioxidant activity of $\mathrm{VE}$ and its derivatives, trolox, VEA, VEP and VES in non-heated and heated microsomes.

\section{Materials and Methods}

\subsection{Chemicals}

The tested compounds, RRR-a-tocopherol (VE), all-rac-a-tocopherol (all-rac-VE), RRR- $\alpha$-tocopherol succinate (VES), RRR-a-tocopherol acetate (VEA), all-rac-atocopherol phosphate (VEP) and trolox (6-hydroxy-2,5,7,8-tetramethyl-chroman-2carboxylic acid) in addition to alkaline phosphatase (Orthophosphoric-monoester phosphohydrolase[alkaline optimum]: EC 3.1.3.1), 16-doxylstearic acid and ABTS (2,2azmobis(3-ethylbenzthiazoline-6-sulfonic acid) were obtained from Sigma (St. Lours, MO, USA). All other used chemicals were of analytical grade purity. 


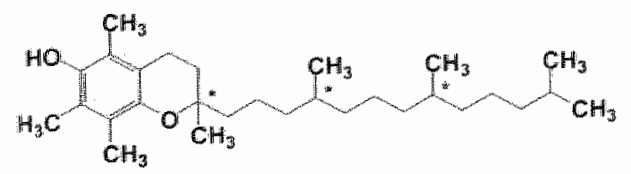

Vurarian<smiles>C=C(CCCC[C@H](C)CCC[C@@]1(C)CCc2c(C)c(C)c(OC(C)=O)c(C)c2O1)CCCC(C)C</smiles>

Whamin $\mathbf{E}$ Acente

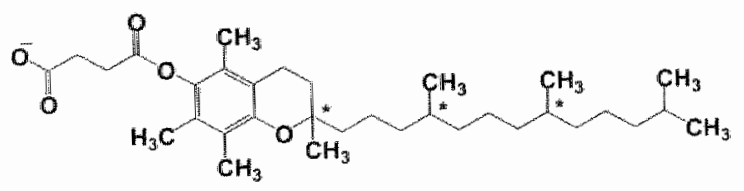

Vitaminu Succinate<smiles>C=C(CCCCC(C)=CCCC(C)C)CCC[C@]1(C)CCc2c(C)c(OP(=O)([O-])[O-])c(C)c(C)c2O1</smiles>
Vitamin E Phosphate<smiles>Cc1c(C)c2c(c(C)c1O)CCC(C)(C(=O)O)O2</smiles>

'Trolon

Fig. 1. Chemical structure of vitamin $\mathrm{E}$ (VE) and its derivatives vitamin $\mathrm{E}$ acetate (VEA), vitamin E succinate (VES), vitamin $\mathrm{E}$ phosphate (VEP) and Trolox. The assymetrical carbon atoms are indicated by an asterisk.

\subsection{Isolation of rat liver microsomes:}

Male Lewis rats, $200-250 \mathrm{~g}$, were killed by decapitation. Microsomes were prepared according to Haenen and Bast (7) with a slight modification. Livers were removed and homogenized $(1: 2 \mathrm{w} / \mathrm{v})$ in ice cold phosphate buffer $(50 \mathrm{mM}, \mathrm{pH} 7.4)$ containing 0.1 $\mathrm{mM}$ EDTA. The homogenate was centrifuged at $10,000 \mathrm{~g}$ for $30 \mathrm{~min}$ at $4{ }^{\circ} \mathrm{C}$. Subsequently, the supernatant was centrifuged at $65,000 \mathrm{~g}$ for $60 \mathrm{~min}$ at $4^{\circ} \mathrm{C}$. The microsomal pellet was resuspended in the phosphate buffer ( $2 \mathrm{~g}$ liver $/ \mathrm{ml})$, corresponding with $1-1.3$ mg protein $/ \mathrm{ml}$, and stored at $-80^{\circ} \mathrm{C}$. Before use the microsomes were thawed and di- 
luted 5 -fold with ice-cold Tris-HCl buffer $(50 \mathrm{mM}, \mathrm{pH} \mathrm{7.4)}$ containing $150 \mathrm{mM} \mathrm{KCl}$ and washed twice followed by centrifugation at $65,000 \mathrm{~g}$ for $40 \mathrm{~min}$ at 4 " $\mathrm{C}$. Finally, the pellet was resuspended in $4 \mathrm{ml}$ Tris-HCl buffer and then used. The protein concentration. was measured according to Smith et al. (8).

\subsection{Lipid peroxidation (LPO) assay}

\subsubsection{Incubation conditions.}

At $37^{\circ} \mathrm{C}, 2150 \mu \mathrm{l}$ of Tris- $\mathrm{HCl} / \mathrm{KCl}$ buffer was added to $1 \mathrm{ml}$ non-heated microsomes or heated microsomes $\left(3 \mathrm{~min}\right.$ at $90^{\circ} \mathrm{C}$ ), the final concentration was $0.5 \mathrm{~g}$ liver $t i s s u e / \mathrm{ml}$. Twentyfive $\mu l l$ of a stock solution of a test compound were added giving a final concentration of 5, 20, or $40 \mu \mathrm{M}$ (VE, trolox, VEA, and VES were dissolved in absolute ethanol, and VEP was dissolved in deionized water). Control experiments showed that at the used concentration, the solvent has no effect on the lipid peroxidation (LPO). Five hundred $\mu$ of an ascorbate solution were added giving a final concentration of $0.2 \mathrm{mM}$. The reaction started by adding $300 \mu \mathrm{l}$ of a freshly prepared ferrous sulfate solution giving a final concentration of $10 \mu \mathrm{M}$. The reaction was stopped after 20 min of incubation as described in section 2.3.2. The concentration that reduces $L P O$ by $50 \%\left(1 C_{50}\right)$ was calculated using the lowest concentration tested giving a protection more than $50 \%$ and the concentration tested that was just below that concentration. A linear relationsluip between the concentration of the antioxidant and the inhibition of LPO was used in the calculation.

\subsubsection{Spectral measurements.}

LPO was assayed by measuring thiobarbituric acid (TBA) reactive material as described previously (7). An aliquot of the incubation mixture $(0.3 \mathrm{ml})$ was stopped by adding 2 $\mathrm{ml}$ of an ice-cold TBA-trichloroacetic acid-HCl-butyllhydroxytoluene (BHT) solution. The mixture was heated for $15 \mathrm{~min}$ at $90^{\circ} \mathrm{C}$ and then centrifuged for 5 min. The absorbance was determined at $535 \mathrm{~nm}$ vs $600 \mathrm{~nm}$. The TBA-trichloroacetic acid-HCl-BH solution was prepared by dissolving $41.6 \mathrm{mg}$ TBA/10 ml trichloroacetic acid $(16.8 \mathrm{w} / \mathrm{v}$ in $0.125 \mathrm{~N} \mathrm{HCl})$. To $10 \mathrm{ml}$ TBA-trichloroacetic acid-HCl $1 \mathrm{ml} \mathrm{BHT}(1.5 \mathrm{mg} / \mathrm{ml} \mathrm{etha-}$ nol) was added. The added chemicals did not interfere with the assay in the concentrations used.

\subsection{The Trolox Equivalent Antioxidam Capacity (TEAC) assay}

The TEAC assay described by Re et al. (9) was used with minor modifications. The ABTS stock solution was prepared by dissolving $30 \mathrm{mg}$ of $\mathrm{ABTS}$ in $7.8 \mathrm{mal}$ of $2.46 \mathrm{mM}$ potassium peroxodisulfate. The ABTS" stock solution was diluted with $100 \mathrm{mM}$ phos- 
Chapter 2

phate buifer (pF 7.4). The absorbance of this radical solution at $734 \mathrm{~nm}$ had to be between 0.68 and 0.73 at $37^{\circ} \mathrm{C}$. For measuring the antioxidant capacity $50 \mu$ of the test compounds were mixed with 950 ul of the ABTS* solution. Absortbance was monitored at $734 \mathrm{~nm}$ for $6 \mathrm{~min}$. The antioxidant capacity was calculated according to van den Berg et al. $(10)$.

\subsection{Vifanin E detemination}

\subsubsection{Conversion of WEP into $V E$.}

VEP $(500 \mu \mathrm{g} / \mathrm{ml})$ was incubated with alkaline phosphatase $(3 \mathrm{U} / \mathrm{ml})$ at $37^{\circ} \mathrm{C}$. The reaction was carricd out in a solution, containing $8.3 \mathrm{mM}$ sodium carbonate, $5.5 \mathrm{mM}$ glucose, $1.2 \mathrm{mM}$ magnesium chloride, $0.5 \mathrm{mM}$ potassium chloride and $0.2 \mathrm{mM}$ zinc sulfate $(\mathrm{pH} \mathrm{7.4)}$. To stop the reaction, $250 \mu \mathrm{l}$ of the reaction mixture was added to a cold solution of absolute ethanol $(2 \mathrm{ml}$ ) with $750 \mu 1$ of deionized water on ice. VE was extracted and determined as described in section 2.5.3.

\subsubsection{VE content of microsomes.}

One mil of non-theated and heated microsomes (1-1.3 $\mathrm{mg}$ protein) was incubated with $100 \mu \mathrm{M}$ of the vitamin $\mathrm{E}$ derivatives for $20 \mathrm{~min}$ at $37^{\circ} \mathrm{C}$. The reaction was stopped by addition of $100 \mu \mathrm{l}$ of $2.5 \% \mathrm{SDS}$, and $2 \mathrm{ml}$ ethanol containing $1 \mathrm{mg}$ BHT to prevent further oxidation. VE was extracted and determined as described in section 2.5.3. Vitamin E nicotinate $(200 \mu \mathrm{g} / \mathrm{ml})$ was used as an internal standard.

\subsubsection{VE extraction and HPLC deternination}

The mixture (from section 2.5.1,2.5.2. or 2.6) was shaken for $5 \mathrm{~min}$, then $3 \mathrm{ml}$ of hexane was added. Again the mixture was shaken for $15 \mathrm{~min}$. After centrifugation the upper hexane layer was aspirated in a conical glass tube and evaporated under nitrogen. The residue was dissolved in $200 \mu 1$ isopropylalcohol for HPLC analysis according to Burton ef al. (11) using a Nucleosil C-18 column and absolute methanol as a mobile phase, with a flow rate of $2 \mathrm{ml} / \mathrm{min}$. VE was detected at $295 \mathrm{~nm}$.

\subsection{Vilamin E phosphate content of microsomes}

One hundred $\mu \mathrm{M}$ of VEP was added to microsomes as described in section 2.3.1. After $1 \mathrm{~h}$ incubation, the samples were centrifuged at $65,000 \mathrm{~g}$ for $40 \mathrm{~min}$. The pellet was resuspended in $4 \mathrm{ml}$ Tris- $\mathrm{HCl}$ and $250 \mu \mathrm{l}$ of $4 \mathrm{M} \mathrm{KOH}$ and then samples were heated at $90{ }^{\circ} \mathrm{C}$ for 3 min for complete rapture of microsomal membrane. After conling (room temperature), the samples were neutralized ( $\mathrm{pH} 7.4)$. At $37^{\circ} \mathrm{C}, 10 \mathrm{U} / \mathrm{ml}$ alkaline phos- 
phatase was added and the samples were incubated for 30 min to convert VEP into VE. Extraction and determination of VE was camied out by the procedure described above in section 2.5.3. Experiments without the addition of alkaline phosphatase were performed as blank.

\subsection{Membrone fluidity of human enythrocytes.}

The membrane fluidity of erythrocytes from healthy donors was measured by means of electron paramagnetic resonance (EPR) spectroscopy. Blood samples were obtained by venipuncture. Heparin was used as anti-coagulant. The plasma and buffy coat were carefully removed after centrifugation at $2000 \mathrm{~g}$ for 10 min at $4{ }^{\circ} \mathrm{C}$. Erythrocytes were washed three times with phosphate-buffered saline (PBS) and finally resuspended in PBS at a haematocrit of $45 \%$. Half $\mathrm{ml}$ of PBS with the test compound (final concentration; $50 \mu \mathrm{M}$ ) was added to $0.5 \mathrm{ml}$ of the erythrocyte containing PBS. After 90 min incubation at $37^{\circ} \mathrm{C}$, spin labeled 16-doxylstearic acid was added and the samples were incubated for $90 \mathrm{~min}$ at $37^{\circ} \mathrm{C}$. Finally, EPR measurements were performed using spectrometer (Bruker EMX, GmbH, Freiburg, Germany) under the following condition: microwave power; $2 \mathrm{~mW}$, modulation amplitude; $1 \mathrm{G}$, scan width; $50 \mathrm{G}$, modulation frequency; $\| 00 \mathrm{kHz}$ and temperature; $30^{\circ} \mathrm{C}$. Membrane fluidity was calculated from the peak height ratio $\left(h_{0} / h_{1}\right)$ as described previously (12).

\subsection{Erythrocyte Hemolysis}

Erythrocyte hemolysis was assessed as described by Neuzil er al. (13) with minor modifications. Erythrocytes were prepared from fresh heparin-treated human blood. One ml blood was diluted 80 times with saline, followed by centrifugation at $2000 \mathrm{~g}$ for 10 min at $4{ }^{\circ} \mathrm{C}$. The pellet was resuspended with $45 \mathrm{ml}$ saline. One $\mathrm{ml}$ of the erythrocyte susm pension was incubated with different concentrations of the test compounds at $37^{\circ} \mathrm{C}$. After $2 \mathrm{~h}$ incubation the samples were centrifuged for $10 \mathrm{~min}$ at $2000 \mathrm{~g}$. Supernatant was diluted 2 times with saline, and the absorbance at $546 \mathrm{~nm}$ was determined.

\subsection{Statistics analysis}

All results are expressed as mean \pm SD. Differences were tested a Student $t$-test with a 9 value of 0.05 .

\section{Results}

The TEAC of trolox is by definition 1. The TEAC of VE and all-rac-VE were $0.97 \pm$ 0.05 and $0.96 \pm 0.03$ respectively. The TEAC of VEA, VES, and VEP were $0.01 \pm 0.02$, $0.01 \pm 0.01$ and $0.01 \pm 0.01$ respectively. 


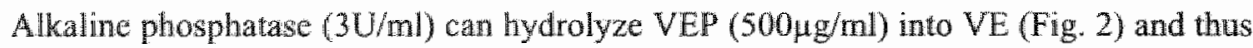
unshield the $\mathrm{OH}$ moicty. The rate of $\mathrm{VE}$ formation was $0.718 \pm 0.048 \mu \mathrm{g} . \mathrm{min}^{-1} . \mathrm{U}^{-1}$.

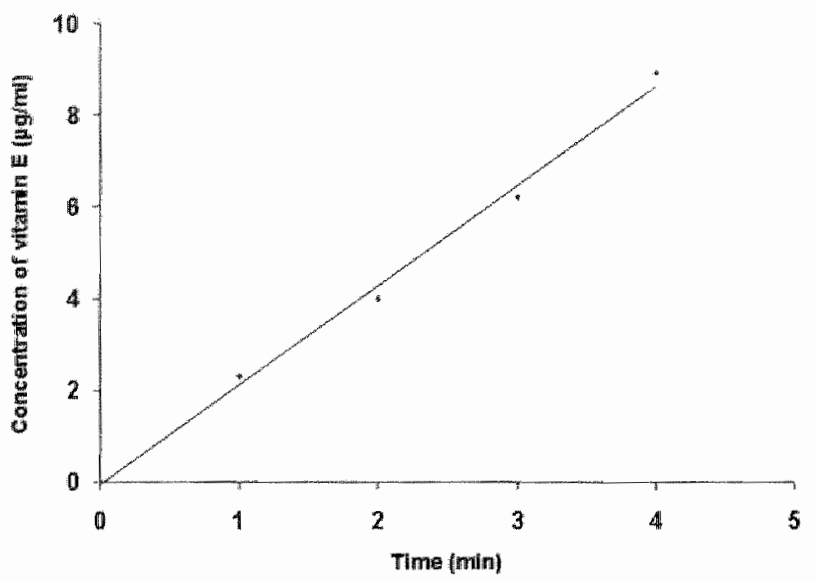

Fig. 2. Hydrolysis of vitamin E phosphate by alkaline phosphatase. Experimental conditions are given in the materials and methods, section 2.5 .1 .

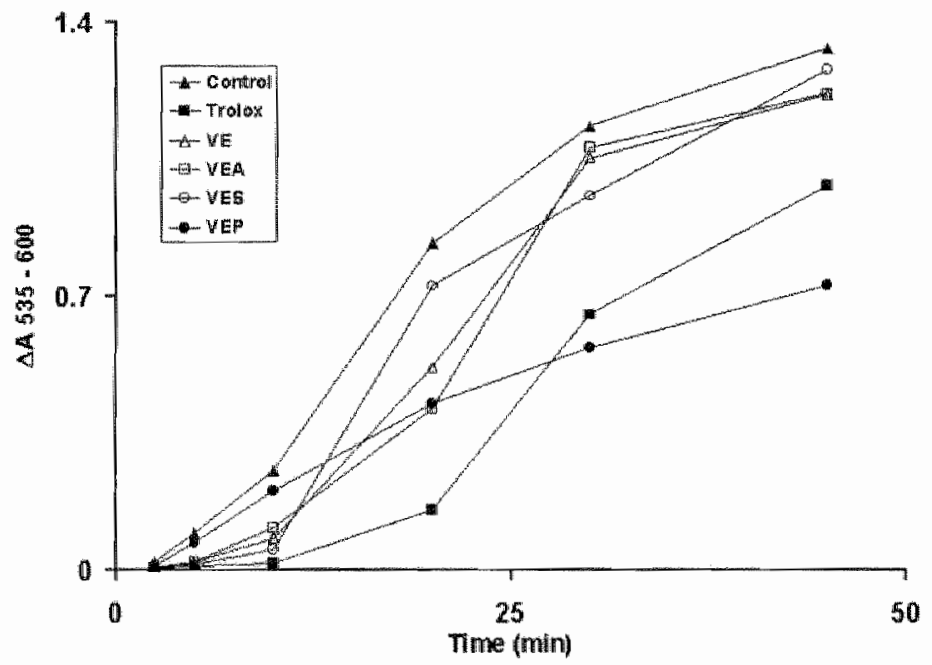

Fig. 3. Time-course of the effect of $20 \mu \mathrm{M}$ of vitamin $\mathrm{E}$ (VE), Trolox, vitamin $\mathrm{E}$ acetate (VEA), vitamin E succinate (VES), and vitamin E phosphate (VEP) on lipid peroxidafion in non-heated microsomes. Experimental conditions are given in the materials and methods, see section 2.3. Values are presented as mean of at least three separate experiments. 


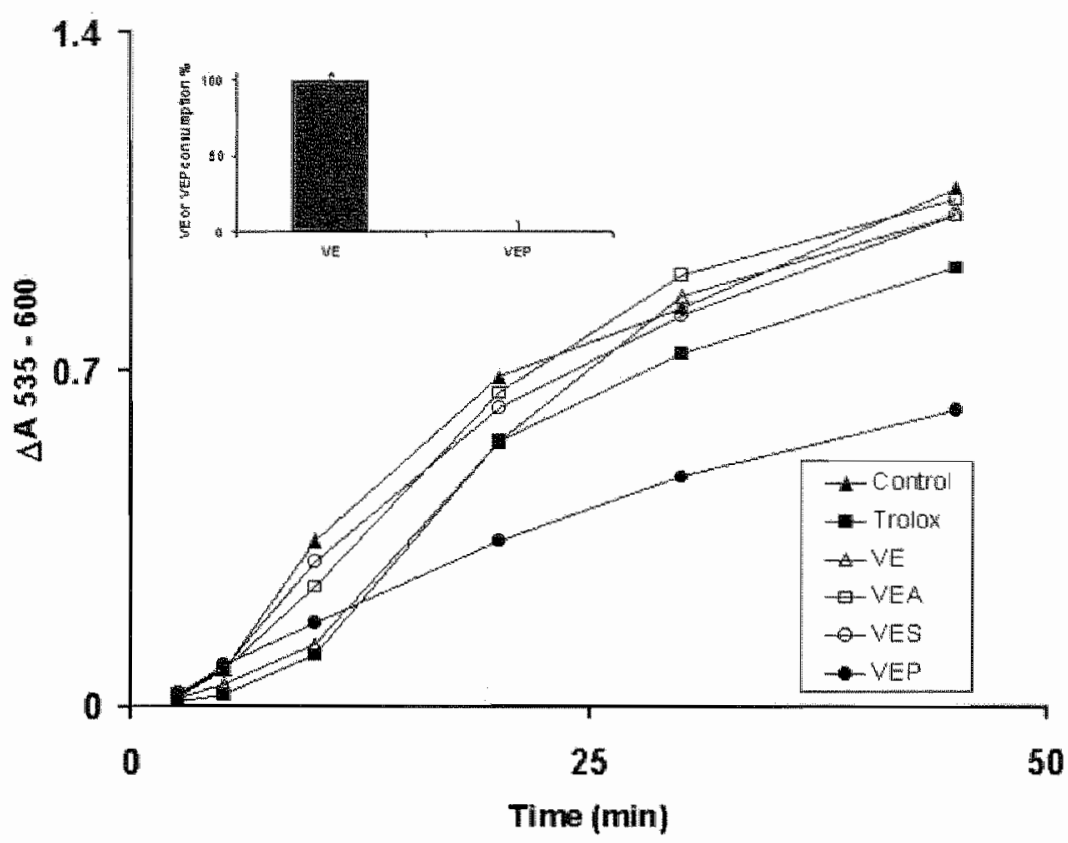

Fig. 4. Time-course of the effect of $20 \mu \mathrm{M}$ of vitamin $\mathrm{E}$ (VE), Trolox, vitamin $\mathrm{E}$ acetate (VEA), vitamin E succinate (VES), and vitamin E phosphate (VEP) on lipid peroxidation in heated microsomes. Experimental conditions are given in the materials and methods, see section 2.3. The insert shows the percentage of VE and VEP consumption. Values are presented as mean of at least three separate experiments.

VE, trolox, VEA, and VES induced a lag time in the time course of LPO in non-heated microsomes (Fig. 3). The antioxidant activities of VE, VEA and VES were approximately the same. The antioxidant activity of trolox was superior to that of VE, VEA or VES. VEP was also a potent antioxidant but showed another profile, i.e. it reduced the extent of LPO without inducing a lag time (Fig. 3).

The protection provided by the test compounds in non-heated microsomes against LPO was dose dependent. The $\mathrm{IC}_{50}$ values of VEP, trolox, VE, VEA, and VES were $25 \pm 2$ $\mu \mathrm{M}, 20 \pm \mathbb{1} \mu \mathrm{M}, 30 \pm 2 \mu \mathrm{M}, 35 \pm 2 \mu \mathrm{M}$, and $>40 \mu \mathrm{M}$, respectively.

Heating of the microsomes did not greatly affect the antioxidant activity of $\mathrm{VE}$ and trolox (Fig. 4), whereas the antioxidant activity of VEA and VES almost completely disappeared. The potent antioxidant effect of VEP in heated microsomes is comparable to that in non-heated microsomes. In heated microsomes the $I C_{50}$ values of $V E P$, trolox, VE, VEA, and VES were $25 \pm 1 \mu \mathrm{M}, 23 \pm 1 \mu \mathrm{M},>40 \mu \mathrm{M},>>40 \mu \mathrm{M}$ and $>>40 \mu \mathrm{M}$, respectively. 
Fomation of VE from VEA, VEP and VES in non-heated and heated microsomes was also measured. VEA showed a larger comversion into $V E$ in non-heated microsomes compared to VES and VEP. No conversion of the esters into VE in heated microsomes could be observed (Fig. 5 ).

To further investigate the mechanisms of protection, the consumption of VE and VEP during the protection against LPO was assessed. It was found that addition of $100 \mathrm{\mu M}$ VE to the microsomes was fully consumed after $1 \mathrm{~h}$ incubation. In contrast $100 \mu \mathrm{M}$ VEP was not consumed during the 1 h incubation with heated microsomes (Fig. 4, insert).

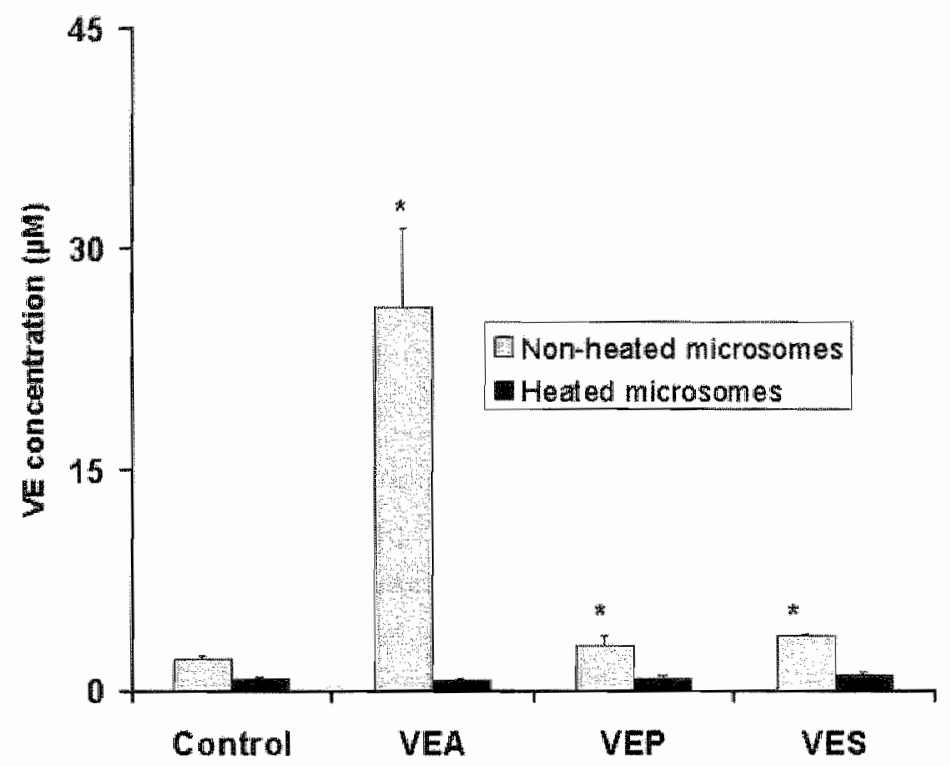

Fig. 5. Formation of vitamin $E$ (VE) from vitamin $E$ acetate (VEA), witamin $E$ succinate (VES) and vitamin $\mathrm{E}$ phosphate (VEP) in non-heated and heated microsomes after 20 min incubation. Experimental conditions are given in the materials and methods, see section 2.5.2. Values are presented as mean $\pm \mathrm{SD}$ of at least three separate experiments. * Indicates a significant change vs control $(\mathrm{p}<0.05)$.

To determine the effect of VEP on biomembranes, membrane fluidity of erythrocytes was monitored. Menbrane fluidity is determined using EPR by calculating the ratio of hoh.1 [12]. At a concentration of $50 \mu \mathrm{M}, \mathrm{VEP}$ induced a significant decrease in membrane fluidity. The peak height ratio with VEP is $8.1 \pm 0.7$ compared to that of control, $\mathrm{h}_{0} / \mathrm{h}_{4}$ is $7.2 \pm 0.2$. Both $\mathrm{VE}$ and all-rac-VE at concentration $50 \mu \mathrm{M}$ have no significant effect on the erythrocyte membrane fluidity (Fig. 6). 


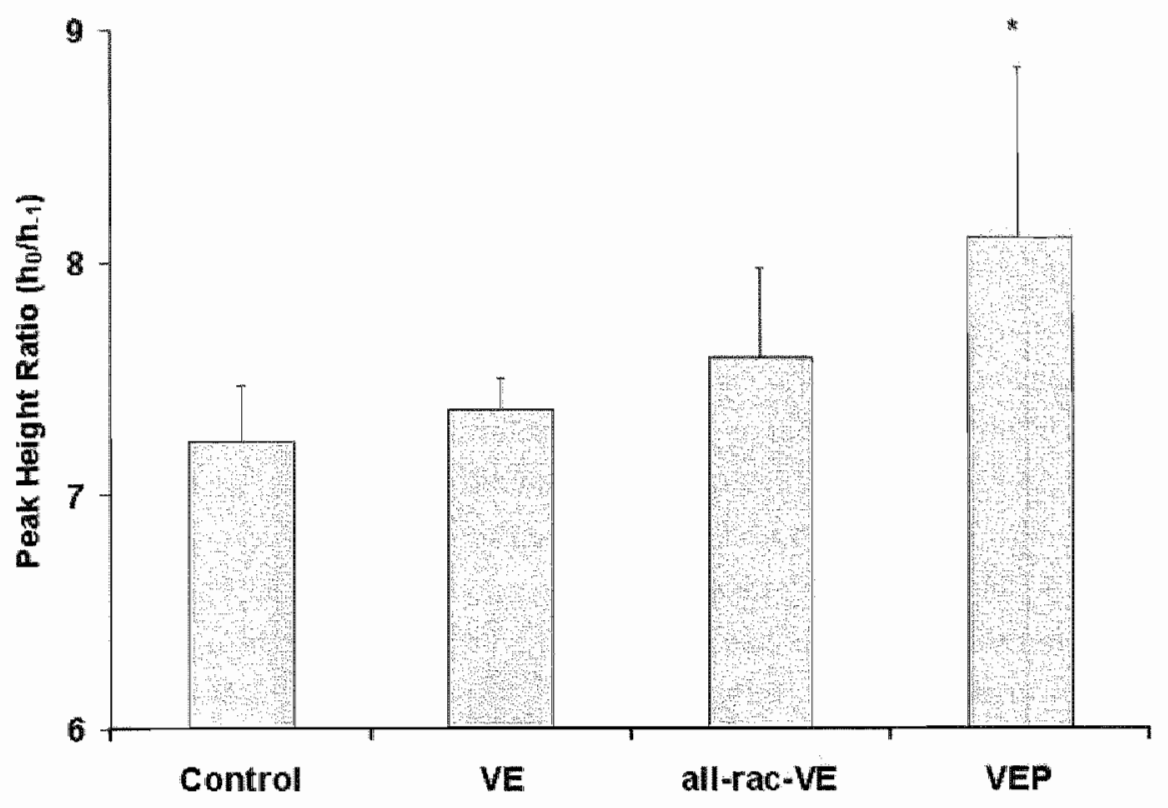

Fig. 6. Effect of VE, all-rac-VE and VEP on membrane fluidity of erythrocytes. Membrane fluidity is expressed as the ratio of the peak height $\left(\mathrm{h}_{0} / \mathrm{h}_{-1}\right)$ [12]. The higher the peak height ratio, the lesser freedom of motion of the spin label in biomenbrane bilayer, indicating a lower membrane fluidity [12]. Experimental conditions are given in the materials and methods, section 2.7. The data are presented as mean \pm SD of at least 3 separate experiments. * Indicates a significant change of VEP vs control. $(p<0.05)$. 


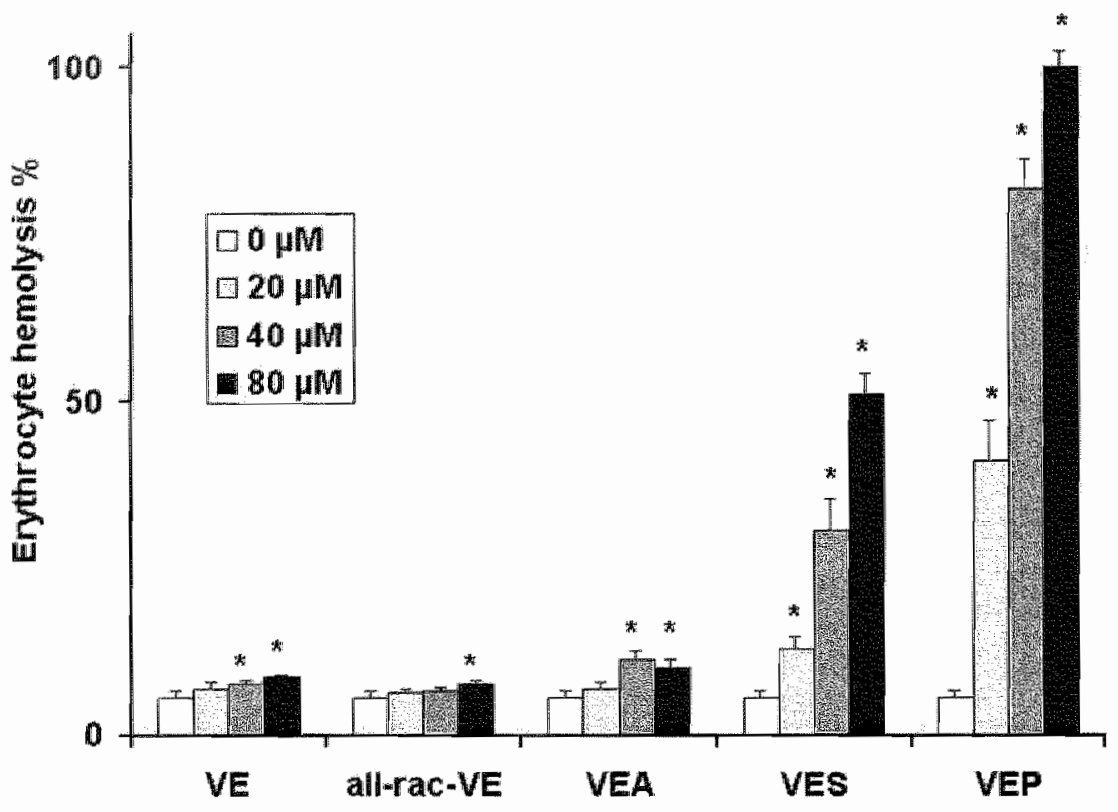

Fig. 7. Induction of hemolysis by vitamin $E$ (VE) and VE esters. Isolated erythrocytes were incubated for $2 \mathrm{~h}$ with different concentrations of compounds at $37^{\circ} \mathrm{C}$. The data are presented as mean \pm SD of at least 3 separate experiments. * Indicates a significant change $\mathrm{vs}$ control $(\mathrm{p}<0.05)$.

Hemolysis of erythrocytes by VE, all-rac-VE, VEA, VES and VEP were also determined (Fig. 7). At a concentration of $80 \mu \mathrm{M}$, VEP induced $100 \%$ erythrocyte hemolysis, whereas the same concentration of VES induced only $50 \%$ erythrocyte hemolysis. VE, all-rac-VE and VEA were not effective in inducing erythrocyte hemolysis.

\section{Discussion}

In the present study the antioxidant action of trolox, VE and several VE esters was compared. Firstly, the ability of these VE-derivatives to scavenge a stable ABTS radical was measured. The obtained data were normalized to trolox, which has a TEAC of 1. The TEAC value of VE was also approximately 1 for either VE or all-rac-VE. This was expected since VE and all-rac-VE contain the same antioxidant moiety as trolox. In contrast, the TEAC of VEA, VES, and VEP was almost 0 . This could be anticipated because the antioxidant moiety in these compounds is shielded by acetate, succinate and phosphate, respectively. The small antioxidant capacity of the esters is possibly due to a small fraction $(<1 \%)$ of free VE. 
The extraordinary antioxidant activity of vitamin $\mathrm{E}$ phosphate

Our results showed that, the phosphate group of VEP can be removed by alkaline phosphatase which results in the formation of VE (Fig. 2) as has previously been demonstrated by Nakayama et al., (14). Esterases can hydrolyze VEA and VES into VE (15, 16).

As expected, VE and trolox decreased LPO induced by the iron/ascorbate system, both in non-heated and heated rat liver microsomes (Fig. 3, 4). This is due to the lree radical scavenging property of the free hydroxyl group. Once VE and trolox are consumed, LPO starts. During the antioxidant activity the chroman head is finally converted into a quinone (6). The higher efficacy of trolox may be due to the absence of the hydrocarbon tail, which makes it less lipophilic in comparison with VE. Similarly, Kagan et al. (17) showed that, decreasing the length of the phytyl chain of $\alpha$-tocopherol from 16 carbon atoms to 11, 6 or 1 decreased the concentration needed to inhibit LPO in viro. No difference in antioxidant effect was found between VE and all-rac-VE indicating that the stereochemistry of the hydrocarbon tail thas no major influence. This is of importance since VEP is only available as all-rac-VEP and the stereochemistry of its tail is probably of minor importance in the in vitro experiments.

The inhibition of LPO by VEA and VES in non-heated microsomes (Fig. 3) occurs as a secondary event following the enzymatic conversion of VEA and VES into VE (Fig. 5) $(15,16)$. In non-heated microsomes the higher antioxidant activity of VEA in comparison to VES is probably due to a more extensive conversion of VEA into VE compared to VES. The lack of inhibition of LPO by VEA and VES in heated microsomes (Fig. 4) corroborates this explanation because denaturation of the enzymes in the microsomes by heating prevented hydrolysis of VEA and VES into VE.

The rate of conversion of VEP into VE was less than that of VEA in non-heated microsomes (Fig, 5). VEP had no direct radical scavenging activity as demonstrated in the TEAC assay. Nevertheless, VEP was a more efficient antioxidant than the other esters and VE not only in non-heated microsomes but also in heated microsomes. Also the profile of the time course of inhibition of $L P O$ points to different mechanism of inhibition. VE, trolox, VEA, and VES induced a lag time in the onset of LPO. VEP induced no lag time, it reduced the extent of LPO. Additionally, in heated microsomes VEP is not consumed during the LPO (Fig. 4, insert). Apparently, the antioxidant effect of VEP is not due to scavenging of free radicals but rather to another mechanism. A cluc for this mechanism may be found in the chemical structure of VEP. VEP has a hydrophilic polar phosphate group attached to the chroman head and the hydrophobic hydrocarbon tail (Fig. 1). This might enable VEP to be incorporated into biomembranes in a such way that its polar lipophobic phosplate group is in the water-membrane interface, and that the lipophilic hydrocarbon chain tail is embedded inside the lipid membrane. In this way VEP could act as a barrier for the transfer of radicals from one polyunsaturated fatty acid to another one. This may shorten the propagation phase of lipid peroxidation, re- 
sulting in less peroxidation. This is in line with the finding that VEP reduces membrane fluidity (Fig, 6). Results from this study also revealed that VEP induces hemolysis in erythrocytes much more efficiently as the other compounds (Fig. 7).

Mabile et al., (15) reported that, trolox exhibited a more potent cytoprotective effect than VE against oxidized LDL induced endothelial cell toxicity, whereas VEA and VES were almost completely ineffective. In contrast, Carin et al., (16) emphasized that VES exerted a more effective antioxidant protection than an equivalent amount of $\mathrm{VE}$ against iron/ascorbate mediated peroxidation in microsomes. In the present study, the rank order of the antioxidant activity of VE and its derivatives in microsomal $L P O$ is trolox $>$ $V E \approx a 11-r a c-V E>V E A>V E S$, Recently, Nakayama et al., (14) reported that pretreatment of cultured mouse skin with VEP provided significant protection greater than VEA against UV-B induced skin damage characterized by reduced LPO, sunburn cell formation, and DNA degradation. Nakayama et al. (14) hypothesized that the potent protective effect of VEP might be due to the high conversion of VEP into VE in cultured mouse skin compared to that of VEA. Our study showed that in lipid membranes VEP has a potent antioxidant effect of its own which is not due to the conversion into VE. The differences in antioxidant activity of the compounds and different mechanisms in the reported studies are probably due to differences in the experimental conditions.

With respect to the antioxidant effect of VES it should be noted that in control microsomes VES and VEP yielded the same amount of VE. VES did induce a small lag time in the time course of LPO. VEP did not induce a lag time. This indicates that the antioxidant effect of VES cannot be explained only by its conversion to VE $(15,16)$. Possibly a moderate detergent like effect of VES, as observed in the hemolysis of erythrocytes, is involved. An antioxidant effect of VES was, however, not found in heated microsomes. The reduction of membrane fluidity by VEP can be explained both the protection against LPO and induction of erythrocyte hemolysis. In various pathological conditions, LPO plays a major role in the etiology. It is speculated that, the extraordinary antioxidant effect of VEP against L.PO might be of importance in the treatment of these pathologies. Dtata on bioavalability and metabolism are needed to support this possible use.

In conclusion, VEP has a potent antioxidant effect of its own in contrast to VEA and VES. The antioxidant mechanism differs from that of VE. The mechanism used by VEP may lead to the development of a new class of antioxidants that might strengthen our therapeutic arsenal against free radical mediated disorders. 


\section{References}

1 Guttridge IM. Free radicals in disease processes: a compilation of cause and consequence. Free Radic Res Commurs. 1993; 19:1411-58.

2 Diplock AT. Antioxidants and disease prevention. Mol Aspects Med. 1994; 15:293-376.

3 Sies H. Oxidative stress: oxidants and antioxidants. Exp Physiol. 1997; 82:291-5.

4 Kamal-Eldin A, Appelqvist $\mathbb{L A}$. The chemistry and antioxidant properties of tocopherols and focotrienols. Lipids. $1996 ; 31: 671-701$.

5 Machlin LJ. Vitamin E. In Handbook of Vitamins, L.J. Machlim (Ed.). New York, Dekker, 1991 , pp. 99.144

6 Bast A, Haenen GRMM. The toxicity of antioxidants and their metabolites, Environ. Toxicol. Phowmacol. 2002; 11:251-58.

7 Haenen GRMM, Bast A. Protection against lipid peroxidation by a microsomal glutathionedependent labile factor. FEBS Lett. 1983; 159:24-8.

8 Smith PK, Krohn RI, Hermanson GT, Mallia AK, Gartner FH, Provenzano MD, Fujimoto EK, Goeke NM, Olson BJ, Klenk DC. Measurement of protein using bicinchoninic acid. And Biochem. $1985 ; 150: 76-85$.

9. Re R, Pellegrini N, Proteggente A, Pannala A, Yang M, Rice-Evans C. Antioxidant nctivity applyng an improved ABTS radical cation decolorization assay. Free Radic Biol Med. 1999; 26: 1231-7.

10 varn den Berg R, Haenen GRMM, van den Berg H, Bast A. Applicability of an improved Trolox equivalent antioxidant capacity (TEAC) assay for evaluation of antioxidant capacity measurements of mixtures. Food Chem. 1999; 66:511-17.

11 Burton GW, Webb A, Ingold KU. A mild, rapid, and efficient method of lipid extraction for use in determining witamin E/lipid ratios. Lipids. 1985; 20: 29-39.

12 Tsuda $\mathrm{K}$, Kinura K, Nishio I. Leptin improves membrane fluidity of erythrocytes in humans wia a nitric oxide-dependent mechanism--an electron paramagnetic resonance investigation. Biochen Bio-phys Res Conmun. 2002; 297:672-81.

13 Neuzil J, Zhat M, Ostermann G, Sticha M. Gellent N, Weber C, Eaton JW, Brunk UT. Alphatocopheryl succinate, an agent with in vivo anti-tumour activity, induces apoptosis by causing lysosomal instability. Biochem J. 2002; 362: 709-15.

14 Nakayama S, Katoh EM, Tsuzuki T, Kobayashi S. Protective effect of alpha-tocopherol-6-Ophosphate against ultraviolet B-induced damage in cultured mouse skin. I lnvest Dermatol. 2003; 121: 406-11.

15 Mabile L, Fitoussi G, Periquet B, Schmitt A, Salvayre R, Negre-Salvayre A. alpha-Tocopherol and trolox block the early intracellular events (TBARS and calcium rises) elicited by oxidized low density lipoproteins in cuttured endothelial cells. Free Radic Biol Med. 1995; 19: 177-87.

16 Carimi R, Poli G, Dianzani MU, Maddix SP, Slater TF, Cheeseman KH. Comparative evaluation of the antioxidant activity of alpha-tocopherol, alpha-tocopherol polyethylene glycol 1000 succinate and alpha-tocopherol succinate in isolated hepatocytes and liver microsomal suspensions. Biochem Pharmacol. 1990; 39: 1597-601.

17 Kagan VE, Serbinova EA, Bakalova RA, Stoytchew TS, Erin AN, Prilipko LL, Evstigneeva RP. Mechanisms of stabilization of biomembranes by alpha-tocopherol. The role of the hydrocarbon chain in the inhibition of lipid peroxidation. Biochem Pharnacol. 1990; 40:2403-13. 



\section{Chapter 3}

\section{Vitamin E phosphate is a novel apoptotic agent}

Bashir M. Rezk, Wim J.F. van der Vijgh, Aalt Bast and Guido R.M.M. Haenen

Submitted 


\begin{abstract}
Vitamin $\mathbb{E}$ succinate (VES) is a well-known potent and selective apoptotic agent. This apoptotic activity has been ascribed to its detergent-like activity. The structurally related compound vitamin $\mathbb{E}$ phosphate (VEP) also has a detergent-like activity. In this study we investigated the ffect of VEP on the osteosarcoma cell line MG-63 using VES as at reference compound. It was found that the antiproliferative effect of VEP on the MG-63 cancer cell line is superior to that of VES. Also the ability of VEP to induce apoptosis in the MG-63 cell line was better than that of VES. The cytotoxic effect of VEP and VES seems to be due to the effect of the intact compounds, since only a minor conversion into VE could be detected. EPR experiments showed that VES and VEP reduce membrane fluidity, whereas vitamin $\mathrm{E}$ (VE) has no effect. In addition, induction of erythrocyte hemolysis by VEP depends on the pH. Our results indicate that the detergent-like activity of these compounds might be involved in their biological effect. VEP meets the structural requirements that have been described for the apoptotic activity of VE esters, i.e. the combination of three structural domains, a functional, a signalling and an orientation domain.
\end{abstract}




\section{Introduction}

Recently, it has been discovered that vitamin $\mathbb{E}$ phosphate (VEP) is endogenously present in plant and amimal tissues, including human tissues. The concentrations of VEP are in general similar to those of vitamin $\mathbb{E}$ (VE). In rat and pig liver VEP levels even surpass those of VE by far (1). In foodstuffs such as chocolate and cheese the concentrations of VEP are 10 to 30 times higher than that of VE (1). We recently demonstrated that VEP interacts with biomembranes in a particular way, $i . e$. it acts as a potent antioxidant by its own, without conversion into VE (2). Moreover, VEP is not consumed during its protection against lipid peroxidation (2). Because VEP reduced membrane fluidity and induced erythrocyte hemolysis, it was suggested that the antioxidant effect of VEP is due to its detergent-like activity (2). VEP contains a charged phosphate group and a long aliphatic group. In biomembranes, the lyydrocarbon tail intercalates with fatty acid residues of phospholipids, while the charged phosphate group faces the cytosol. In this way it acts as a detergent.

In 1982, Prasad and Edwards-Prasad reported that vitamin E succinate (VES) induced inhibition of proliferation and cell death of murime melanoma B-16 cells in culture (3). Subsequently, it has been shown that VES is a potent growth inhibitor of a variety of malignant cell types in vitro (4-11) and in vivo (12-15). The antitumour activity of VES seems to be selective for cancer cells, since VES treatment is not toxic to normal cells $(7,13)$. Although the precise mechanism for the growth inhibition activity by VES remains unclear, it might be attributed to the detergent-like action of VES $(8,12)$. The detergent activity of VES is due to the charged succinyl group and the long aliphatic hydrocarbon tail $(8,12)$.

Due to the structural similarity between VEP and VES and the similar detergent-like activity, VEP may display a similar anti-proliferative activity as $V \mathbb{E S}$. The present study has been designed to investigate the effect of VEP on the asteosarcoma cell line $\mathrm{MG}-63$, using VES as a reference compound.

\section{Materials and Methods}

\section{Chemicals}

Vitamin $\mathbb{E}$ (VE), vitamin $\mathrm{E}$ succinate (VES), vitamin E phosphate (VEP) and 16doxylstearic acid were obtained from Sigma (St. Louis, MO, USA). All other used chemicals were of analytical grade purity. 


\section{Cell Culnure}

Osteosarcoma cells (MG-63) were maintained in Dulbecco's modified Eagle's medium (DMEM, Sigma) supplemented with 10\% fetal bovine serum (FBS), $2 \mathrm{mM} \mathrm{L-}$ glutamine, $100 \mathrm{U} / \mathrm{m}$ penicillin, and $100 \mu \mathrm{g} / \mathrm{ml}$ streptomycin at $37^{\circ} \mathrm{C}$ in a humidifed atmosphere of $5 \% \mathrm{CO}_{2}$ in air.

\section{Viability assay}

MG-63 cells were seeded into 6-well plates at $0.5 \times 10^{6}$ cells per well and were cultured for $24 \mathrm{~h}$ in DMEM. Then the medium was replaced with $2.7 \mathrm{ml}$ of balanced salline solution and $300 \mu \mathrm{l}$ of medium, and in addition $24 \mu \mathrm{l}$ of the tested compounds was added lead to the desired final concentration of $80 \mu \mathrm{M}$. Control cells were treated with $24, \mu \mathrm{M}$ of both solvents, i.e. either deionised water (for VEP) or ethanol (for VE or VES). After $6 \mathrm{~h}$ of incubation the cells were collected and tested for viability. Determination of cell number viability was assessed by the exclusion of trypan blue. Cells stained blue were counted as non-viable, whereas those excluding the dye were regarded as viable. Results were expressed as percentage cell death, which - because the controls mainly contained a neglectable number of dead cells - was expressed as number of dead cells/(number of dead cells + viable cells).

\section{Proliferation assay (qualitative and quantitative)}

MG-63 cells were plated in flasks with a bottom of $25 \mathrm{~cm}^{2}$ to $90-97 \%$ confluence. The medium was replaced with $4.5 \mathrm{ml}$ of balanced saline solution and $500 \mu \mathrm{l}$ of medium, and in addition $40 \mu 1$ of the tested compounds was added to lead a final concentration of 80 $\mu \mathrm{M}$. Control cells were treated with both solvents, i.e. either deionised water (for VEP) or ethanol (for VE or VES). After 4 h of incubation the balanced saline solution was replaced by medium and the cells were incubated further for $26 \mathrm{~h}$. Photomicrographs were taken for a qualitative examination. For a quantitative determination, cells were harvested and then counted with a hemocytometer. The antiproliferative effect was calculated as (number of control cells - number of treated cells)/number of control cells.

\section{DNA fragmentation assay for apoptosis}

MG-63 cells were seeded into Lab-Tek Chamber Silde at $0.1 \times 10^{6}$ cells $/ \mathrm{ml}$ per chamber and cultured in DMEM. After 24 th the medium was replaced with $900 \mu$ of balanced saline solution and $100 \mu \mathrm{l}$ of medium, and in addition $8 \mu$ of the test compound was added to lead a final concentration of $80 \mu \mathrm{M}$. Control cells were treated with both solvents, i.e. either deionised water (for VEP) or ethanol (for VE or VES). After $4 \mathrm{~h}$ incubation the balanced saline solution was replaced by medium and further incubated for 
26 h. Cells were washed with PBS and then fixed with $3.7 \%$ formaldehyde. After 30 min of incubation the cells were treated with $0.2 \%$ triton $\mathrm{X}$ - 100 and finally, stained with DAPI. Slides were evaluated microscopically. Cells with nuclei containing clearly condensed chromatin or cells with fagmented nuclei were counted and defined as apoptotic cells. Because the controls did not contain a noticeable number of apoptotic cells, the percentage of apoptotic cells was calculated as number of apoptotic cells (number of apoptotic cells + number of non-apoptotic cells).

\section{Vitamin E determination}

MG-63 cells were seeded into 6-well plates at $0.5 \times 10^{6}$ cells per well and were cultured for $24 \mathrm{~h}$ in DMEM. Then the medium was replaced with $2.7 \mathrm{ml}$ of balanced saline solution containing $300 \mu l$ of medium, and the cells were treated with $24 \mu 1$ of the tested compounds leading to a final concentration of $80 \mu \mathrm{M}$. After 2 h of incubation the reaction was stopped by addition of $100 \mu 1$ of $2.5 \% \mathrm{SDS}$, and $2 \mathrm{ml}$ ethanol containing $\mathbb{\mathrm { m } g}$ BHT to prevent further oxidation. VE was extracted and determined as described in the following paragraph. Vitamin $E$ nicotinate $(200 \mu \mathrm{g} / \mathrm{ml})$ was added as an intemal standard.

The mixture was shaken for $5 \mathrm{~min}$, then $3 \mathrm{ml}$ of hexane was added. Again the mixture was shaken for 15 min. After centrifugation the upper hexane layer was aspirated into a conical glass tube and evaporated under nitrogen. The residue was dissolved in $200 \mu 1$ isopropylalcohol for HPLC analysis according to Burton et al. (16) using a Nucleosil C18 column and absolute methanol as the mobile phase, with a flow rate of $2 \mathrm{ml} / \mathrm{min}$. VE was detected at $295 \mathrm{~nm}$.

\section{Membrane fluidity of human eryrhrocytes.}

The membrane fluidity of erythrocytes from healthy donors was measured by means of electron paramagnetic resonance (EPR) spectroscopy. Blood samples were obtained by venipuncture. Heparin was used as an anticoagulant. The plasma and buffy coat werc carefully removed after centrifugation at $2000 \mathrm{~g}$ for $10 \mathrm{~min}$ at $4^{\circ} \mathrm{C}$. Erythrocytes were washed three times with phosphate-buffered saline (PBS) and finally resuspended in PBS to a hematocrit of $45 \%$. PBS $(0.5 \mathrm{ml})$ with the test compound (final concentration $50 \mu \mathrm{M})$ was added to $0.5 \mathrm{ml}$ of the erythrocyte suspension. Controls were treated with both solvents, i.e. deionised water (for VEP) and ethanol (for VE or VES). After 90 min of incubation at $37^{\circ} \mathrm{C}$, spin labelled 16-doxylstearic acid was added and the samples were incubated for $90 \mathrm{~min}$ at $37^{\circ} \mathrm{C}$. Finally, EPR measurements were performed using an EPR spectrometer (Bruker EMX, GmbH, Freiburg, Germany) under the following conditions: microwave power $2 \mathrm{~mW}$; modulation amplitude $1 \mathrm{G}$; scan width $50 \mathrm{G}$; modulation frequency $100 \mathrm{kHz}$ and temperature $30^{\circ} \mathrm{C}$. Membrane fluidity was calcu- 
lated from the peak height ratio (ho/h-1) as described previously (17). The higher the peak ratio, the lesser the freedom of the motion of the spin label in the biomembrane bilayer, indicating a lower membrane fluidity (17)

\section{Erythrocyle Hemolysis}

Erythrocyte hemolysis was assessed as described by Neuzil et al. (8) with minor modifications. Erythrocytes were prepared from freshly obtained heparin-treated human blood One $\mathrm{ml}$ blood was diluted 80 times with of PBS (pH 6.4 or pH 7.4) followed by centrifugation at $2000 \mathrm{~g}$ for $10 \mathrm{~min}$ at $4^{\circ} \mathrm{C}$. The pellet was resuspended with $45 \mathrm{ml} \mathrm{PBS}$ either of $\mathrm{pH} 6.4$ or $\mathrm{pH} 7.4$. One ml of the erythrocyte suspension was incubated with different concentrations of VEP at $37^{\circ} \mathrm{C}$. Controls were treated with both solvents, i.e. either deionised water (for VEP) or ethanol (for VE or VES). After 2 h of incubation, the samples were centrifuged for 10 min at $2000 \mathrm{~g}$. The supernatant was diluted 2 times, and the absorbance at $546 \mathrm{~nm}$ was determined.

\section{Statistical analysis}

All results are expressed as mean $\pm \mathrm{SD}$. Differences between the treatments were tested with Student's t-test.

\section{Results}

In the viability assay with MG-63 cells VEP and VES induced cell death in a dose dependent way (Fig. 1). At a concentration of $40 \mu \mathrm{M}(\mathrm{n}=5)$ and $80 \mu \mathrm{M}(\mathrm{n}=13)$ the effect of VEP $(45 \pm 5 \%$ and $85 \pm 7 \%$ of cell death, respectively) was superior $(p<0.001$ for both concentrations) to that of VES $(29 \pm 6 \%$ and $70 \pm 7 \%$ of cell death, respectively). The lowest concentration of $20 \mu \mathrm{M}$ did not result in a significant difference in cytotoxicity between VEP and VES $(16 \pm 3 \%$ vs $14 \pm 2 \%$ of cell death, respectively $(\mathrm{n}=3))$. As shown in Fig. I (insert), at a concentration of $80 \mu \mathrm{M}$ both VEP and VES hardly showed a conversion into VE $(1 \pm 0.4 \%$ and $4.6 \pm 0.45 \%$, respectively $(\mathrm{n}=3))$.

The cytotoxic effect of the VE esters was confirmed by their effect in the proliferation assay. The quantitative assay confirmed the qualitative impression that VEP is a potent antiproliferative agent. The antiproliferative effects of VEP. VES and VE were $75 \pm 2 \%$ $(n=5), 41 \pm 5 \%(n=5)$ and $12 \pm 3 \%(n=5)$, respectively. A typical experiment of the qualitative antiproliferative effect is shown on the cover of this thesis; panel $A$ is the control, panel $B$ is VE, panel C is VES and panel D is VEP. The rank order of the potency of three compounds is VEP $>$ VES $>$ VE. The difference between these effects were all highly significant, i.e. $p<0.0003$.

The apoptotic effect of VEP and VES was clearly observed in the MG-63 cells by DNA fragmentation and nuclear condensation. At a concentration of $80 \mu \mathrm{M}$ the percentage of 
apoptotic cells was significantly higher after VEP $(64 \pm 11 \%, n=21)$ than after VES $(46 \pm 9 \%, \mathrm{n}=21)$ with a p-value of $10^{-6}$. VE had no apoptotic activity.

The membrane fluidity of erythrocytes, as measured five-fold by the ratio of the peak heights $\left(h_{0} / h_{-1}\right)$, decreased significantly after treatment with $50 \mu \mathrm{M}$ of VEP and VES $\left(h_{0} / h_{.1}=8.1 \pm 0.7\right.$ and $8.1 \pm 0.3$, tespectively) in comparison to the controls $(7.2 \pm 0.2)$ with p-values of 0.03 and 0.001 , respectively. VE had no influence on the membrane fluidity $\left(h_{0} / h_{1}=7.36 \pm 0.13\right)$. The decreased membrane fluidity by VEP and VES was also significantly changed in comparison to the effect of VE (p-values of 0.05 and 0.001 , respectively).

VEP induced hemolysis of erythrocytes which was concentration and pH dependent. Hemolysis increased when the concentration of VEP was increased or the $\mathrm{pH}$ was lowered (Fig. 2),

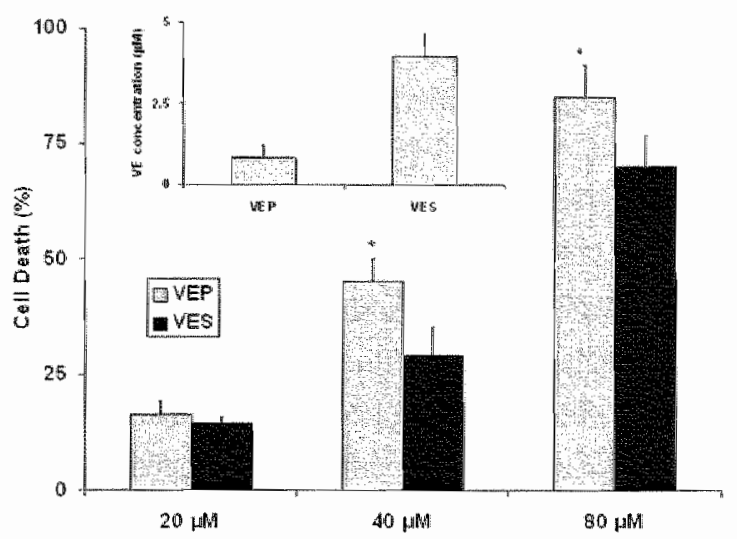

Fig. 1. Cytotoxic effect of VES and VEP in MG-63 cells. Cells were incubated with different concentrations of VES and VEP. Percentages of cell death are shown. The insert shows the formation of VE from $80 \mu \mathrm{M}$ VES and VEP in MG-63 cells after $2 \mathrm{~h}$ of incubation. Values are presented as mean \pm S.D. * Indicates a significant difference between VEP versus VES $(p<0.001)$. 


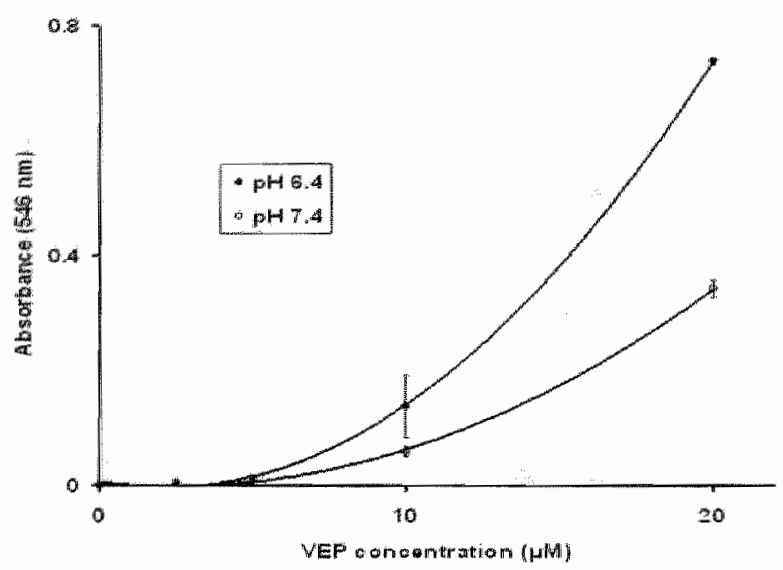

Fig. 2. Induction of hemolysis by VEP. Isolated erythrocytes were incubated for $2 \mathrm{~h}$ with different concentrations of VEP at $\mathrm{pH} 6.4$ or $\mathrm{pH} 7.4$ at $37^{\circ} \mathrm{C}$. The data are presented as mean \pm S.D. of three separate experments.

\section{Discussion}

Several studies have shown that VES induces growth inhibition and apoptotic activity on a variety of human and rodent cancer cell lines without affecting the proliferation of normal cells in vitro (4-11) as well as in vivo (12-15). Several authors have reported that VES might be a highly selective anticancer agent. It was suggested that VES is a promising anticancer drug or adjuvant, which is applicable in clinical practice. The goal of the present study is to determine whether VEP inhibits osteosarcoma cell proliferation and induces cell death and apoptosis. The effects of VEP are compared to those of VES. VEP induced cell death in a dose dependent manner and was more potent than VES. The conversion of VES or VEP into VE in MG-63 was very low, indicating that the induction of cell death by either VES or VEP is due to a direct effect of the parent compounds. In contrast to the stability of VEP in the osteosarcoma cell line, Nakayama et al. (18) recently reported that in cultured mouse skin VEP showed a massive conversion into VE by alkaline phosphatase. Furthermore, daily supplementation of VEP ( 30 $\mathrm{mg} / \mathrm{kg}$ ) in rats for 32 days increased levels of VEP $(62 \%)$ as well as VE $(40 \%)$ in the liver, indicating a possible conversion of VEP into VE (1). The low conversion of VEP in the cancer cell line MG-63 and the substantial conversion of VEP in normal cells, cultured mouse skin (18), and liver tissue (1) indicate that differences in hydrolysing enzymes, such as esterases and phosphatases exist between cancer and normal cells. This difference is used in the clinical application of amifostine as a protector of healthy tissues during chemo- and/or radiotherapy (19). Amifostine is a phosphorylated thiol and the removal of the phosphate group occurs at a higher rate in normal tissue com- 
pared to cancer tissue (19). In this way, more of the protective thiol is fomed in nomat tissue than in tumour tissue, leading to protection of healthy tissues without comprising the antitumour effect of chemo-and/or radiotherapy (19).

Of the tested compounds, VEP appeared to be the most potent inhibitor of cell proliferation. VE has the lowest potency. The effect of VE is dependent on the form of VE used. The form of VE used in the present study, a-tocopherol, inhibits cell proliferation while a chemically closely related form of $\mathrm{VE}, 3$-tocopherol, is known to be ineffective (20). Esterification of the $\mathrm{OH}$ moiety of $\alpha$-tocopherol by succinate or phosphate boosts the inhibition of MG-63 cell proliferation. Again VEP was the most potent compound tested.

VEP also appared to be most potent in inducing DNA fragmentation and nucleus condensation. Birringer et al. (9) found that neither trolox succinate nor phytyl succinate caused apoptosis. Methylation of the free succinyl carboxyl group (giving VE methyl succinate) completely abolished the apoptotic activity of VES (9). This indicates that all parts of the molecule (i.e. the free succinate group, the chroman head and the phytyl tail) are essential for the induction of apoptosis by VES. Vitamin E glutarate has a very poor apoptotic activity compared to that of VES, vitamin $\mathrm{E}$ maleate and vitamin $\mathrm{E}$ fumarate. Apoptotic activity also differs between vitamin E oxalate, vitamin E malonate and VES. The relative potency of these VE esters correlates with the flexibility of the terminal carboxyl containing moiety (11); the longer the terminal dicarboxylic moiety, the more flexible this moiety and the lower the apoptotic effect. The phosphate group is not llexible and, based on analogy with the VE esters, this might be an important feature of VEP in its apoptotic activity.

In all the apoptotic vitamin $\mathbb{E}$ esters three structural domains can be recognized (Fig 3 ). Domain $l$ is considered as functional domain which is the hydrophilic part of the deter gent-like molecule of VES and VEP. Domain II is regarded as signalling domain, which is accountable for cell signalling activity of VE, VES and VEP. Domain III is an orientation domain, which mediates embedding of VES or VEP in the biomembranes.

The mechanism by which VES induces apoptosis is not fully understood. A combination of membrame destabilizing activity and dysregulation of signalling pathways may be involved. Destabilization of the cell membrane probably occurs due to the detergent like action of VES. VEP also has a detergent like activity (2).

The effect of VE, VEP and VES on membrane fluidity has been tested. Both VES and VEP decreased membrane fuidity of erythrocytes, whereas VE has no significant effect. Our recent study (2) showed that VES and VEP induced erythrocyte hemolysis. Previously, Neuzil et al. (8) reported that both $\alpha$-tocopherol succinate and $\beta$-tocopherol succinate induced hemolysis to erythrocytes. 


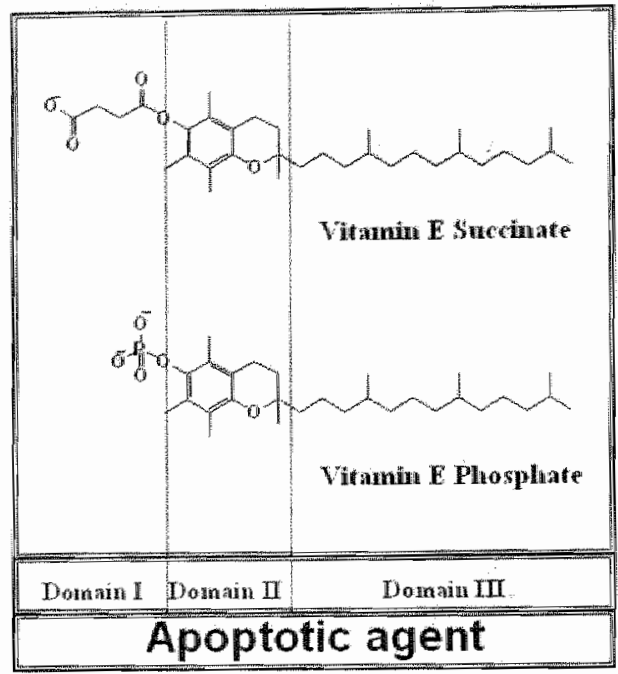

Fig. 3. Structures of VES and VEP showing 3 major domains. The domains are a functional domain (domain D), a signaling domain (domain II), and an orientation domain (domain III). For apoptotic activity, the three domains are required. VEP is the VE derivative that has the highest activity of the VE esters tested.

The detergent-like activity of VES increased with acidic $\mathrm{pH}$ (8). VES can exist in solution in two forms: the deprotonated charged species, and its protonated uncharged counterpart. The latter can enter cells by passive diffusion (8). Almost $99 \%$ of the total VES will be charged at neutral $\mathrm{pH}$. The protonated uncharged form will increase 25 . fold at $\mathrm{pH} 6.2(8)$. The apoptotic activity of VES in Jurkat and MCF-7 cell lines was higher at acidic pH which may be due to the higher diffusion rate of protonated VES over cell membranes at acidic pH (8). The pH dependent effect might contribute to the selective toxicity of VES to cancer cells $(7,13)$, since the $\mathrm{pH}$ of normal tissues is neutral compared to the acidic pH found in many tumours (21). Interestingly, we found that the toxicity of VEP on erythrocyles is also higher at acidic pH. Possibly, protonation of the phosphate group is involved, although the acidity (the pKa value) of VEP is not known. Thus, beside higher dephosphorylation in normal versus cancer lissue, also the more acidic $\mathrm{pH}$ in tumour cells may contribute to a higher toxicity of VEP in tumour cells.

VEP is an important constituent in our diet which has been overlooked in the past, because HPLC techniques for the measurement of VE did not detect VEP (1). Nevertheless, various prominent health effects of VEP have been reported. VEP has been promoted as a radioprotector. Felemovicius et al. (22) reported that a chronic oral supplementation of rats with VEP $(5 \mathrm{mg} / \mathrm{ml})$ significantly protected their intestine against acute inadiation. Pre-treatment of cultured mouse skin with a solution of $0.5 \%$ of VEP 
(9.4 mM) substantially protected against UV-B triggered skin damage. Also a signifi. cant beneficial effect of VEP in combination with semen plasma protein was observed on sperm survival. These effects have been related to the ability of VEP to protect against lipid peroxidation, sumburn cell damage and DNA degradation (18). We have confirmed that VEP is indeed a potent inhibitor of lipid peroxidation (2).

Recently, Munteanu et al. (23) reported that mixture of VEP (VEPm) of biological origin containing VEP (55.3\%), di-VEP (30.6\%), VE (5\%), inorganic phosphate (2.6\%), water $(1.9 \%)$, oleic acid $(1 \%)$ and impurities $(3.57 \%)$, modulated cell proliferation and gene expression in rat aortic smooth muscle cells (RASMC) and human THP-I monocytic leukaemia cells at a relatively low concentration. At higher concentrations, VEPm induced apoptosis in human THP-1 monocytic leukaemia cells. Munteanu et al. (23) focussed on a beneficial role of VEPm in atherosclerosis and inflammation. In our opinion, the apoptotic effect of VEPm on monocytic leukaemia cells might be of interest too.

We conclude that VEP induces cell death, inhibits cell proliferation and provokes apoptosis in the MG-63 cell line, probably due to a membrane destabilising activity by acting as a detergent. VEP fits in the structural requirements that have been described for the apoptotic activity of VE esters, i.e. the combination of three structural domains, a functional, a signalling and an orientation domain. Due to its potent biological activities and the presence of relatively high amounts in the diet and our body it is expected that VEP will play a role in health. Clinical studies are, however, needed to substantiate this claim.

\section{References}

1 Ognu E, Gianello R, Libinaki R, Smallidge A, Bak R. Geytenbeck S, Kannar D, West S. (Eds.). Vi. tamin E phosphate: An endogenous form of vitamin E. Medimond S.r.I., 2003.

2 Rezk BM, Haenen GRMM, van der Vijgh WJF, Bast A. The extraorinary antioxidant activity of witamin E phosphate. Biochem Btophys Acto. 2004; 1683: 16-21

3 Prasad KN, Edwards-Prasad I. Effects of tocopherol (vitamin E) acid succinate on mophological alterations and growth inhibition in melanoma cells in culture. Cancer Res. 1982; 42:550.5.

4 Kline K, Cochan GS, Sanders BG. Growth-inhibitory effects of vitamin $\mathbb{E}$ succinate on retrowirustransformed tumor cells in vitro. Nutr Cancer. 1990;14:27-41.

5 Turley JM, Ruscetti FW, Kim SI, Fu T, Gou FV, Birchenall Roberts MC. Vitamin E succinate inhibits proliferation of BT 20 human breast cancer cells: increased binding of cyclin A negatively regullates E2F transactivation activity. Cancer Res. 1997; 57: 2668-75.

6 Yamamoto $S_{*}$ Tamai H, Ishisaka R, Kanno T, Arita K, Kobuchi H, Utsumi K. Mechanism of alphat tocopheryl succinate-induced apoptosis of promyelocytic leukemia cells. Free Radic Res. 2000; 33: $407-18$

7 Neuzil J, Weber $T$, Gellert $\mathbb{N}$, Weber $C$. Selective cancer cell killing by alpha-tocopheryl succinate. Br 3 Cancer. $2001 ;$ 84: 87-9. 
8 Meuzil J, Zharo M, Ostemann G, Sticha M, Gielleri N, Weber C, Eaton JW, Brunk UT. Alphatocopheryl succinate, an agent with in vivo anti-tumour activity, induces apoptosis by causing lysom somal instabify, Biochem $7.2002 ; 362: 709-15$.

9 Birringer $M$, EyTina JH, Salvatore BA, Neuzil J. Vitamin E analogues as inducers of apoptosis: structure function relation. Br./ Cancer. 2003, 88: 1948-55

10 Wu $\mathrm{K}, \mathrm{Zhao} \mathrm{Y}, \mathrm{Li} \mathrm{GC}, \mathrm{Yu}$ WP. c-Jun $\mathrm{N}$-terminal kinase is required for vitamin $\mathrm{E}$ succinate-induced apoptosis in human gastric cancer cells. World J Gastroenterol. 2004; 10: 1110-4.

11 Kogure K, Hama S, Kisaki M, Takemasa H, Tokumura A, Suzuki 1, Fukuzawa K. Structural characteristic of terminal dicarboxylic moiety required for apoptogenic activity of alpha-tocopheryl esters. Biochim Biophys Acta. 2004; 1672: $93-9$.

12 Neuzil , Weber $\mathbb{T}$, Schroder A, Lu M, Ostermann G, Gellert N, Mayne GC, Olejnicka B, NegreSalvayre A, Sticha M, Coffey RJ, Weber C. Induction of cancer cell apoptosis by alpha-tocopheryl succinate: moleculat pathways and structural requirements. FASEB J. 2001; 15: 403-15.

13 Weber T, Lu M, Andera L, Lahm H, Gellert $N$, Fariss MW, Korinek V, Sattler W, Ucker DS, Terman $A$, Schroder A, Er W, Brunk UT, Coffey RJ, Weber C, Neuzil J. Vitamin E succinate is a poteni novel antineoplastic agent with high selectivity and cooperativity with tumor necrosis factor-related apoptosis-inducing ligand (Apo2 ligand) in wivo. Clin Cancer Rex. 2002; 8: 863-9.

14 Barnett KT, fokum FD, Malafa MP. Vitamin E succinate inhibits colon cancer liver metastases. „ Surg Res. 2002; 106: 292-8.

15 Tomasetti M, Gellert N, Procopio A, Neuzil J. A vitanin E analogue suppresses malignant mesothelioma in a preclinical model: a future drug against a fatal neoplastic disease? Int J Cancer. 2004; 109 : $641=2$.

16 Burton GW, Webb A, Ingold KU. A mild, rapid, and efficient method of lipid extraction for use in determining witamin EApid ratios, Lipids: 1985; 20:29-39.

17 Tsuda K. Kimura K, Nishio I. Leptin improves membrane fluidity of erythrocytes in humans via a nitric oxide-dependent mechanism--an electron paramagnetic resonance investigation. Biochem Biophys Res Commun. 2002; 297: 672-81.

18 Nakayana S, Katoh EM. Tsuzuki T. Kobayashi S. Protective effect of alpha-tocopherol-6-Ophosphate against ultraviolet B-induced damage in cultured mouse skin. Invest Dermatal. 2003; 121 : 406-11.

19 Orditura M, De Vita F, Roscigno A, Infusino S, Alriemma A, lodice P, Ciaramella F, Abbate $G$. Catalano G. Amifostine: A selective cytoprotectwe agent of normal tissues from chemo-radiotherapy induced toxicity (Review). Oncol Rep 1999; 6: 1357-62.

20 Azzi A, Stocker A. Vitamin E: non-antioxidant roles. Prog Lipid Res. 2000; 39: 231-55.

21 Gorweck LE, Seetharaman K. Celluletr pH gradient in tumor versus nomal tissue: potential exploitation for the treatment of cancer. Cancer Res. 1996; 56: 1194-8.

22 Felemovicius I, Bonsack ME, Baptista ML, Delaney IP. Intestinal radioprotection by vitamin E (alpha-tocopherol). Anm Shrg. 1995; 222: 504-8; discussion 508-10.

23 Munteanu A, Zingg JM, Ogru E, Libinaki R, Gianello R, West S, Negis Y, Azzi A. Modulation of cell proliteration and gene expression by alpha- tocopheryl phosphates: relevance to atherosclerosis and inflammation. Brochem Biophss Res Commun. 2004:318:311-6. 


\section{Chapter 4}

The antioxidant activity of phloretin: the disclosure of a new antioxidant pharmacophore in flavonoids

Bashir M. Rezk, Guido R.M.M. Haenen, Wim J.F, van der Vijgh, and Aalt Bast

Biochim. Biophys. Res. Comm. 2002; 295: 9-13 


\begin{abstract}
Phloretin is a dihydrochalcone flavonoid that displays a potent antioxidant activity in peroxyritrite scavenging and the inhibition of lipid peroxidation. Comparison with structurally related compounds revealed that the antioxidant phramacophore of phloretin is 2,6-dihydroxyacetophenone. The potent activity of 2,6-dihydroxyacetophenone is due to stabilization of its radical vatautomerisation. The antioxidant pharmacophore in the dihydrochalcone phloretin, i.e. the 2,6-dihydroxyacetophenone group, is different from the antioxidant pharmacophores previously reported in flawonoids.
\end{abstract}


The antioxidant activity of phloretin the disclosure of a new ...

\section{Intraduction}

Generation of reactive oxygen species and reactive nitrogen species in wivo are involved in a wide range of human diseases, including cancer, cardiovascular, pulmonary and neurological diseases (1). Hence, agents with the ability to protect against these reactive spectes may be therapeutically useful. In line with this hypothesis is the widely accepted view that the positive health effects of thavonoids can be attributed to their antioxidant activity. Flavonoids are a group of more than 5000 different natural polyphenols sub. stances. They are abundantly present in green vegetables, fruits, olive and soybean oils, red wine, chocolate, and teas (2). The flavonoids are classified into different categorles. Within each category there is a variation in number and arrangement of hydroxyl moieties as well as sugar groups. Several antioxidant phamacophores in the flavonoids have been described (3-6).

Chalcones (1,3-diaryl-2-propen-1-ones) are flavonoids lacking a heterocyclic $\mathrm{C}$ ring. Also this category of llavonoids displays a broad spectrum of bioactivities such as anticancer, antifungal, antibacterial, antiviral and antiinflammatory properties (7). Dihydrochalcones which do not have $\alpha-\beta$ double bond comprise phloretin [ $\beta$-(4hydroxyphenyl)-1-(2,4,6-trihydroxypropiophenone) and its glucoside, phloridzin (phloretin 2- $\beta$-D-glucose) (Fig. 1). These compounds are abundantly present in apples (8). The goal of the present study is to examine the antioxidant activity of phloretin and to determine the pharmacophore responsible for antioxidant activity of phloretin.

\section{Materials and Methods}

\subsection{Chemicals}

Phloretin [ $\beta$-(4-hydroxyphenyl)-1-(2,4,6-trihydroxypropiophenone], phloridzin (phloretin-2- $\beta$-D-glucose), phloroglucinol $\quad(1,3,5$-trihydroxybenzene) $\quad 2,4,6-$ trihydroxyacetophenone, 2,4-dihydroxyacetophenone, 2,6-dihydroxyacetophenone, 2hydroxyacetophenone and $\mathrm{KO}_{2}$ were obtained from Fluka. Resorcinol (1,3dihydroxybenzene), phenol and dihydrorhodamine-123 (DHR-123) were obtained from Sigma. 2-Hydroxy-6-methoxyacetophenone was obtained from Aldrich. Nitrogen monoxide was obtained from AGA (Hamburg, Germany). All other chemicals were of the highest grade of purity.

\subsection{Synthesis of peroxynitrite}

Potassium oxoperonitrate (ONOOK) was produced from the reaction of solid $\mathrm{KO}_{2}$ with NO-gas as deseribed by Koppenol er al. (9). Briefly, the NO-gas slowly flowed over the mixture of $\mathrm{KO}_{2}$ and quartz-sand, which was constantly stirred and kept on ice. The 
mixture was poured into a cold potassium bydroxide solution. Addition of manganese dioxide removes the hydrogen peroxide that results from excess decomposition of potassium superoxide. The solution with peroxynitrite was obtained by filtering of the sand and manganese dioxide. The concentration of peroxynitrite was determined spectrophotometrically at $302 \mathrm{~nm}$.

\subsection{Penorynitrite scavenging}

Peroxynitrite scavenging was measured by the oxidation of DHR-123 as described by Kooy et al. (10). In short, the desired concentrations of the test compounds were added to one $\mathrm{ml}$ of $100 \mathrm{mM}$ phosphate buffer at $37^{\circ} \mathrm{C}$. The final concentration of DHR-123 in phosphate bufter was $5 \mu \mathrm{M}$. During mixing the final concentration, $0.6 \mu \mathrm{M}$, of peroxynitrite was added. The fuorescent product, rhodamine-123, was measured by fluorescence detection with excitation and emission wavelengths of 500 and $536 \mathrm{~nm}$, respectively. The effects are expressed as the concentration giving $50 \%$ inhibition of the oxidation of DHR $\left(\mathrm{IC}_{50}\right)$.

\subsection{Isolation of rat liver microsomes}

Male Lewis rats, $200-250 \mathrm{~g}$, were killed by decapitation. Microsomes were prepared according to Haenen and Bast (11) with a slight nodification. Livers were removed and homogenized $(1: 2 \mathrm{w} / \mathrm{v})$ in ice cold phosphate buffer $(50 \mathrm{mM}, \mathrm{pH} 7.4)$ containing 0.1 $\mathrm{mM}$ EDTA. The homogenate was centrifuged at $10,000 \times \mathrm{g}$ for $30 \mathrm{~min}$ at $4{ }^{\circ} \mathrm{C}$. Subsequently, the supernatant was centrifuged at $65,000 \times \mathrm{g}$ for $60 \mathrm{~min}$ at $4^{\circ} \mathrm{C}$. The microsomal pellet was resuspended in the phosphate buffer $(2 \mathrm{~g}$ liver $/ \mathrm{ml}$ ), corresponding with 1-1.3 $\mathrm{mg}$ protein/ml, and stored at $-80^{\circ} \mathrm{C}$. Before use the microsomes were thawed and washed twice, with ice-cold Tris-HCl buffer ( $50 \mathrm{mM}, \mathrm{pH} 7.4)$ containing $150 \mathrm{mM}$ $\mathrm{KCl}$, followed by centrifugation at $65,000 \times \mathrm{g}$ for $40 \mathrm{~min}$ at $4{ }^{\circ} \mathrm{C}$. Finally, the pellet was resuspended in $4 \mathrm{ml}$ Tris- $\mathrm{HCl}$ buffer and then used. The protein concentration was measured according to Smith ex al. (12).

\subsection{Lipid peroxidation assay}

At $37^{\circ} \mathrm{C}, 250 \mu \mathrm{l}$ of microsomes was added to $540 \mu \mathrm{l}$ of $\mathrm{Tris}-\mathrm{HCl} / \mathrm{KCl}$ buffer. Ten $\mu \mathrm{l}$ of the test compounds with different concentration were added. Ascorbate solution (125 il) was added giving a final concentration of $0.2 \mathrm{mM}$. The reaction was started by adding $75 \mu \mathrm{l}$ of a freshly prepared ferrous chloride solution giving a final concentration of $10 \mu \mathrm{M}$. Lipid peroxidation was assayed by measuring thiobarbituric acid (TBA) reactive material. The incubation mixture $(1 \mathrm{ml})$ was stopped by adding $2 \mathrm{ml}$ of an icecold TBA-trichloroacetic acid-HCl-butyllyydroxytoluene (BHT) solution. The mixture was heated for $15 \mathrm{~min}$ at $90^{\circ} \mathrm{C}$ and then centrifuged for $5 \mathrm{~min}$. The absorbance was de- 
termined at $535 \mathrm{~nm}$ vs $600 \mathrm{~nm}$. The TBA-trichloroacetic acid-HCl-BHT solution was prepared by dissolving $41.6 \mathrm{mg}$ TBA/10 $\mathrm{ml}$ trichloroacetic acid $(16.8 \mathrm{w} / \mathrm{v}$ in $0.125 \mathrm{~N}$ HCl). To $10 \mathrm{ml}$ TBA-trichloroacetic acid-HCl $1 \mathrm{ml} \mathrm{BHT}(1.5 \mathrm{mg} / \mathrm{ml}$ ethanol) was added. The added chemicals did not interfere with the assay in the concentrations used.

\section{Results}

Phloretin is a potent antioxidant in peroxynitrite scavenging and the inhibition of lipid peroxidation. The concentration of phloretin needed to scavenge $50 \%$ of the peroxynitrite $\left(\mathrm{IC}_{50}\right)$ is $3.1 \mu \mathrm{M}$ and the concentration of phloretin needed to inhibit $50 \%$ of the lipid peroxidation is $24 \mu \mathrm{M}$ (Fig. 1). Occupation of $2-\mathrm{OH}$ by glucose decreased the antioxidant activities of phloridzin 18 times in comparison to phloretin. The hydroxyl groups of sugar moiety have no role in the antioxidant activity of phloridzin, since the $\mathrm{IC}_{50}$ of glucose more than $1000 \mu \mathrm{M}$ for either peroxynitrite scavenging or inhibition of lipid peroxidation.

It has been shown that the antioxidant activity of flawoinoids resides in the aromatic OH-groups (6). To determine the role of the different functional groups in phlloretin, structurally related compounds were tested. Phenol is a very poor antioxidant. Introducing more $\mathrm{OH}$ groups in meta position, similar to the A-ring of phloretin, gives resorcinol or phloroglucinol. Resorcinol and phloroglucinol have a substantial higher antioxidant activity compared to phenol, however, it is still far less than that of phloretin. This points toward a substantial contribution of the carbonyl group in phloretin. However, 2-hydroxyacetophenone is a very poor antioxidant, its activity is even lower than that of phenol (Fig. 1). Remarkably, 2,4,6-trihydroxyacetophenone has an activity that is similar to that of phloretin. Surprisingly, the antioxidant activity of 2,6dihydroxyacetophenone is comparable to that of $2,4,6$-trihydroxyacetophenone, whereas 2,4-dihydroxyacetophenone is a very poor antioxidant (Fig. 2). 2-Hydroxy-6methoxyacetophenone displayed virtually no antioxidant activity. 


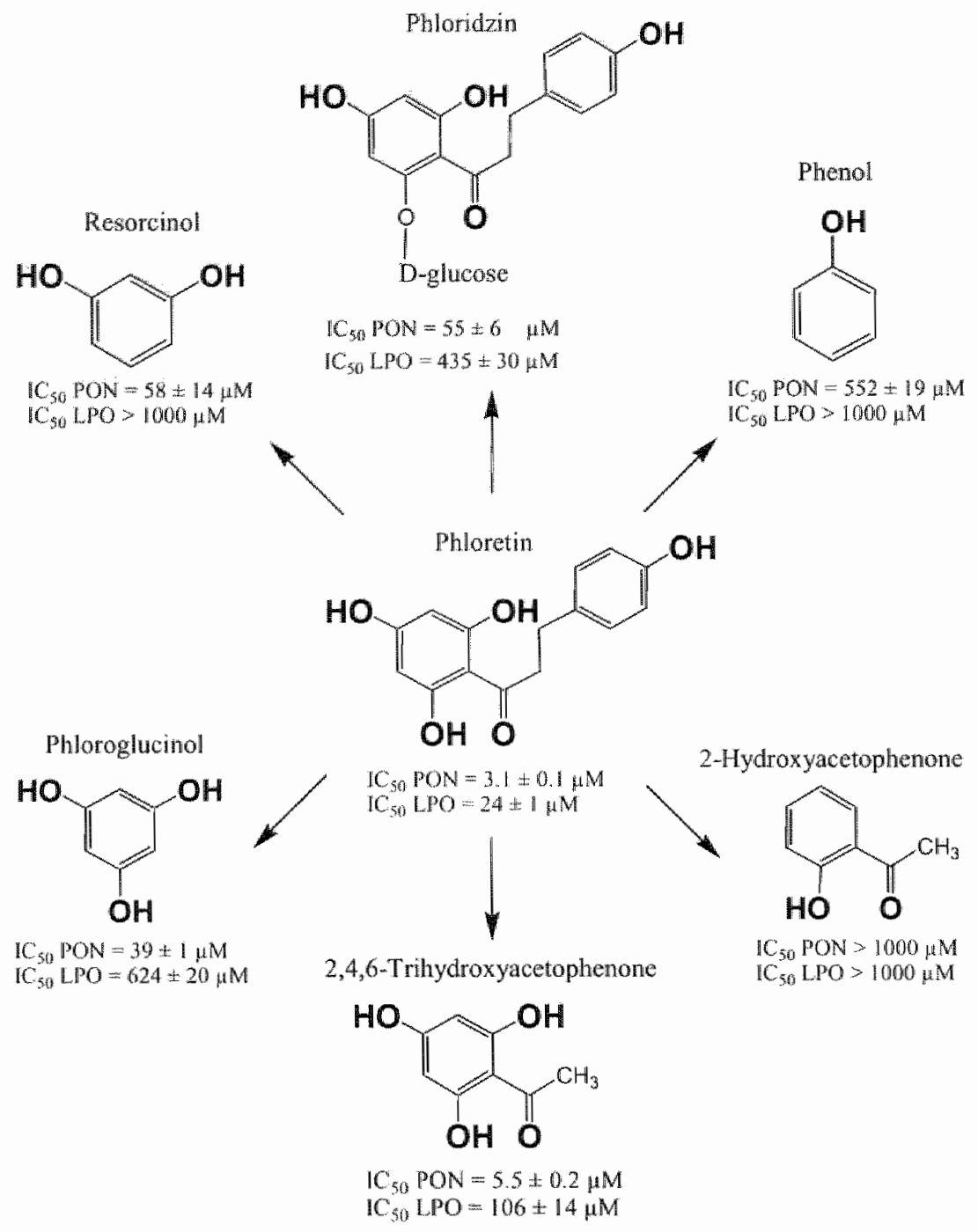

Nig 1. The antioxidant activity of dihydrochalcones (phloretin and phloridzin) and structurally related compounds in peroxynitrite scavenging and the inhibition of lipid peroxidation. The activity is expressed as the concentration of the compound that gives $50 \%$ scavenging of the peroxynitrite $\left(\mathrm{CC}_{50} \mathrm{PON}\right)$ and the concentration that is needed to inhibit $50 \%$ of the lipid peroxidation ( $1 C_{50}$ LPO). Values are presented as mean 2 SD of at least three separate experiments. 
2-Hydroxyacetophenone<smiles>CC(=O)c1ccccc1O</smiles>

$I C_{50 \mathrm{P}} \mathrm{PON}>1000 \mathrm{\mu M}$ $1 \mathrm{C}_{\mathrm{SO}} \mathrm{LPO}>1000 \mu \mathrm{M}$
2-Hydroxy-6-methoxyacetophenone<smiles>COc1cccc(O)c1C(C)=O</smiles>

$1 C_{50} \mathrm{PON}>1000 \mu \mathrm{M}$

$1 C_{50} \mathrm{LO}=1000 \mu \mathrm{M}$
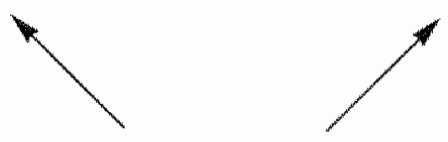

2,4,6-Trihydroxyacetophenone<smiles>CC(=O)c1c(O)cc(O)cc1O</smiles>

$1 C_{50} \mathrm{PON}=5.5 \pm 0.2 \mathrm{\mu M}$

${ }^{1 C_{5 B}} \mathrm{LPO}=106 \pm 14 \mu \mathrm{M}$

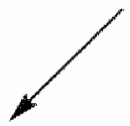

2,4-Dihydroxyacetophenone

2,6-Dihydroxyacetophenone<smiles>CC(=O)c1ccc(O)cc1O</smiles>

$1 C_{50} \mathrm{PON}>1000 \mu \mathrm{M}$

$1 C_{50} \mathrm{LPO}>1000 \mathrm{HM}$<smiles>CC(=O)c1c(O)cccc1O</smiles>

$1 \mathrm{C}_{50} \mathrm{PON}=7.8+1.11 \mathrm{MM}$

$\mathrm{IC}_{\text {SI }} \mathrm{LPO}=95 \pm 2 \mu \mathrm{M}$

Fig 2. The antioxidant activity of 2,4,6-trihydroxyacetophenone and structurally related compounds in peroxynitrite scavenging and the inhibition of lipid peroxidation. "The activity is expressed as the concentration of the compound that gives $50 \%$ scavenging of the peroxynitrite (IC 50 PON) and the concentration that is needed to ishibit $50 \%$ of the lipid peroxidation $\left(\mathrm{IC}_{50} \mathrm{LPO}\right)$. Values are presented as mean $\mathbb{\mathrm { SD }}$ of at least three separate experiments.

\section{Discussion}

Phloretin is a relatively potent antioxidant in peroxymitrite scavenging and inhibition of lipid peroxidation. The potent antioxidant activity of phloretin has also been found in other assays, e.g. hydroxyl radical scavenging $(3,13)$ and 1,1-diphenyl-2-picrylhydrazyl 
radical scavenging (7). Comparison with structurally related compounds it was found that the activity of phloretin does not reside only in the three hydroxyl groups of ring $A$. Their activity is enhanced by the carbonyl group. Remarkably, introduction of a carbonyl group in phenol (giving 2-hydroxyacetophenone) reduces the antioxidant activity, whereas introduction of the same group in phloroglucinol (giving 2,4,6trihydroxylacetophenone) increases the antioxidant activity. The activity of $2,4,6$ trihydroxylacetophenone is comparable to that of plaloretin.

Based on NMR data, it has been reported that in 2-hydroxyacetophenone the hydroxyl group forms an intramolecular hydrogen bridge with the adjacent double bound oxygen (14). This will drastically reduce radical scavenging by means of hydrogen donation, explaining the very poor antioxidant activity of 2 -hydroxylacetophenone. In $2,4,6$ trihydroxylacetophenone there is evidence that no intramolecular hydrogen bridge between the carbonyl group and one of the aromatic hydroxyl group is formed (14). Moreover, an intramolecular hydrogen bridge can only be formed with one of the aromatic hydroxyl groups, indicating that the carbonyl group cannot reduce the activity of all aromatic hydroxyl groups in 2,4,6-trihydroxyacetophenone. This can explain why the carbonyl group cannot effectively block the antioxidant activity of $2,4,6$ trihydroxylacetophenone as in 2-hydroxyacetophenone.

Remarkable is also the difference in activity between 2,6-dihydroxylacetophenone, with an activity identical to 2,4,6-trihydroxylacetophenone, and 2,4-dihydroxylacetophenone, with virtually no antioxidant activity. This indicates that the effect of the carbonyl group is not due to electron donation via the aromatic ring, since this effect is comparable for the 4 and 6 position.

An explanation for the potent antioxidant activity of 2,6-dihydroxylacetophenone might be found in the possible stabilisation of the radical that is formed after hydrogen abstraction. As shown in figure 3, the free electron that is generated due to hydrogen abstraction of one of the hydroxyl groups can be delocalized over the three oxygen atoms present in the molecule. This involves a keto-enol transformation of the carbonyl group, and the transfer of an alpha hydrogen atom of the carbonyl group to the oxygen radical. In this way the unpaired electron is transferred to the carbonyl group. The umpaired electron can then be transferred to the other aromatic hydroxyl group by a hydrogen transfer. Such a stabilization of the radical is not possible in the radical of $2,4-$ dihydroxylacetophenone, which explains the poor antioxidant activity of 2,4dihydroxylacetophenone.

Our explanation is confirmed by the poor antioxidant activity of 2-hydroxy-6methoxyacetophenone (Fig. 2). The radical of this compound can also not be stabilized in the same way as 2,6-dihydroxylacetophenone. In phloridzin, one of two hydroxyl groups adjacent to the carbonyl group has been substituted by a sugar moiety. 


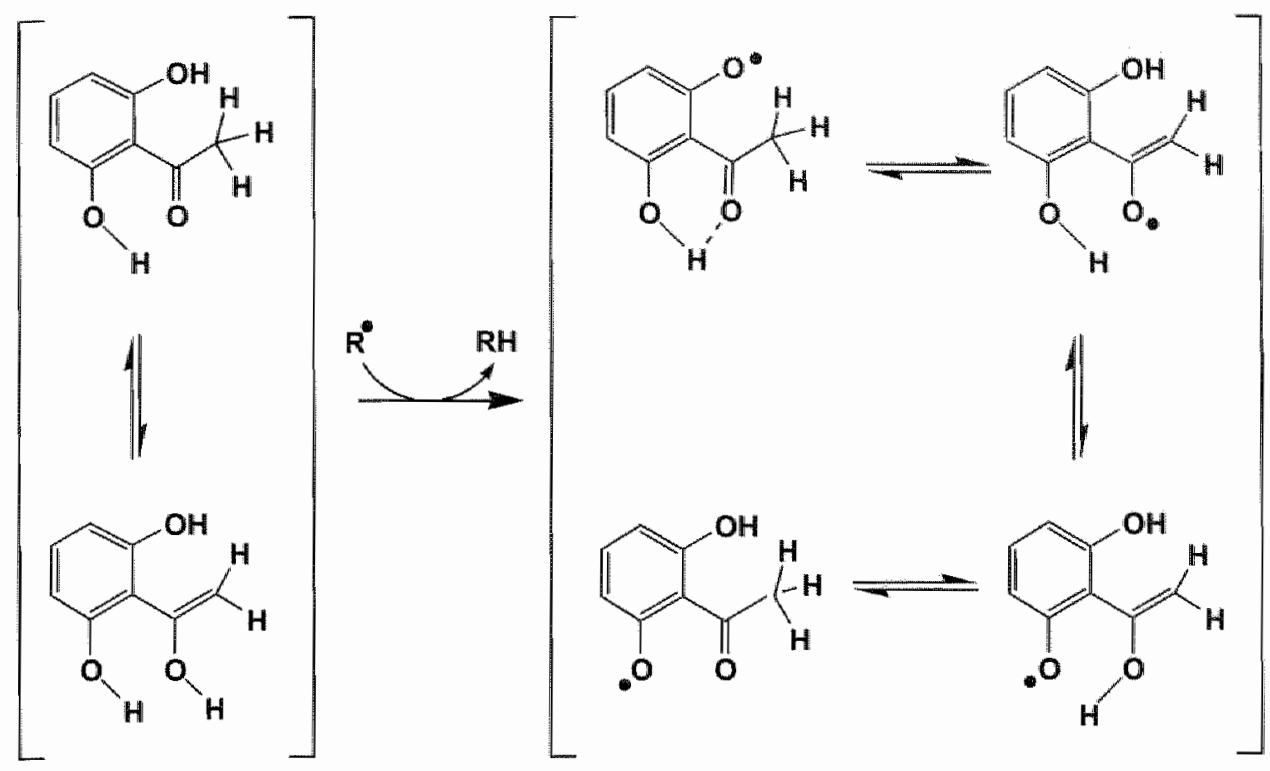

Fig 3. The proposed mechanism for the antioxidant activity of 2,6 -dihydroxyacetophenone.

Subsequently, also in this compound stabilization of its radical as in the radical of 2,6 dihydroxylacetophenone cannot be achieved. This explains the relatively poor antioxidant activity of phloridzin compared to phloretin. It has been reported that in another group of flavonoids, i.e. the flavonols, two different pharmacophores can be found, i.e. on the B-ring or the AC-ring (Fig. 4) $(5,6)$. In ring B this is the catechol moiety and the activity of one of the hydroxyl groups is enhanced by the electron donating effect of the other one. In the AC-ring the llydroxyl group at position 3 is the most reactive one and its activity is enthanced by the electron donating effect of the hydroxyl groups at position 5 and 7 . In the dihydrochalcone phloretin another pharmacophore is present, i.e. the 2,6 dihydroxyacetophenone group. It is proposed that delocalisation of the unpared electron in the radical that is obtained after hydrogen abstraction is essential for its antioxidant activity.

One of the pharmacophore in flavonols, i.e. the AC ring, has a strong chemical resemblance with the pharmacophore in phloretin, i.e. the 2,6-dihydroxyacetophenone group. In both pharmacophores there are two aromatic hydroxyl groups with a carbonyl group in between and an intramolecular hychrogen bridge can be formed with either hydroxyl group. Methylation of one of the aromatic hydroxyl groups in 2,6 . dihydroxyacetophenone abolishes the activity of the compound. In contrast, $2,3,5,7$. tetra-O-methyl-quercetine still thas a potent antioxidant effect (6). "This points toward a fundamental difference between both pharmacophores. In the $\mathrm{AC}$ ring an electronic ef- 
fect is important, whille in 2,6-dihydroxyacetophenone tautomerisation is proposed to play a pivotal role.

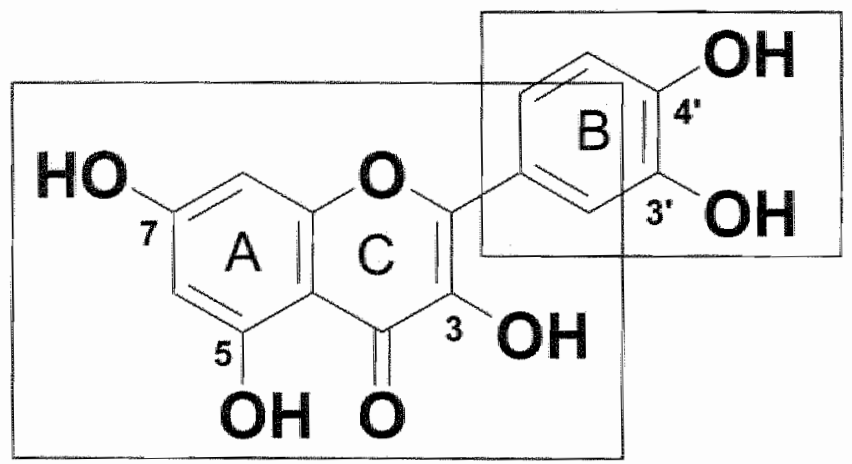

Fig 4. The antioxidant pharmacophores in flavonols. Two different pharmacophores have been proposed, i.e. the catechol group in ring $B$ and the three hydroxyl groups in ring $\mathrm{AC}$. The activity of the $3-\mathrm{OH}$ group is enhanced by an electron donating effect of the hydroxyl groups at position 5 and 7 .

This indicates that within the chemically heterogeneous group of flavonoids different pharmacophores with different characteristics can be found in the various categories.

\section{References}

1 Gutteridge IM. Free radicals in disease processes: a compilation of cause and consequence. Free Radic. Res. Conmmun. 1993; 19:141-58.

2 Hertog M. Hollman $P_{*}$ wan de Purte $B$. Content of potential anticarcinogonic ftavonoids of tea infu* sions, wines, and fruit juices. J Agric. Food Chem. 1993:41:1242-46.

3 Bors W, Heller W, Michell $C$, Saran M. Flavonoids as antioxidants: Determination of radicalseavenging efficiencies. Mertin. Entymol. 1990; 186:343-55.

4 Rice-Evans CA, Miller NJ, Paganga O. Structure-antioxidant activity relationships of flavonoids and phenolic acids. Fre Radic. Biol Med. 1996; 20:933-56.

5 Hatenen GRMM, Paquay JBG, Korthouwer REM, Bast A. Peroxynitrite scavenging by flavonoids. Brochens. Biophys. Res. Commonr. 1997:236:591-3.

6 Heijnen CGM, Haenen GRMM, Vekemans JAJM, Bast A. Peroxynitrite scavenging of flavonoids: structure activity relationship. Environ Toxicol. Pharanacol 2001; 10:199-206.

7 Calliste C, Le Bail J, Trouillas P, Pouget C, Habrioux G, Chulia A, Duroux J. Chalcones: Structural requirements for antioxidant, estrogenic and antiproliferative activities. Anticancer Res. 2001; 21: $3949-56$.

8 Crespy V, Aprikian O, Morand C, Besson C, Manach C, Demigné C, Rémésy C. Bioavailability of phloretin and phloridzin in rats. J. Nutr. 2002; 132:3227-30. 
9 Koppenol W H, Kissner R, Beckmar JS. Symtheses of poroxyntrite; to go widh the flow or on solid grounds? Merh Enzymol 1996; 269: 296m302.

10 Kooy NW, Royall JA, Ischiropoulos H, Beckman SS. Peroxynitritemediated oxidation of dhydrothodamine 123. Free Radic. Biol. Med. 1994; 16:149-56.

11 Haenen GRMM, Bast A. Protection against ipid peroxidation by a glutathione dependent heat lam bile factor. FEBS Leit. 1983; 159: 24-8.

12 Smith PK, Kromn Rl, Hemanson GT, Mallia AK, Grantmer FH, Provenzario MD, Füimoto EK, Goeke NM, Olson BJ, Klenk DC. Measurnen of protein using bicinchononinic acid. Anal. Biochem. 1985; $150: 76-85$.

13 Bors W, Michel $C$, Saran M. Antioxidants: Their function and machanism as radical seavengers, in: G. Cohin, RA. Greenwald (Eds), Oxy radicals and the ir scavenger systems. Vol. II. Mol. Agpech. EIsevier Science, Rotterdim. 1983, pp. 38-43.

14. Mathesen L, Maltend KE, Sund RB. Hydrogen bond fomation ans basis for radical scavenging activity: A structure-actiwity study of C-methylated ditydrochalcones from Myrica gale and structurally related acetophenones. Free Radic. Biol. Med. 1997;22:307-11. 



\section{Chapter 5}

Lipoic acid protects efficiently only against a specific form of peroxynitrite induced damage

Bashir M. Rezk, Guido R.M.M. Haenen, Wim J.F. van der Vijgh, and Aalt Bast

J Biol Chem. 2004; 279: 9693-7 


\begin{abstract}
The ability of the sulphur containing compounds glutathione (GSH), glutathione disulphide (GSSG), S-methylglutathione (GSMe), lipoic acid (LA) and dihydrolipoic acid (DHLA) to protect against hypochlorous acid (HOCl) mediated damage and peroxynitrite (ONOOH) induced damage has been compared. Protective activity was assessed in competition assays by monitoring several detectors, i.e. dihydrorhodamine-123 (DHR123) oxidation, $\alpha_{1}$-antiproteinase $\left(\alpha_{1}-\mathrm{AP}\right)$ inactivation and glutathione-S-transferase PI1 (GST-P 1-1) inactivation. In addition, nitration of tyrosine was measured to assess protection of the sulphur containing compounds against ONOOH. For protection against $\mathrm{HOCl}$, the efficacy of the antioxidant was controlled by the ratio of the reaction rate of the antioxidant and the detector molecule with the oxidant. The rank order of the activity of the antioxidants (GSH $>$ DHLA $\approx$ LA $\approx$ GSMe $>$ GSSG) appeared to be independent of the detector used. However, the rank order of the antioxidants against ONOOH induced damage is strongly dependent on the detector. LA was 40 times less active than GSH in the inhibition of ONOOH induced DHR-123 oxidation, whereas LA was 20 times more active than GSH in preventing the inhibition of GST-P1-1 by ONOOH. This points to different molecular mechanisms of ONOOH damage to DHR123 compared to ONOOH damage to GST-P1-1. LA is a poor antioxidant in protecting against the form of $\mathrm{ONOOH}$ damage involved in DHR-123 oxidation. In the form of ONOOH toxicity involved in GST-P1-1 inhibition, LA is the most potent sulphur containing antioxidant in our series. It is proposed that an intermediate product in which both sulphur atoms of LA have reacted is involved in the reaction of ONOOH with LA. The high potency of LA to protect GST-P1-1. against $\mathrm{ONOOH}$ might be of therapeutic interest.
\end{abstract}


Lipoic acid protects efficiently against a specific form of peroxymitrite-induced dimage

\section{Introduction}

Some sulphur containing compounds are efficient antioxidants and can protect against danage induced by peroxynitrite $(\mathrm{ONOOH})(1-5)$ and hypochlorous acid ( $\mathrm{HOCl})(6,7)$. $\mathrm{ONOOH}$ and $\mathrm{HOCl}$ are highly effective antibacterial agents lormed by neutrophils in innate immunity (8). Uncontrolled and excessive production of the reactive species, however, will cause collateral damage to surrounding tissue at the site of inflammation, e.g. LDL oxidation or DNA, RNA and protein damage (9-13). ONOOH is known to mediate both one- and two-electron oxidation reactions, whereas $\mathrm{HOCl}$ predominantly gives two-electron oxidation $(14,15)$

It has been found that lipoic acid (LA) is a very potent protector against ONOOH mediated damage (1-4). In contrast, preliminary studies in our laboratory indicated that $L A$ is a very poor protector against $\mathrm{ONOOH}$ mediated oxidation of dihydrorhodamine- 123 (DHR-123). This controversy might originate from differences in the procedures used to assess the antioxidant activity of LA. The activity of an antioxidant is usually determined by quantifying the ability of the antioxidant to prevent damage induced by a reactive species to a detector. Den Hartog et $a \%$. (7) emphasized that the efficacy of an antioxidant depends on the reaction rate of the oxidant with the detector molecule relative to the reaction rate of the oxidant with the antioxidant. This was illustrated by the difference in protecting activity against $\mathrm{HOCl}$ of several sulphur containing antioxidants using different detectors (7). The slower the reaction of the detector with the oxidant, the higher the apparent activity of a protector. The objective of the present study is to further examine the antioxidant activity of sulphur containing compounds in the presence of different detectors (protein and non-protein), and different oxidants (ONOOH and $\mathrm{HOCI}$ ) in order to resolve the apparent discrepancy in the efficacy of $L A$ in several antioxidant assays. The results show that, with $\mathrm{HOCl}$, the rate of the reaction of $\mathrm{HOCl}$ with the oxidant relative to that of the detector is essential. With ONOOH, the rnoleculat mechanism of damage and protection is decisive for the efficacy of the antioxidant.

\section{Materials and Methods}

\subsection{Chemicals}

Elastase, $\alpha_{1}$-antiproteinase $\left(\alpha_{\|}-\mathrm{AP}\right)$, glutathione S-transferase P-1-1 (GST-P1-11), GSH, GSS, GSMe, 1-chloro-2,4-dinitrobenzene (CDNB) L-tyrosine, 3-nitro-L-tyrosine, 5,5dithio-bis(2-nitrobenzoic acid) (DTNB) and Sodium hypochlorite (NaOCl) were obtained from Sigma Chemical Co. (St. Louis, MO, USA). Dihydrorhodamine-123 (DHR123) and $\mathrm{KO}_{2}$ were obtained from Fluka Chemie GmbH (Buchs, Switzerland). LA and B-LA were obtained from Asta Medica AG (Frankfurt, Gemany). Nitrogen monoxide 
was obtained from AGA (Hamburg, Germany). All other chemicals were of the highest grade of purity.

\subsection{Synthesis of $P O N$}

Potassium oxpperonitrate was produced from the reaction of solid $\mathrm{KO}_{2}$ with $\mathrm{NO}$-gas as described by Koppenol et al. (16). Briefly, the NO-gas was slowly led over the mixture of $\mathrm{KO}_{2}$ and quartz-sand, which was constantly stirred and kept on ice. The mixture was poured into a cold potassium hydroxide solution. Manganese dioxide was used to remove the hydrogen peroxide that results from decomposition of the excess of potassium superoxide. A solution with ONOOH was obtained by filtering off the sand and manganese dioxide. The concentration of ONOOH was determined spectrophotometrically at $302 \mathrm{~nm}$.

\subsection{Oxidation of DHR-123}

The use of DHR-123 as a detector to monitor protection against ONOOH and HOCI induced oxidation was based on the procedure described by Kooy ef al. (17). In short, 100 $\mu$ of the desired concentration of the test compound was added to $0.9 \mathrm{ml}$ of $100 \mathrm{mM}$ phosphate buffer at $37^{\circ} \mathrm{C}$. DHR-123 was added to give a final concentration of $5 \mu \mathrm{M}$. During vortexing $10 \mu \mathrm{l}$ of $\mathrm{ONOOH}$ or $\mathrm{HOCl}$ was added giving a final concentration of $0.6 \mu \mathrm{M}$ or $5 \mu \mathrm{M}$, respectively. The fluorescent product, rhodamine-123, was measured by fluorescence detection with excitation and emission wavelengths of 500 and $536 \mathrm{~mm}$, respectively. The effects are expressed as the concentration giving $50 \%$ inhibition of the oxidation of DHR (IC 50 ). Control experiments showed that the test compounds in a concentration of $500 \mu \mathrm{M}$ did not affect the fluorescence.

\subsection{Elastase assay}

Elastase activity was used as a detector according to the procedure described by Haenen and Bast (6), with minor modifications. The reagents were dissolved in potassium phospluate buffer (19 mM) pH 7.4 , containing $140 \mathrm{mM} \mathrm{NaCl}$. Twenty $\mu \mathrm{g}$ of $\alpha_{1}-\mathrm{AP}$ was preincubated at $37^{\circ} \mathrm{C}$ for 5 min with the test compounds in the desired concentration. During vortexing, $10 \mu l$ of $\mathrm{ONOOH}$ was added. The final concentration of ONOOH was $150 \mu \mathrm{M}$. After 5 min incubation, $5 \mu \mathrm{g}$ elastase was added. After 10 min incubation, 50 M.l of a $10 \mathrm{mM}$ solution of $\mathrm{N}-\mathrm{t}-\mathrm{BOC}-\mathrm{I}$-alanine p-nitrophenol ester in methanol was added. The increase in absorption at $410 \mathrm{~nm}$ was determined. Control experiments showed that the test compounds in a concentration of $100 \mu \mathrm{M}$ did not affect the activity of control or ONOOH inactivated $\alpha_{1}-A P$. 
Lipoic acid protects efficiently against a specific form of peroxynitrite-induced damage

\subsection{Ghuthathone-S-transferase PI-1 assay}

GST-P1-1 $(5 \mu \mathrm{g} / \mathrm{ml})$ was mixed with the test compound in $100 \mathrm{mM}$ potassium phosphate buffer ( $\mathrm{pH}$ 6.5) and the mixture was incubated at $37^{\circ} \mathrm{C}$ for 1 min. During vortexing $\mathrm{ONOOH}$ ( $10 \mu \mathrm{M}$, final concentration) was added. After 2 min incubation $1 \mathrm{mM}$ of CDNB and $1 \mathrm{mM}$ GSH were added. GST PI-1 activity was monitored spectrophotometrically by recording the increase in absorbance at $340 \mathrm{am}(18)$.

\subsection{Nitrotyrosine assay}

Under vortexing $10 \mu \mathrm{l}$ of $\mathrm{ONOOH}$ solution (final concentration $150 \mu \mathrm{M}$ ) was added to a solution containing $100 \mu \mathrm{M}$ L-tyrosine in $100 \mathrm{mM}$ potassium phosphate buffer ( $\mathrm{pH} 7.4$ ) and the test compound in the desired concentration. This mixture was incubated for 5 min. Measurement of 3-nitrotyrosine was carried out by using HPLC. The eluent was 50 $\mathrm{mM} \mathrm{KH} \mathrm{KO}_{4} / \mathrm{K}_{2} \mathrm{HPO}_{4} \mathrm{pH} 7.0$ with $5 \%$ acetonitrile $(\mathrm{w} / \mathrm{w})$. The column was a bypersil BDS-C18 column (150 mm x $4.6 \mathrm{~mm}$ ) (Supelco Inc. Bellefonte, PA, USA). The UV detector was set at $278 \mathrm{~nm}$.

\subsection{LA and GSH consumption by ONOOH and HOCl}

Hundred $\mu$ of the antioxidant (dissolved in $100 \mathrm{mM}$ phosphate buffer) was added to $700 \mu$ l of $100 \mathrm{mM}$ phosphate buffer at $37^{\circ} \mathrm{C}$ giving a final concentration of $100 \mu \mathrm{M}$. During vortexing, $100 \mu \mathrm{l}$ of the desired concentration of ONOOH or $\mathrm{HOCl}$ was added. GSH was determined spectrophotometrically by addition of $100 \mu \mathrm{l}$ of $6 \mathrm{mM}$ DTNB at $412 \mathrm{~nm}$ (19). LA was determined using HPLC and UV detection at $333 \mathrm{~nm}$. A hypersil BDS-C18 column (150 mm x $4.6 \mathrm{~mm}$ ) (Supelco Inc. Bellefonte, PA, USA) was used. The mobile phase was $10 \mathrm{mM}$ phosphate solution in water ( $\mathrm{pH} 2.7$ )/acetonitrile $(65: 35$, $\checkmark / v)$. The samples were acidified before HPLC analysis ( $\mathrm{pH} 2.6-2.9$ ). Determination of $\beta$-LA was performed on the same HPLC system at $230 \mathrm{~nm}$. The mobile phase was $0.15 \%$ acetic acid in water/acetonitrile $(75: 25, \mathrm{~W} / \mathrm{v})$.

\section{Results}

Protection against HOCl was assessed in competition assays, using the detector mole

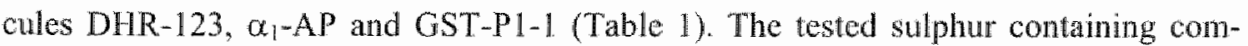
pounds all had a prominent protective effect against HOCL, except GSSG which only had a moderate protective effect against HOCl with DHR-123 as a detector molecule.

The protective effect of these sulphur containing compounds against ONOOH was also assessed in competition assays using the detector molecules DHR-123, $\alpha_{1}$-AP, GSTPI-1 and tyrosine (Table 2). GSH efficiently protected these detector molecules against ONOOH, the $\mathrm{IC}_{50}$ of GSH was practically independent of the detector. GSSG could not 
protect any of the detector molecules used against ONOOH. Methylation of GSH (giving (GSMe) abolished the ability to protect against oxidation of DHR-123 and nitration of tyrosine with ONOOH. GSMe still had a considerable protecting activity against ONOOH when $\alpha_{1}$-AP was used as a detector and to a lesser extend when GST P1-1 was used as a detector. Dihydrolipoic acid (DHLA), a dithiol, had a protective effect against ONOOH that was slightly lower than that of GSH when DHR-123 was used as detector. DHLA efficiently protected $\alpha_{1}-\mathrm{AP}$ or tyrosine against ONOOH mediated inhibition. Lipoic acid (LA), a compound that contains an intramolecular disulfide, was hardly effective in the prevention of DHR -123 oxidation by $O N O O H$, but it potently protected against ONOOH induced $\alpha_{1}-\mathrm{AP}$ damage and tyrosine nitration. Remarkably, both LA and DHLA have very potent protecting activity against ONOOH when GST-P1-1 was used as a detector. Their protective effect against ONOOH with this detector was approximately 20 times as potent than that of $\mathrm{GSH}$.

Table 1. The protecting activity of several sulphur containing compounds against $\mathrm{HOCl}$ induced damage assessed using different detectors.

\begin{tabular}{lccc} 
Compound & $\begin{array}{c}\mathrm{IC}_{50} \mathrm{HOCl}-\mathrm{DHR}-123 \\
(\mu \mathrm{M})\end{array}$ & $\begin{array}{c}\mathrm{IC} 50 \\
(\mu \mathrm{MOCl})_{1}-\mathrm{AP}\end{array}$ & $\begin{array}{c}\mathrm{IC}_{50} \\
\text { HOCl-GST-P1-1 } \\
(\mu \mathrm{M})^{* * *}\end{array}$ \\
\hline Reduced glutathione & $1.3 \pm 0.5$ & 20 & 0.3 \\
S-methylglutathione & $1.5 \pm 0.7$ & 35 & $\mathrm{ND}$ \\
Glutathione disulfide & $9 \pm 1$ & $>200$ & $>200$ \\
Lipoic acid & $5 \pm 3$ & 30 & 1.2 \\
Dihydrolipoic acid & $3.3 \pm 0.6$ & 29 & $\mathrm{ND}$ \\
\hline
\end{tabular}

Detectors used are DHR-123 oxidation, $\alpha_{1}$-AP inactivation, and GST-P1-1 inhibition. The activity is expressed as the $I C_{50}$ value, the concentration needed to reduce the HOCl-induced inbibition or oxidation by $50 \%$. The lower the $1 \mathrm{C}_{50}$, the more potent the compound. Values are presented as mean \pm S.D. of at least three separate experiments. $\mathrm{ND}$, no data

* Data taken from Haenen and Bast (6).

* * Data taken from den Hartog et al. (7). 
Lipoic acid protects efficiently against a specific form of peroxynirrite-induced damage

Table 2. The protecting activity of several sulphur containing compounds against ONOOH mediated damage assessed with different detectors.

\begin{tabular}{lcccc}
\hline Compound & $\begin{array}{c}\mathrm{IC}_{50} \text { ONOOH- } \\
\mathrm{DHR}-123 \\
(\mu \mathrm{M})\end{array}$ & $\begin{array}{c}\mathrm{IC}_{50} \text { ONOOH- } \\
\alpha_{1}-\mathrm{AP}(\mu \mathrm{M})\end{array}$ & $\begin{array}{c}\mathrm{IC}_{50} \text { ONOOH- } \\
\text { GST-PI- }-1 \\
(\mu \mathrm{M})\end{array}$ & $\begin{array}{c}\mathrm{C}_{50} \text { ONOOH- } \\
\text { Tyrosine }(\mu \mathrm{M})\end{array}$ \\
\hline Reduced glutathione & $26 \pm 9$ & $38 \pm 19$ & $17 \pm 1$ & $20 \pm 1$ \\
S-methylglutathione & $>1000$ & $52 \pm 6$ & $104 \pm 3$ & $>200$ \\
Glutathione disulfide & $>1000$ & $>500$ & $>200$ & $>200$ \\
Lipoic acid & $924 \pm 66$ & $17 \pm 2$ & $0.9 \pm 0.1$ & $24 \pm 1$ \\
Dihydrolipoic acid & $56 \pm 9$ & $17 \pm 1$ & $1.0 \pm 0.1$ & $23 \pm 1$ \\
\hline
\end{tabular}

Detectors used are DHR-123 oxidation, $\alpha_{1}$-AP inactivation and GST-PI-1 inactivation and tyrosine nitration. The activity is expressed as the $\mathrm{IC}_{50}$ value, the concentration needed to reduce the $\mathrm{ONOOH}$ induced oxidation, inhibition or nitration by $50 \%$. The lower the $\mathrm{IC}_{50}$, the more potent the compound. Values are presented as mean $\pm \mathrm{SD}$ of at least three separate experiments.

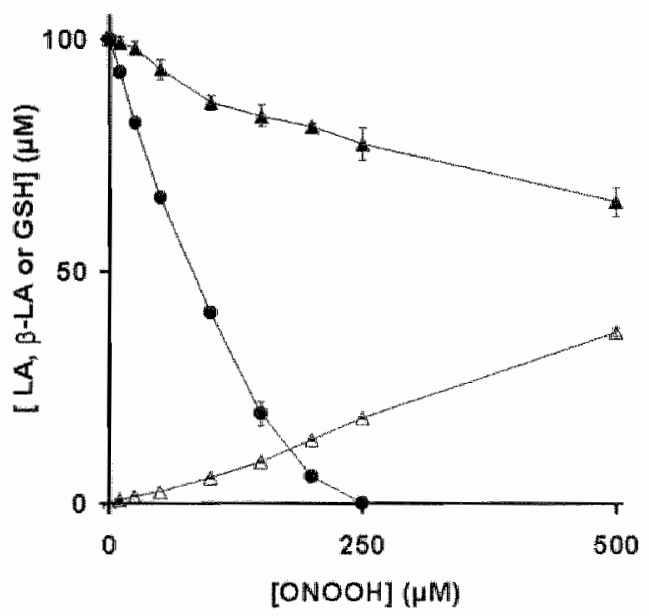

Fig. 1. LA or GSH concentration after the addition of a varying initial concentration of ONOOH $(0-500 \mu \mathrm{M})$ to a solution containing $100 \mu \mathrm{M} \mathrm{LA}$ or $100 \mu \mathrm{M}$ GSH. The formation of $\beta$-LA from LA was also determined. The symbols are as follows: closed circle, GSH; closed triangle, LA; and open triangle, $\beta$-LA. Based on the GSH consumption at a low concentration of $\mathrm{ONOOH}$, the stoichiometry of the reaction is $\approx 1: 1$. Values are presented as mean \pm S.D. of at least three separate experiments. 


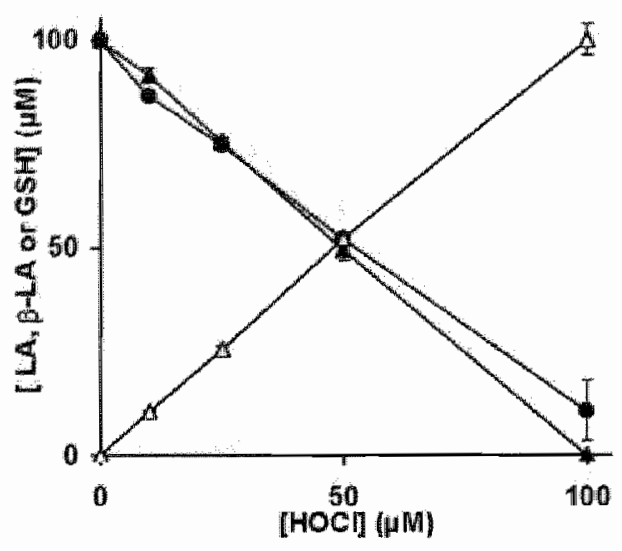

Fig. 2. LA or GSH concentration after addition of a varying initial concentration of HOCl $(0-100 \mu \mathrm{M})$ to a solution containing $100 \mu \mathrm{M}$ LA or $100 \mu \mathrm{M}$ GSH. The formation of $\beta$-LA from LA was also determined. The symbols are as follows: closed circle, GSH; closed triangle, LA; and open triangle, $\beta$-LA. Based on the GSH or LA consumption, the stoichiometry of the reaction of GSH or LA with $\mathrm{HOCl}$ is $1: 1$. Values are presented as mean \pm S.D. of at least three separate experiments.

The difference in protecting activity against ONOOH between GSH and LA prompted us to perform additional experiments. The consumption of GSH and LA by different concentrations of $\mathrm{ONOOH}$ was determined (Fig. 1). The stoichiometry of the initial reaction of GSH was approximately 1, i.e. 1 molecule of GSH reacts with 1 molecule of ONOOH. The apparent stoichiometry of LA was more than 1 . With a five-fold excess of ONOOH over LA, less than half of the LA was consumed. The product formed was $B-L A$, the thiosulfinate of $L A$ which has four possible isomers $(4,6)$.

The stoichiometry of the initial reaction of GSH with $\mathrm{HOCl}$ was comparable to that of LA, i.e. 1 molecule of the antioxidant reacts with $\mathbb{1}$ molecule of the oxidant (Fig. 2 ). The product formed by the reaction of LA with HOCl was $\beta$-LA (Fig. 2).

\section{Discussion}

Some sulphur containing compounds can form an effective line of defense against reactive oxygen and nitrogen species. The aim of the present study is to further examine the antioxidant activity of sulphur containing compounds in order to explain the difference in activity observed in some assays. The present study demonstrated differences in protecting activity of sulphur containing compounds against $\mathrm{HOCl}$ mediated oxidation of different detectors. This can be explained by the rate of the reaction of the sulphur antioxidant with $\mathrm{HOCl}$ relative to the rate ol the reaction of the detector with $\mathrm{HOCl}$. The rank order of the antioxidants is independent of the detector used. The ostensible activ- 
Lipoic acid protects efficiently against a specific form of peroxymitrite-induced damage

ity of a poor antioxidant can be upgraded by using a slowly reacting detector. This is nicely shown by the relatively high potency of $\mathrm{GSSG}$, a compound that reacts sluggishly with $\mathrm{HOCl}(6)$, to protect DHR-123 against HOCl mediated oxidation (Table 1) because DHR-123 reacts just as sluggishly with HOCL as GSSG. GSSG does not protect faster reacting detectors, e.g. $\alpha_{-}-\mathrm{AP}$ and GST-P1-1 against HOCl damage. Similarly, Den Hartog et al. (7) reported that, acetylcholinesterase is efficiently protected by GSSG against HOCl induced damage. This can also be explained by the relatively slow reaction of the target, acetylcholinesterase, with HOCl. Probably also other proclaimed

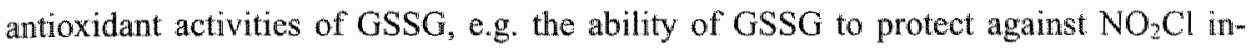
duced DNA damage (20), are the result of a relatively slow reacting detector (DNA). In wivo $\mathrm{NO}_{2} \mathrm{Cl}$ will probably react with other cellular targets than DNA. In such a case, the reported antioxidant effect of GSSG is of course physiologically irrelevant.

GSH protected all the tested detectors efficiently against ONOOH, whereas GSSG is not a protector against ONOOH (Table 2). GSMe did not protect DHR-123 and tyrosine, while it did protect the targets GST-P $1-1$ and $\alpha_{1}-A P$ against ONOOH-induced inhibition. One of the vulnerable groups in $\alpha_{1}$-AP is methionine. Oxidation of methionine. in $\alpha_{1}$-AP results in a loss of activity (21). Since in methionine and GSMe a chemically identical group is attacked by $O N O O H$, i.e. the S-methyl group (21), it was anticipated that $\alpha_{1}-\mathrm{AP}$ is protected by GSMe. The relatively high $\mathrm{IC}_{s_{0}}$ of GSMe with DHR-123 and tyrosine can be explained by arguing that the reaction rate of these detectors with ONOOH is higher than that of GSMe, whereas the lower IC 50 of GSMe with $\alpha_{1}-\mathrm{AP}$ or GST-PL-1 indicates that the reaction rate of ONOOH with these detectors is comparable to the reaction rate of $\mathrm{ONOOH}$ with GSMe. This explanation is in line with the explanation described above for the difference in activity of an antioxidant towards $\mathrm{HOCl}$ in different assays. The efficacy of an antioxidant depends on the detector used.

The most striking result is the finding that the antioxidants LA and DHLA protect GSTP1-1 far more efficiently against ONOOH than GSH (Table 2). In contrast, LA provides a very poor protection against ONOOH induced DHR-123 oxidation (Table 2). GSSG was not able to protect the ONOOH mediated oxidation of DHR-123, a - AP, GST-PI-1 or tyrosine (Table 2). Moreover, the rank order in potency of the antioxidants is not similar for the four detectors used (Table 2). This implies that a difference in protective activity of $L A$ is not solely due to the difference in reactivity of the detectors. The low consumption of LA by ONOOH compared to GSH is peculiar (Fig. 1). At equimolar concentrations of LA and ONOOH $(100 \mu \mathrm{M})$ the consumption of LA was only $13 \%$. The relatively low consumption of $\mathrm{LA}$ by $\mathrm{ONOOH}$ was also noted previously. Trujillo and Radi (4) reported that only $25 \%$ of LA was consumed when $5 \mathrm{mM}$ of LA was mixed with $5 \mathrm{mM}$ ONOOH. This denotes that the protection of GST-PI-1 against ONOOH by LA, that is superior to the protection offered by GSH, is not due to direet scavenging of ONOOH by LA. Apparently the mechanism of protection of GST-PI-I 
against ONOOH by LA differs from the protection by GSH against ONOOH mediated DHR-123 oxidation. Also the difference in rank order of potency of LA and GSH abtained with the different detectors points to different mechanisms of damage and protection.

Tyrosine residues play a critical role in the GST inactivation by ONOOH (22). Previous studies $(2,3)$ and the results presented in table 2 revealed that $L A$ offered an efficient protection against $\mathrm{ONOOH}$ induced tyrosine nitration. The $1 \mathrm{C}_{50}$ value of $L A$ is 6 times lower than the initial concentration of $\mathrm{ONOOH}$ with tyrosine as a detector $\left(\mathrm{IC}_{50}=24\right.$ $\mu \mathrm{M}$, initial concentration of $\mathrm{ONOOH}=150 \mu \mathrm{M}$ ) and more than 10 times lower than GST-PI- $\mathbb{L}\left(\mathrm{CC}_{50}=0.9 \mu \mathrm{M}\right.$, initial concentration of ONOOH $\left.=10 \mu \mathrm{M}\right)$. A similar difference was reported in the study of Whiteman et al. (2), the $I C_{50}$ value of $L A$ for the inhibition of tyrosine nitration was 10 times as low as the initial concentration of $O N O O H$. Theoretically, in a standard competition assay the minimal IC so of the antioxidant is equal to half of the initial concentration of oxidant, i.e. when the antioxidant reacts much faster than the detector.

The explanations of Whiteman et al. (2) for the very low $I C_{50}$ of LA compared to that of the initial concentration of ONOOH were that (i) one molecule of $L A$ can scavenge several ONOOH molecules and (ii) LA can combine with reactive intermediates. The first explanation, viz. that LA scavenges several ONOOH molecules, does not seem probable. The oxidation products of LA that is formed by ONOOH is identical to that formed by HOCl (Fig. 1, 2), i.e. B-LA. This two electron oxidation product of LA is formed after a reaction of one LA with probably one ONOOH (4) or one $\mathrm{HOCl}(23)$. This makes it unlikely that $L A$ reacts with several ONOOH molecules. The second explanation of Whiteman et al. (2), i.e. that LA can combine with the reactive intermediates of ONOOH seems more plausible. Whiteman er al. (2) stated that these intermediate products of $\mathrm{ONOOH}$ could be $\mathrm{NO}_{2}$ " and $\mathrm{NO}_{2}{ }^{*}$.

Interestingly, Nakagawa et al. (3) reported that LA is a selective inhibitor of tyrosine nitration by $\mathrm{ONOOH}$, but $\mathrm{LA}$ does not inhibit ONOOH induced dityrosine formation from tyrosine. They argued that ONOOH has two reactive forms, i.e. a caged biradical $\left[\mathrm{ONO}^{\circ} \ldots \mathrm{OH}^{\circ}\right]$ and a caged bipolar $\left[\mathrm{ONO}^{*} \ldots \mathrm{OH}\right]$ form. The caged biradical form of ONOOH yields dityrosine and the caged bipolar form of ONOOH yields nitrotyrosine. LA was suggested to protect against the bipolar form only, whereas thiol containing compounds such as GSH and DHLA protect against both the bipolar and the biradical form. Although this explanation is highly speculative, it nicely fits within our experimental data. The oxidation of DHR-123 could, just as the oxidation of tyrosine into dityrosine, be mediated by the biradical form of $\mathrm{ONOOH}$ and is therefore inhibited by sulfhydryl containing compounds and not by LA. Based on the prominent protective activity of LA, GST-P1-1 inactivation by ONOOH would be mediated by the bipolar form of $\mathrm{ONOOH}$. 
The major finding that is in conflict with this theory is the reported reaction of ONOOH by LA with a stochiometry of $1: 1$ with a second order rate constant of $1400 \mathrm{M}^{-1} \mathrm{~s}^{-1}$, which is almost identical to that of GSH (1350 $\left.\mathrm{M}^{-1} \mathrm{~s}^{-1}\right)$ (4). Trujillo and Radi (4) determined this rate constant by monitoring ONOOH consumption in a stopped-flow spectrophotometer. In the same study the relatively low consumption of $L A$ by $O N O O H$, identical to the observation depicted in figure 1, was also reported. This finding, i.e. the low consumption of LA in this study and study of Trujillo and Radi (4), is conflicting with the reported very high second order rate constant. The consumption of LA by increasing amounts of ONOOH should have been identical to that of GSH, as shown in Figure 2 for HOCl. As shown in Figure 1, this is clearly not the case for LA consumption by ONOOH. The low consumption of LA by $\mathrm{ONOOH}$ is better in line with the hypothesis that oniy a part of the ONOOH, i.e. the bipolar form, reacts with LA. It should be noted that Trujillo and Radi (4) calculated the apparent second order rate constant by dividing the observed rate of $O N O O H$ consumption by the concentration of LA and the concentration of ONOOH. If only part of the $O N O O H$ is able to react with LA, i.e. the bipolar form, the concentration of the bipolar form should have been used in the calculation instead of the total amount of $\mathrm{ONOOH}$. Consequently, the apparent second order rate constant of the reaction of the bipolar form of ONOOH with LA would have been higher than the reported value of the rate of the second order reaction of $\mathrm{ONOOH}$ with LA. GSH reacts with both forms of $\mathrm{ONOOH}$ and therefore the second order rate constant of GSH cannot be adjusted in the same way as for LA. This would make the true second order rate constant of the reaction of the bipolar form of ONOOH with LA higher than that with GSH. This could explain the higher efficacy of LA compared to GSH in the protection of GST-PI-1. 


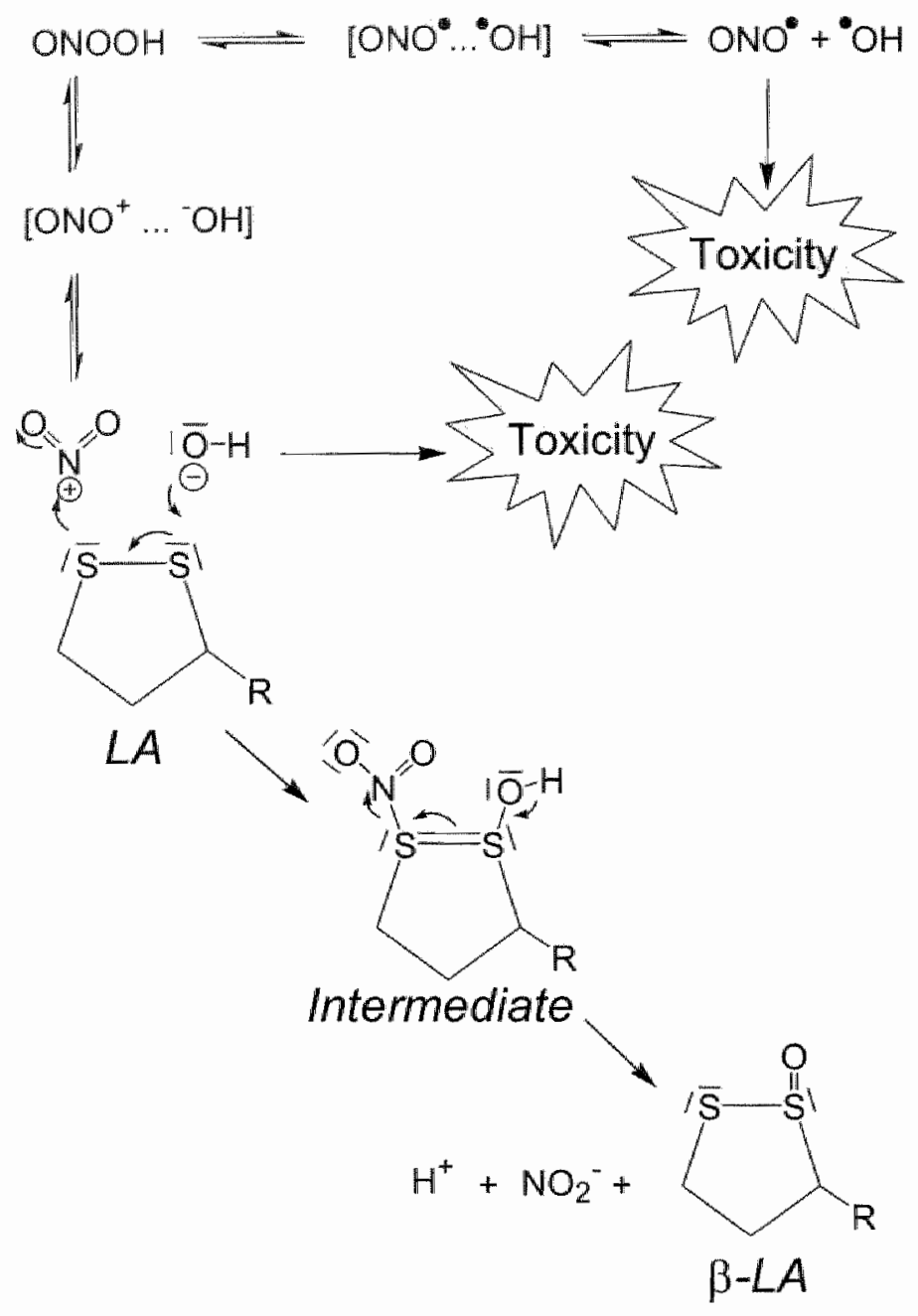

Fig. 3. Proposed reaction of $L A$ with ONOOH. ONOOH can be converted into a biradical [ONO ... OH] or bipolat $[\mathrm{ONO}$... OH] form. LA reacts with the bipolar form. One of the sulfur atoms of LA binds to the positively charged nitrogen. A dlouble bond is created using one of the clectron pairs of the second sulfur atom, and the negatively charged oxygen of the bipolar form of $\mathrm{ONOOH}$ binds to the second sulfur atom. The intermediate that is formed in this way decomposes to give $\beta-\mathrm{LA}$ and $\mathrm{NO}_{2}{ }^{\circ} \mathrm{R}=\left(\mathrm{CH}_{2}\right)_{4}$ $\mathrm{COOH}$

The question arises where the high protection of LA originates from. It is not the reactivity of the separate sulphur atoms, they are far less reactive than the sulphur in GSH. The most prominent feature of $L A$ is that the sulphur atoms are neighboring in a fivemember ring. The orientation of the sulphur atoms in the 1,2-dithiolane ring causes a partial overlap of the lone $p_{2}$ electron pairs of the sulphur atoms. As a consequence the 
$p_{x}$ orbitals combine into binding and antibinding orbitals. The filled antibinding orbital facilitates the ability of LA to donate electrons or in other words this facilitates the ability of LA to reduce oxidants such as $\mathrm{ONOOH}$ and act as antioxidant. This the explanation for the reactivity of LA compared to a linear disulphide, such as GSSG, where an overlap of the $\mathrm{p}_{z}$ electron pair is partially absent (6).

In the reaction scheme proposed (Fig. 3), the antibinding electron pair binds one of the sulphur atoms to the positively charged nitrogen of the bipolar form of $\mathrm{ONOOH}$. The binding electron that already has a partial double bond character (due to interchange with the free d-levels of the neighboring sulphur atoms) forms a double bond between the sulphur atoms. As a result, the sulphur atom that is not bound to the nitrogen becomes positively charged and the negatively charged oxygen of the bipolar form of $\mathrm{ONOOH}$ binds to this sulphur atom. The intermediate that is formed in this way decomposes to give $\beta$-LA and $\mathrm{NO}_{2}{ }^{\prime}$ as shown in Figure 3. In this reaction scheme it is crucial that the $p_{z}$ orbitals of the two sulphur atoms have been converted into a filled binding and antibinding orbital. Trujillo and Radi (4) have shown that the net reaction is that LA plus $\mathrm{ONOOH}$ are converted into $\beta-\mathrm{LA}$ and $\mathrm{NO}_{2}{ }^{-}$which is consistent with the proposed scheme.

In conclusion, the results obtained from this study underline that in the efficacy of a free radical scavenger, the reaction rate of the oxidant with the antioxidant relative to the reaction rate of the oxidant with the detector is a major determinant factor. This is illustrated by the difference in protection of the sulphur containing compounds against $\mathrm{HOCl}$ induced damage to different targets. The difference in protection against $\mathrm{ONOOH}$ of these sulphur containing antioxidants obtained with different targets illustrated that the molecular mechanisms of the damage inflicted by the reactive species and the molecular mechanism of protection by the antioxidant is of equal importance as the rate for the efficacy of the free radical scavenger. $\mathrm{ONOOH}$ damage proceeded wia at least two mechanisms. LA does not protect against all forms of ONOOH damage. LA is a poor antioxidant in the form of $\mathrm{ONOOH}$ toxicity involved in DHR-123 oxidation. However, in the form of ONOOH toxicity involved in GST-P1-1 inactivation, LA is the most potent sulphur containing antioxidant in our series. It is proposed that an intermediate product in which both sulphur atoms of LA have reacted is involved in the reaction of ONOOH with LA. The high potency of LA to protect GST-PI-I against ONOOH might be of interest for the therapeutic action of this drug.

\section{References}

1 Whiteman M, Halliwell B. Thiols and disulphides can aggravate peroxynitrite-dependent inactivation of alphal-antiproteinase. FEBS Lett. 1997; 414: 497-500. 
2 Whitenan M, Tritschller Hallwwell B. Protection against peroxynitrite-dependent tyrosine nitration and alpha I-antiproteinase inactivation by oxidized and reduced lipoic acid. FEBS Let. 1996; 379: $74-6$.

3 Nakagawa $H$, Sumiki $E$, Takusagawa $M$, lkota N, Matsushina $Y$, Ozawa $T$. Scavengers for peroxynitrita: inhibition of tyrosine nitration and oxidation with tryptamine derivatives, alpha-lipoic acid and symihetic compotnds. Chem Pharm Ball (Tokyo). 2000; 48: 261-5.

4 Trujillo $M$, Radi $R$ Peroxymitrite reaction with the reduced and the oxidized forms of lipoic acid: new insights into the reaction of peroxynitrite with thiols. Arch Biochem Biophys. 2002; 397: $91-8$.

5 Kirsch M, Lehnig M, Korth HG, Sustmann R, de Groot $H$. Inhibition of peroxynitrite-induced nutration of tyrosine by glutathione in the presence of carbon dioxide through both radical repair and peroxynitrate Formation. Chemistry. 2001; 7:3313-20.

6 Haenen GRMM, Bast A. Scavenging of hypochlorous acid by lipoic acid. Biachem Pharmacol. j.991; 42: 2244-6.

7 den Hartog GJ, Haenen GRMM, Vegt E, wan der Vigh WJF, Bast A. Efficacy of HOCI scavenging by sulfur-containing compounds: antioxidant activity of glutathione disulfide? Brol Chem. 2002; 383: $709-13$.

8 Hampton $\mathrm{MB}$, Kette AJ, Winterboum $\mathrm{CC}$. Inside the neutrophil phagosome: oxidants, myeloperoxidase, and bacterial killing. Blood. 1998; 92:3007-17.

9 White CR, Brock TA, Chang LY, Crapo J, Briscoe P, Ku D, Bradley WA, Gianturco SH, Gore J, Freeman BA, of al. Superoxide and peroxynitrite in atheroscherosis. Proc Nar Acad Sci U S A. 1994; 91: 1044-8.

10 Jenner AM, Ruiz JE, Dunster C, Halliwell B, Mamn GE, Siow RC. Vitamin C protects against hypochlorous Acid-induced glutathione depletion and DNA base and protein damage in human wascular smooth muscle cells. Arterioscler Thromb Vasc Biol. 2002; 22: 574-80.

11 Radi R, Beckman JS, Bush KM, Freeman BA. Peroxynitrite oxidation of sulthydryls. The cytotoxic potential of superoxide and nitric oxide. I Biol Chem. 1991; 266:4244-50.

12 den Hartog GJ, Vegt E, van der Vijgh WJF, Haenen GRMM, Bast A. Hypochlorous acid is a potent inhibitor of acetylcholinesterase. Toricol Appl Phowmacol. $2002 ; 181: 228-32$.

13 van Hanten RIM, den Hartog GIM, Evelo CT, Haenen GRMM, Bast A. Hypochorous acid is a potent inhibitor of GST PI-1. Chem Biol Interact. 2001; 138: 77-83.

14. Terentis AC, Thomas SR, Burr JA, Liebler DC, Stocker R. Vitamin E oxidation in human atheroscletotic lesions. Circ Rex. 2002; 90: 333-9.

15 Priyadarsini KI, Kapoor S, Naik DB. One- and twowelectron oxidation reactions of trolox by peroxynitrite. Chem Rey Toxicol. 2001; 14:567-71.

16 Koppenol WH, Kissner R, Beckman IS. Syntheses of peroxynitrite: to go with the flow or on solid grounds? Methods Enzymol. 1996, 269: 296-302

17 Kooy NW, Royall JA, Ischiropoulos $H_{3}$ Beckman JS. Peroxynitrite-mediated oxidation of dihydrorhodamine 123. Free Radic Biol Med. 1994; 16: 149-56.

18 Mannervik 3 , Guthenberg C. Glutathione transferase (human placenta). Methods Enzymol. 1981; 77 231.5 .

19 Anderson ME. Determination of glutathione and glutathione disulfide in biological samples. Methods Enzymol 1985: 113:548-55.

20 Chen HJ, Wu SB, Chang CM. Biological and dietary antioxidants protect against DNA nitration induced by reaction of hypochlorous acid with nitrite. Arch Biochen Biophys. 2003; 415: 109-16. 
21 Evans MD, Pryor WA. Cigarette smoking, emphysema, and damage to alpha 1-proteinase inhibitor. Am J Physiol. 1994: 266: L593-611.

22 Wong PS, Eiserich IP, Reddy S, Lopez CL, Cross CE, van der Vliet A. Inacrivation of glutathione Stransferases by nitric oxide-derived oxidants: exploring a role for tyrosine nitration. Arch Biochen Biophys. 2001; 394: 216-28.

23 Biewenga $G$, de Jong J, Bast A. Lipoic acid favors thiolsulfinate formation after hypochlorots acid scavenging: a study with lipoic acid derivatives. Arch Biochem Brophys. 1994; 312: 114-20. 



\section{Chapter 6}

Tetrahydrofolate and 5-methyltetrahydrofolate are folates with high antioxidant activity. Identification of the antioxidant pharmacophore

Bashir M. Rezk, Guido R.M.M. Haenen, Wim J.F. van der Vijgh, and Aalt Bast

FEBS Letters. 2003; 555: $601-5$ 


\begin{abstract}
The presumed protective effect of folic acid on the pathogenesis of cardiovascular, hematological and neurological diseases and cancer has been associated with the antioxidant activity of folic acid. Peroxynitrite (PON) scawenging activity and inhibition of lipid peroxidation (LPO) of the physiological forms of folate and of structurally related compounds were tested. It was found that the fully reduced forms of folate, i.e. tetrahydrofolate (THF) and 5-methyltetrahydrofolate (5-MTHF), had the most prominent antioxidant activity. It appeared that their protection against LPO is less pronounced than their PON scavenging activity. The antioxidant activity of these forms of folic acid resides in the pterin core, the antioxidant pharmacophore is 4-hydroxy-2,5,6triaminopyrimidine. It is suggested that an electron donating effect of the 5-amino group is of major importance for the antioxidant activity of 4-hydroxy-2,5,6triaminopyrimidine. A similar electron donating effect is probably important for the antioxidant activity of THF and 5-MTHF.
\end{abstract}


Tetrahydrofolate and 5-methylhydrofolate are folates with high antioxidant activity

\section{Introduction.}

Folates function as cofactors in the transfer and utilization of one carbon groups. This plays a key role in the biosynthesis of purines and pyrimidines and regeneration of methionine (1). Folic acid (FA) is made up of a pterin moiety (purine and pyrazine fused together) that is linked to the side chain containing $p$-aminobenzoic acid (pteroic acid) and glutamic acid (Fig. 1). FA exists in lactam and lactim tuatomeric forms. The lactam form has a 4-OH moiety on the purine-type ring (Fig. 1). $\mathbb{F}$ is in vivo reduced to dihydrofolate (DHF) and subsequently to tetrahydrofolate (THF). THF is enzymatically converted into 5-methyltetrahydrofolate (5-MTHF), the actual active form (1). Epidemiological studies have shown that FA supplementation can significantly reduce the risk of cardiovascular and hematological diseases, $(2,3)$ neurological and neuropsychiatric disorders, $(4,5)$ neural tube defects (6) and cancer including cervical, lung, brain, pancreatic, colorectal and breast cancer $(7,8)$. The production of reactive oxygen species, reactive chlorine species and reactive nitrogen species ate implicated in these pathologies. Therefore, the antioxidant activity of FA has been suggested to be involved in the presumed effect of FA on health $(9,10)$. There is no consensus about the free radical scavenging activity of FA. One study (10) suggested that the 4-OH group on the pterin ring has an important role. Another study (11) indicated that the side chain, i.e. $\mathrm{N}$-(p-aminobenzoyl)-L-glutamic acid, is more important, since the products formed by nitration of FA were identified as 10-nitrofolate and 12-nitrofolate. The present study was designed to further examine the antioxidant activity of folic acid and its physiological metabolites and to determine which part of the molecule is important for this activity.

\section{Matterials and methods}

\subsection{Chemicals}

Folic acid (FA), 7,8-dihydrofolate (DHF), 2,4-diamino-6-thydroxypyrimidine, 4hydroxy-2,5,6-triaminopyrimidine and $\mathrm{KO}_{2}$ were obtained from Fluka Chemie GmbH (Buchs, Switzerland). 2-Amino-4-hydroxypyrimidine, 5,6,7,8-tetrahydrofolate (THF), 5-metliyl-5,6,7,8-tetrahydrofolate (5-MTHF), 5,6,7,8-tetrahydrobiopterin ( $\mathrm{BH}_{4}$ ), leucopterin and dihydrorhodamine-123 (DHR-123), 2,2'-azinobis(3-ethylbenzthiazoline-6sulfonic acid (ABTS) were obtained from Sigma Chemical Co. (St. Louis, MO, USA). All other chemicals were of the highest grade of purity available. 


\subsection{Isolation of that liver microsomes}

Male Lewis rats, 200-250 g, were killed by decapitation. Microsomes were prepared according to Haenen and Bast (12) with a slight modification. Livers were removed and homogenized $(1.2 \mathrm{w} / \mathrm{v})$ in ice cold phosphate buffer $(50 \mathrm{mM}, \mathrm{pH} 7.4)$ containing 0.1 mM EDTA. The homagenate was centrifuged at $10,000 \mathrm{~g}$ for $30 \mathrm{~min}$ at $4{ }^{\circ} \mathrm{C}$. Subsequently, the supernatant was centrifuged at $65,000 \mathrm{~g}$ for 60 min at $4{ }^{\circ} \mathrm{C}$. The microsomal pellet was resuspended in the phosphate buffer ( $2 \mathrm{~g}$ liver tissue/mol), corresponding with $1-1.3 \mathrm{mg}$ protein $/ \mathrm{ml}$, and stored at $-80^{\circ} \mathrm{C}$. Storage of microsomes at $-80^{\circ} \mathrm{C}$ has no effect on the oxidation state of microsomes in the in wiro assay. Before use the microsomes were thawed and diluted 5-fold with ice-cold Tris- $\mathrm{HCl}$ buffer $(50 \mathrm{mM}, \mathrm{pH} 7.4)$ containing $150 \mathrm{mM} \mathrm{KCl}$ and washed twice followed by centrifugation at $65,000 \mathrm{~g}$ for 40 min at $4{ }^{\circ} \mathrm{C}$. Finally, the pellet was resuspended in $4 \mathrm{ml}$ Tris-HCl buffer and then used.

\subsection{Lipid peroxidation assay}

\subsubsection{Incubation conditions}

Lipid peroxidation assay was carried out according to Haenen and Bast (12) with a minor modification. At $37^{\circ} \mathrm{C}, 450 \mu \mathrm{l}$ of Tris- $\mathrm{HCl} / \mathrm{KCl}$ buffer was added to $250 \mu \mathrm{l}$ of microsomes, the final concentration was $0.5 \mathrm{~g}$ liver tissue/ $\mathrm{ml}$. One hundred $\mu \mathrm{l}$ of a solution containing one of the test compounds were added to achieve the desired concentration. A solution of ascorbate $(125 \mu 1)$ was added giving a final concentration of $0.2 \mathrm{mM}$. The reaction was started by adding $75 \mu$ l of a freshly prepared ferrous sulfate solution giving a final concentration of $10 \mu \mathrm{M}$. After $20 \mathrm{~min}$ incubation, the reaction was stopped as described in spectral measurements. The effects are expressed as the concentration giving $50 \%$ inhibition of lipid peroxidation (LPO IC 50 ).

\subsubsection{Spectral measurements.}

Lipid peroxidation was assayed by measuring thiobarbituric acid (TBA) reactive mate rial (12). The incubation mixture ( $1 \mathrm{ml}$ ) was stopped by adding $2 \mathrm{ml}$ of an ice-cold TBA-trichloroacetic acid-HCl-butylhydroxytoluene (BHT) solution. The mixture was heated for $15 \mathrm{~min}$ at $90^{\circ} \mathrm{C}$ and then centrifuged for 5 min. The absorbance was determined at $535 \mathrm{~nm}$ is $600 \mathrm{~nm}$. The TBA-trichloroacetic acid-HCl-BHT solution was prepared by dissolving $41.6 \mathrm{mg}$ TBA/ $10 \mathrm{ml}$ trichloroacetic acid $(16.8 \mathrm{w} / \mathrm{v}$ in $0.125 \mathrm{~N} \mathrm{HCl})$. To $10 \mathrm{ml}$ TBA-trichloroacetic acid-HCI $1 \mathrm{ml} \mathrm{BHT}(1.5 \mathrm{mg} / \mathrm{ml}$ ethanol) was added. The added chemicals did not interfere with the assay in the concentrations used. 
Tetrahydrofolate and 5-methylhydrofolate are folates with high antioxidant activity

\subsection{Symthesis of peroxymitrite}

Potassium oxoperonitrate (ONOOK) was produced from the reaction of solid $\mathrm{KO}_{2}$ with NO-gas as described by Koppenol et al. (13). Briefly, the NO-gas slowly flowed over the mixture of $\mathrm{KO}_{2}$ and quartz-sand, which was constantly stirred and kept on ice. The mixture was poured into a cold potassium hydroxide solution. Addition of manganese dioxide removes the hydrogen peroxide that results from excess decomposition of potassium superoxide. The solution with peroxynitrite was obtained by filtering off the sand and manganese dioxide. The concentration of peroxynitrite was determined spectrophotometrically at $302 \mathrm{~nm}$.

\subsection{Oxidaiion of DHR-123}

Peroxynitrite scavenging was measured by the oxidation of DHR-123 as described by Kooy ef al. (14). In short, $100 \mu$ of the desired concentration of the test compound were added to $0.9 \mathrm{ml}$ of $100 \mathrm{mM}$ phosphate buffer at $37^{\circ} \mathrm{C}$. The final concentration of DHR123 in phosphate buffer was $5 \mu \mathrm{M}$. During mixing $10 \mu l$ of peroxynitrite (in $0.01 \mathrm{M}$ $\mathrm{NaOH}$ ) was added giving the final concentration, $0.6 \mu \mathrm{M}$. The fluorescent product, rhodamine-123, was measured by fluorescence detection with excitation and emission wavelengths of 500 and $536 \mathrm{~nm}$, respectively. The effects are expressed as the concentration giving $50 \%$ inhibition of the oxidation of DHR- $123(\mathrm{PON} \mathrm{IC} 50)$.

\subsection{The Trolox Equivalent Antioxidant Capacity (TEAC) assay}

The TEAC assay modified by Arts et al. (15) was used. The ABTS stock solution was prepared by dissolving $30 \mathrm{mg}$ ABTS in $7.8 \mathrm{ml}$ of $2.46 \mathrm{mM}$ potassium peroxodisulfate. The ABTS stock solution was diluted with $100 \mathrm{mM}$ phosphate buffer ( $\mathrm{pH} 7.4$ ) to give an absorbance at $734 \mathrm{~nm}$ between 0.68 and 0.73 at $37^{\circ} \mathrm{C}$. The concentration of $\mathrm{ABTS}$ was determined using a molar extinction coefficient of $1.5 \times 10^{4} \mathrm{M}^{-1} \mathrm{~cm}^{-1}$. For measuring the antioxidant capacity, a fixed concentration of the test compounds in this experiment, $5 \mu \mathrm{M}$, was mixed with the different concentrations $(0-46 \mu \mathrm{M})$ of the ABTS solution. Absorbance was monitored at $734 \mathrm{~nm}$ after $6 \mathrm{~min}$ incubation at $37^{\circ} \mathrm{C}$. The total amourt of ABTS" scavenged by the antioxidant, i.e. "a" in the formula, was calculated using the exponential formula $y=a\left(1-e^{(-b x)}\right)$ (Sigma Plot, version 7$)$. In this formula $y$ is the reduction of the ABTS concentration after 6 minutes and $x$ is the initial ABTS concentration. The TEAC value is determined using the equation $T E A C$ w compound $=a /(5 x$ 1.9). In which 5 is the concentration of the test compound in $\mu \mathrm{M}$ used in the experiment and 1.9 is the average concentration of ABTS that is scavenged per $\mu \mathrm{M}$ trolox. 


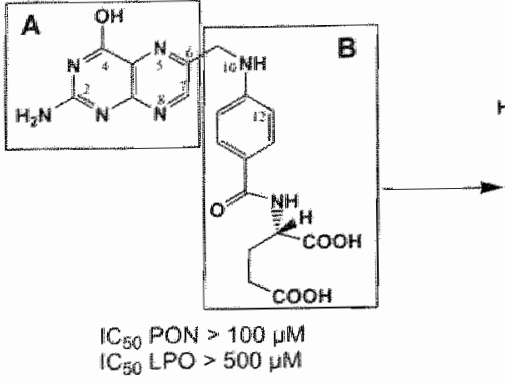

5-Mathy-5,6,7,8-tetrathydrofolic acid<smiles>CN1c2c(O)nc(N)nc2NCC1CNc1ccc(C(=O)N[C@@H](CCC(=O)O)C(=O)O)cc1</smiles>

$I_{560} P O N=0.9 \pm 0.1 \% \mathrm{M}$ $\| C_{50} L P O>500 \mu M$

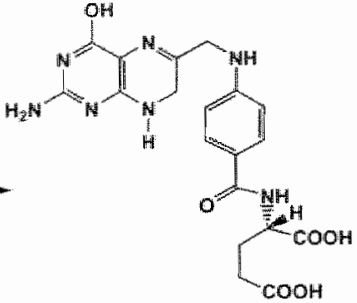

$1 C_{50} P O N=2.4 \pm 0.3 \mu M$

$1 C_{50} \mathrm{LPO}>500 \mathrm{\mu H}$

1

$5,6,7,9$. Totrahyedrofolic asid<smiles>Nc1nc(O)c2c(n1)NCC(CNc1ccc(C(=O)N[C@@H](CCC(=O)O)C(=O)O)cc1)N2</smiles>

$1 \mathrm{C}_{50} \mathrm{PON}=\$ .5 \pm 0.2 \mathrm{HM}$ $1 \mathrm{C}_{50} \mathrm{LPO}=189+26 \mu \mathrm{M}$

Fig. 1. The antioxidant activity of folic acid and its physiological metabolites measured by PON scavenging and inhibition of LPO. The activity is expressed as the concentration of the compound that gives $50 \%$ scavenging of peroxynitrite (IC 50 PON) and the concentration that is needed to inhibit $50 \%$ of lipid peroxidation (IC 50 LPO). FA is made up of two parts viz. a pterin moiety (A) and a $\mathrm{N}$-(p-aminobenzoyl)-L-glutamic acid part (B). The numbering of the most important atoms is also shown in the chemical structure of FA. Values are presented as median \pm half of the range of at least three separate experiments.

\section{Results}

Fig. 1 gives an overview of the antioxidant activities of FA and its physiological melabolites. The concentration of FA needed to prevent the PON mediated oxidation of DHR- 123 by $50 \%\left(\mathrm{IC}_{50} \mathrm{PON}\right)$ is higher than $100 \mu \mathrm{M}$ and the concentration of FA needed to inhibit LPO by $50 \%\left(\mathrm{CC}_{50} \mathrm{LPO}\right)$ is higher than $500 \mu \mathrm{M}$. Reduction of FA to DHF increased the PON scavenging activity $\left(\mathrm{IC}_{50} \mathrm{PON}=2.4 \mu \mathrm{M}\right)$, whereas the concentration needed to inhibit LPO by $50 \%$ was still above $500 \mu \mathrm{M}$. Reduction of DHF to 
THF resulted in a more than 3 fold increase in the ability to protect against LPO and also the ability to scavenge PON was increased. The PON scavenging activity of 5 MTHF compared to that of THF was higher (the $\mathrm{IC}_{50}$ values were $0.9 \mu \mathrm{M}$ and $1.5 \mu \mathrm{M}$, respectively) and the protective effect against $L P O$ was lower (the $\mathrm{IC}_{S 0}$ values were above $500 \mu \mathrm{M}$ and $189 \mu \mathrm{M}$, respectively). The TEAC values of THF and 5-MTHF were equivalent to $1.8 \pm 0.1$, and $0.7 \pm 0.1 \mu \mathrm{M}$ trolox, respectively (Fig. 2).

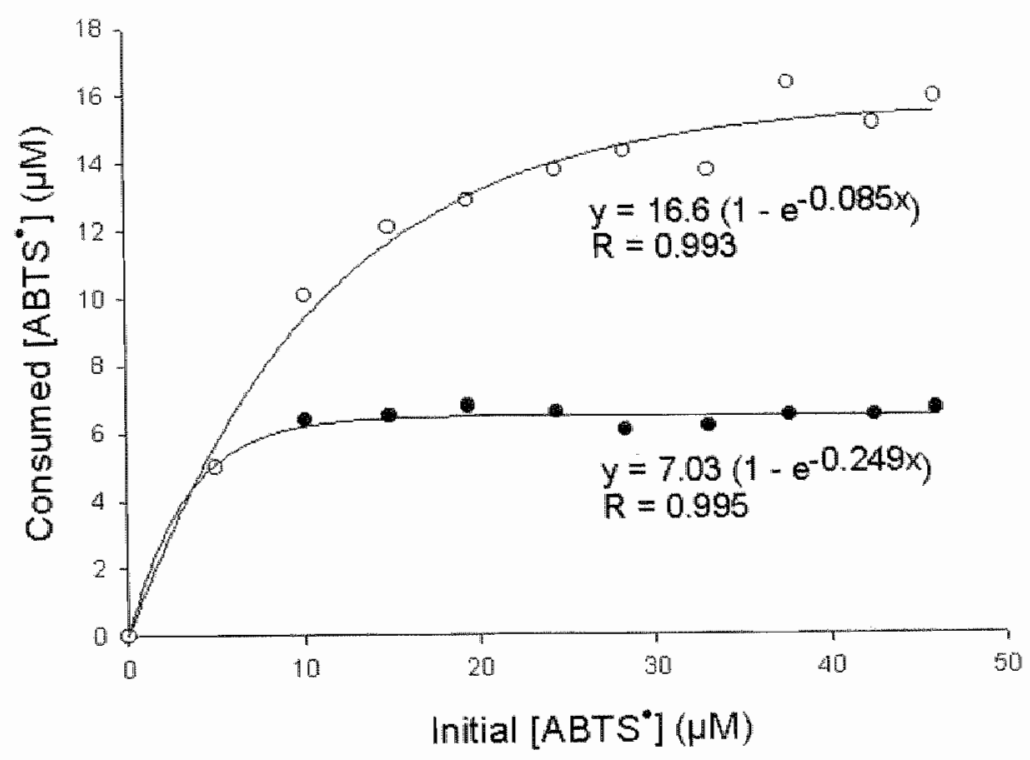

Fig. 2. Determination of the TEAC of THF and 5-MTHF. The reaction of $5 \mu \mathrm{M}$ THF (open circles) and $5 \mu \mathrm{M}$ of 5 -MTHF (closed circles) with various concentrations of $\mathrm{ABTS}^{*}$ was assessed. The concentration of $\mathrm{ABTS}^{*}$ that is consumed by the antioxidant in 6 minutes ( $y$ in the formula) is plotted against the initial concentration of ABTS" $(x$ in the formula). This could be fitted according to the exponential formula given in the figure. $\mathrm{R}$ is the correlation coefficient of the fit. The TEAC of THF (median \pm half of range, $n=3$ ) is $1.8 \pm 0.1$ and that of $5-M T H F$ is $0.7 \pm 0.1$ 
4-Hydroxypyinidine<smiles>Oc1ccncn1</smiles>

$$
\begin{aligned}
& 1 C_{50} P O N=500 \mu M \\
& 1 C_{50} \mathrm{LPO}>500 \mu \mathrm{M}
\end{aligned}
$$

4-Hydroxy-2-aminopymidise<smiles>Nc1nccc(O)n1</smiles>

$1 C_{50} P O N>500 \mu N$

$\mathrm{HC}_{50} \mathrm{LPO}>500 \mathrm{HM}$

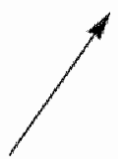

4-Hydraxy-2,6idiaminopyrimidine
Pterin<smiles>Nc1nc(O)c2nccnc2n1</smiles>

$1 \mathrm{C}_{50} \mathrm{PON}>500 \mu \mathrm{M}$ $1 \mathrm{C}_{50} \mathrm{LPO}>500 \mathrm{WM}$ 4-mydroxy-2,5,6-triaminopymimidise<smiles>Nc1cc(O)nc(N)n1</smiles>

$$
\begin{array}{ll}
\| C_{50} P O N=0.8 \pm 0.3 \mu M & 1 C_{50} P O N=143 \pm 18 \mu M \\
1 C_{50} L P O=55 \pm 2 \mu M & 1 C_{50} L P O>500 \mu M
\end{array}
$$

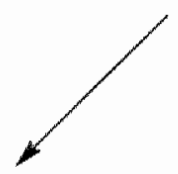

Leicopterin<smiles>Nc1nc(O)c2[nH]c(=O)c(=O)[nH]c2n1</smiles>

$1 C_{50} P O N=27 \pm 8 \mu N$

$1 C_{60} \angle P O>500$ HM

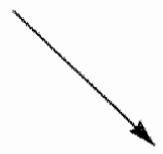

$5,6,7,8$-Tetrahydro-L-biopterin<smiles>C[C@@H](O)[C@H](O)C1CNc2nc(N)nc(O)c2N1</smiles>

$1 \mathrm{C}_{50} \mathrm{PON}=0.5 \mathrm{~s} .2 \mu \mathrm{M}$ $\# C 50 \mathrm{LPO}=86 \pm 1 \mu \mathrm{M}$

Fig. 3. The antioxidant activity of 4-hydroxy-2,5,6-triaminopyrimidine and structurally related compounds measured by PON scavenging and the inhibition of LPO. The activity is expressed as the concentration of the compound that gives $50 \%$ scavenging of peroxynitrite ( $\left(\mathrm{C}_{50}, \mathrm{PON}\right)$ and the concentration that is needed to inhibit $50 \%$ of lipid peroxidation $\left(\mathrm{IC}_{50} \mathrm{LPO}\right)$. Values are presented as median \pm half of the range of at least three separate experiments.

FA can be split into two parts viz. a $\mathrm{N}$-(p-aminobenzoyl)-L-glutamic acid part and a pterin moiety. The $\mathrm{IC}_{50}$ of $\mathrm{N}$-( $p$-aminobenzoyl)-L-glutamic acid was higher than 500 $\mu \mathrm{M}$ for either PON scavenging or inhibition of LPO (data not shown). As shown in Fig- 
Tetrahydrofolate and 5-methylhydrofolate are folates with high antioxidant activity

ure 3 , the antioxidant activity of tetrahydrobiopterin $\left(\mathrm{BH}_{4}\right)$ was comparable to that of THF $\left(\mathrm{IC}_{50} \mathrm{LPO}=86 \pm 1 \mu \mathrm{M}, \mathrm{IC}_{50} \mathrm{PON}=0.5 \pm 0.2 \mu \mathrm{M}\right)$. The antoxidant activity of 4 hydroxy-2,5,6-triaminopyrimidine was also comparable to that of THF. Removing the 5 amino group or the 5 and the 6 amino group of 4-hydroxy-2,5,6-triaminopyrimidine drastically reduced the antioxidant activity. Pterin also displayed no antioxidant activity, whereas leucopterin has a moderate PON scavenging activity.

\section{Discussion}

An antioxidant effect of $\mathrm{FA}$ and its physiological metabolites might be involved in some of the positive health effects. The rationale for the present study is to determine the antioxidant activity of the various endogenous folates and to elucidate which moiety of the molecule determines this activity. FA has a poor antioxidant activity in $\mathrm{PON}$ scavenging and LPO inhibition. Its physiological metabolites are more active. Joshi et al. (10) reported that $500 \mu \mathrm{M}$ of FA induced a $37 \%$ inhibition of LPO, which corresponds to the protection we found, i.e. $\mathrm{IC}_{50} \mathrm{LPO}>500 \mu \mathrm{M}$. Based on this partial inhibition by a relatively high concentration, Joshi et al. (10) speculated on a physiological relevance of FA as an antioxidant. We think that the minor protective effect of FA on LPO is physiologically not relevant. The marginal antioxidant effect of $\mathbb{F}$ A is also seen from its poor PON scavenging activity.

Reduction of FA to DHF results in a more prominent PON scavenging activity than that of FA, whereas the $\mathrm{IC}_{50}$ for inhibition of $L P O$ is still higher than $500 \mu \mathrm{M}$. Further reduction to THF and conversion to 5-MTHF enhanced the PON scavenging activity even more. The fully reduced forms, i.e. THF and 5-MTHF were the most active compounds by inhibiting LPO. 5-MTHF had a relatively lower activity in the protection against LPO than THF ( $500 \mu \mathrm{M}$ of 5 -MTHF induced $46 \%$ LPO inhibition), whereas the PON scavenging activity of 5-MTHF was superior to that of THF. Compared to other compounds, the protective effect of the folates against LPO seems less relevant than their PON scavenging activity. For example, the flavonoid quercetin is much more potent in inhibiting $\mathrm{LPO}\left(\mathrm{IC}_{50}\right.$ of quercetin $\left.=9 \mu \mathrm{M}\right)(16)$ than the folates, whereas its PON scavenging activity is in the same order of magnitude $\left(\left[C_{50}\right.\right.$ of quercetin $\left.=0.53 \mu \mathrm{M}\right)(17)$

To determine the pharmacophore which is responsible for the antioxidant activity of the reduced forms of folic acid, structurally related compounds were tested. The minor importance of the side chain for the antioxidant activity is demonstrated by (i) the absence of antioxidant activity of $\mathrm{N}$-( $p$-aminobenzoyl)-L-glutamic acid, (ii) the large difference in activity of the various folates which all contain the same side chain and (iii) the antioxidant activity of $\mathrm{BH}_{4}$ (that lacks the side chain) which is comparable to that of THF. Apparently, the antioxidant activity resides in the pterin moiety. An optimal antioxidant activity is achieved when the pterin ring is in its reduced form. By comparing structur- 
ally related compounds (Fig 3), it was found that the antioxidant pharmacophore of the fully reduced form of folates, i.e. THF, is 4-hydroxy-2,5,6-triaminopyrimidine.

The potency of substituted phenols for PON scavenging and protection against LPO is governed by the electron donating effect of the substituent $(16,17)$. The higher the electron donating effect, the higher the antioxidant activity. The electron donating effect of a substituent depends on the nature as well as the position of the substituent. For example, the activity of strong electron donating group, such as the hydroxyl group, on the ortho and para position is much higher than that on the mera position. This can explain the potent antioxidant activity of catechol (hydroxyl group at the ortho position; $\mathrm{IC}_{50}$ $\left.\mathrm{LPO}=10 \mu \mathrm{M}, 1 \mathrm{C}_{50} \mathrm{PON}=2.7 \mu \mathrm{M}\right)(16,17)$ and hydroquinone (hydroxyl group at the para position; $\left.I C_{50} L \mathrm{PO}=156 \mu \mathrm{M}, I_{50} \mathrm{PON}=1.8 \mu \mathrm{M}\right)(16,17)$ compared to that of resorcinol (hydroxyl group at the mera position; $\mathrm{IC}_{50} \mathrm{LPO}>1000 \mu \mathrm{M}, 1 \mathrm{C}_{50} \mathrm{PON}=42.5$ $\mu \mathrm{M})(16,17)$. For comparison, for phenol the $\mathbb{L C} \mathrm{C}_{50} \mathrm{LPO}$ is $>1000 \mu \mathrm{M}$ and the $\mathbb{I C}_{50} \mathrm{PON}$ is $263 \mu \mathrm{M}(16,17)$. An amino group has an even higher electron donating effect than a hydroxyl group. For 2-aminophenal, the $\mathrm{IC}_{50} \mathrm{LPO}$ is $5 \pm 0.5 \mu \mathrm{M}$ and the $\mathrm{IC}_{50} \mathrm{PON}$ is $0.6 \pm 0.1 \mu \mathrm{M}$. Similarly, the $I C_{50}$ LPO of 4 -aminophenol is $12 \mu \mathrm{M}$ and the $I C_{50}$ PON is $0.9 \mu \mathrm{M}(16,17)$. In analogy with the difference in activity due to the position of the substituent given above, it is suggested that the 5 amino group of 4-hydroxy-2,5,6triaminopyrimidine is of major importance. The location of this potent electron donating group at the ortho position of the 4 hydroxyl group will boost the activity of the aromatic hydroxyl group, and can explain the potent activity of 4-hydroxy-2,5,6triaminopyrimidine to a great extent.

In leucopterin, the electron withdrawing effect of the carbonyl groups next to the 5 and 6 amino group will reduce the electron donating effect the 4-hydroxyl group receives. This can explain the lower antioxidant activity of leucopterin compared to 4-hydroxy2,5,6-triaminopyrimidine and $\mathrm{BH}_{4}$.

A difference in electron donating effect may also explain the higher PON scavenging activity of 5 -MTHF compared to THF. The methyl group at the 5 amino group in 5 MTHF will slightly enhance the electron donating effect of the 5 -amino group. Based on the TEAC, the number of radicals that can be scavenged by 5-MTHF is lower than that of THF. Possibly, this can explain the low activity of 5.MTHF in the protection against LPO compared to that of THF. The actual antioxidant effect of folates in wivo might depend on both reduction by the enzyme 5,10-methylenetetrahydrofolate (MTHFR) and consumption which is related to vitamin $B_{12}$ and homocysteine level.

In conclusion, FA is a poor antioxidant. The more the FA is reduced, the higher its antioxidant activity becomes: THF and 5-MTHF are the folates with the most prominent antioxidant activity. The antioxidant pharmacophore of THF and 5MTHF, i.e. 4hydroxy-2,5,6-triaminopyrimidime, resides in the pterin moiety. It is suggested that an electron donating effect of the 5 amino group is of major importance in the antioxidant 
activity of 4-hydroxy-2,5,6-triaminopyrimidine. A similar electron donating effect is probably involved in the antioxidant activity of THF and S.MTHF.

\section{References}

I Stanger, O. Physiology of folic acid in health and disease. Cum. Drag Metob. 2002; $3: 211-23$.

2 Verhar, M.C., Stroes, E. and Rabelink, T.J. Folates and cardiowasculat disease, Arrerioscler. Thomb. Warc. Brol 2002;22:6n13

3. Lindenbaum, J. and Nath, B.J. Megaloblastic anaemia and neutrophil hypersegmentation, B. $d$. Howmatol. $1980 ; 44: 511-13$.

4 Mamzoor, M. and Runcie, J. Folate-responsive neuropathy: repont of 10 cases. Br. Med A. 1976; 1 : $1176 m 8$.

5 Aper, J.E. and Fava, M. Nutrition and depression: the wole of folate. Nur, Rev. 1997: 55: 145-9.

6 Daly, L.E., Kirke, P.N., Molloy, A., Weir, D.G. and Scott, J.M., Folata levels and neural tube defocts. Implications for prevention. JAMA. 1995;274: \$698-1702.

7 Duthe, S.J., Narayanam, S., Brand, G.M., Pirie, L. and Grant, G. Impact of folate deficiency on DNA stability. J. Nur $2002 ; 132: 2444 \mathrm{~S}-9 \mathrm{~S}$.

8 Akoglu, B., Faust, D., Milovic, V. and Stein, J. Folate and chemoprevention of colorectat wancer: ls S-methyl-tetrahydrofolate an active antiprohferative agent in folate-treated colon-cancer cells? Nipinion. $2001: 17: 652-3$.

9 Nakmo, E., Higgins, J.A. and Powers, H.J. Folate protects against oxidative modilication of human LDL. Br. J. Nur. 2001;86:637-9.

10 Joshi, R., Adhikari, S, Patro, B.S., Chattopadtyay, S. and Mukherjee, T. Free radical seavenging behavior of folic acid: evidence for possible antioxidant activity. Free Radic Biol. Med. 2001; 30 : $1390-9$.

11 Nakamura, M., Nagayoshi, R., ljiri, K., Nakashima-Matsushita, M., Takeuchi, T. and Matsuyama, "T. Nitration and chlorination of folic acid by peroxyntrite and hypochlorous acid, and the seloctive binding of 10-nitro-folate to folate receptor beta. Biochem. Bioptys. Res. Commun. 2002; 297: 123844.

12 Henen, G.R.M.M. and Bast. A. Prolection against lipid peroxidation by a microsomal glathionedependent labile factor. FEBS Lent $1983 ; 159 ; 24-8$

13 Koppenol. W. H. Kissner, R. and Beckman, J.5. Syntheses of peroxynitrite: to go with the flow of on solid grounds? Meth. Enzynol. 1996; 269:296-302.

14 Kooy, N. W., Royall, J. A., Ischiropoulos H. and Beckman I. S. Peroxymitrte-mediated oxidation of dilyydrorhodamine 123. Fue Radic. Biol. Med. 1994; 16:149\%56. Arts MJT, Dallinga JS, Voss H.P, Henen GRMM, Bast A. Hew approach to assiss the total surtioxidant capacity using the TEAC assay. Food Chew. 2004; $88: 567-70$

16 Heijnen, C.G., Haenen, G.R., Oostwet, R.M., Stalpers, E.M. and Bast, A. Protection of Iavonoids against lipid peroxidation: the structure activity relationship revisited. Free Radic. Res. 2002; 36 : $575-81$

17 Hejinen, C.G.M., Haenen, G.R.M.M., Vekemans, J.A.J.M. and Bast, A. Peroxynitrite scavenging of favonoids: structure activity relationship. Enwron. Toxicol. Pharmacol. 2001; 10; 199-206 



\section{Chapter 7}

Summary and conclusions 


\section{Summary}

In this thesis, antioxidants were studied from a toxicological point of view. The fundament of toxicology is the risk-benefit aralysis. Antioxidants are applied to counteract free radical damage, process associated with numerous pathological conditions. A great deal of people takes antioxidant supplements in the belief that these compounds promote health. Antioxidants may, however, also have negative effects on health. The most striking example is the increase in the risk of getting lung cancer induced by a high $\beta$-carotene consumption in smokers. The positive as well as the negative health effects have to be assessed and related to each other to provide a rationale for the use of an antioxidant. The work performed in this thesis focuses on the beneficial effects of antioxidants and the need to understand the molecular mechanism of these effects.

In the general introduction it is discussed that antioxidants display very diverse biological effects. First of all, an antioxidant is often not a clearly defined compound. Of vitamin $\mathrm{E}, 40$ different vitamers exist and over 5,000 different flavonoids have been identified. Secondly, antioxidants are converted in our body into several metabolites that also contribute to the biological effect of the parent compound. Additionally, antioxidants not only display various antioxidant activities, but they may also possess some prominent non-antioxidant effects. In the original research described in this thesis the molecular mechanisms of 4 antioxidants that were selected based on their toxicological relevance were explored, i.e. vitamin E phosphate, phloretin, lipoic acid and folic acid. Vitamin $E$ esters were regarded as precursors of vitamin $E$ which only display an antioxidant activity after hydrolysis to vitamin $E$. In Chapter 2 , however, it is described that vitamin $E$ phosphate (VEP) has a potent antioxidant effect of its own without conversion into VE when tested as a protector against lipid peroxidation in non-heated and heated rat liver microsomes. Moreover, in contrast to VE, VEP is not consumed during this protection. Of the VE csters, VEP is most potent in inducing haemolysis of erythrocytes. EPR experiments using the spin label 16-doxylstearic acid showed that VEP reduces membrane fluidity, in contrast to VE. This indicates that VEP acts as a detergent and forms a barrier that might inhibit the transfer of tadicals from one polyunsaturated fatty acid to another.

In analogy to VES, the detorgent character of VEP suggests that it might be possible to use VEP as a novel apoptotic agent. In Chapter 3 we investigated the effect of VEP on the osteosarcoma cell line MG-63. VEP induced cell death, antiproliferative effects and DNA degradation to an even higher extent than vitamin E succinate (VES). An explanation for the more potent apoptotic effect of VEP compared to that of VES may be due to inflexibility of VEP. It is also suggested that the biological effect of VEP may be caused by a combination of membrane destabilisation and deregulation of signalling pathways. These activities of VEP are extra relevant since the recent discowery of VEP 
in food and in our body where the levels of VEP sometimes equal or even surpass those of vitamin $E$ itselt.

The beneficial health effect of flavonoids has attracted a great deal of attention of the general public as well as of researchers in the field of mutrition. As elegantly shown in the recent thesis of Chantal Beerens-Heijnen (Maastricht University, 2004), the mom lecular mechanism of action of all 5,000 flavonoids is not identical. Two different nutricophores could be identified within a subgroup of the flavonoids, the flavonols. A nutricophore is defined as a specific structural element of a nutrient where the biochemical activity that is responsible for the health promoting effect of that compound resides. Within the dihydrochalcones, another subgroup of the flavonoids with phloretin as the most prominent compound, a third nutricophore within the flavonoids was identified (Chapter 4). Phloretin was a potent antioxidant in peroxymitrite (ONOOH) scavenging and inhibited lipid peroxidation. Substitution of the 2-OH group by glucose giving phloridzin decreased the antioxidant activity 18 times in comparison to phloretin. Comparison with structuraly related compounds revealed that the nutricophore of phloretin is 2,6-dilhydroxyacetophenone. The potent antioxidant activity of 2,6-dihydroxyacetophenone might be explained by tautomerisation which may stabilise its radical that is formed after hydrogen abstraction. Thus, the 2,6-dihydroxyacetophenone is a new nutricophore which differs from those previously reported in flavonoids.

In Chapter 5, the antioxidant activity of lipoic acid (LA) was studied. It was found that, depending on the target that had to be protected, lipoic acid was either a poor or an extremely potent scavenger of $O N O O H . L A$ is a poor antioxidant in protecting against dihydrorhodamine-123 oxidation by $\mathrm{ONOOH}$. However, in protecting against glutathioneS-transferase P1-1 (GST-P1-1) inactivation by ONOOH, LA is the most potent sulphurcontaining antioxidant in our series. The impact of this finding is that in one type of ONOOH-induced damage lipoic acid is the preferred compound for protection, while in the other type of damage by the same reactive species LA is of no value. A nolecular mechamism explaining this discrepancy was given. In the dithiolane ring of $L A$ the orientation of the two neighbouring sulphur atoms can explain the antioxidant potential of LA. It is proposed that both sulphur atoms play a crucial role in the reaction of a specific form of ONOOH with LA. The potency of LA to protect GST-PI-1 against ONOOH might be of therapeutic interest.

In the last experimental chapter (Chapter 6), the antioxidant effect of folic acid (FA) was studied. The metabolites of FA which contain the most prominent antioxidant activity, i.e. tetraliydrofolate (THF) and 5-methyltetrahydrofolate (5-MTHF), were established and the nutricophore of these metabolites was identified. The antioxidant activity of these forms of FA resides in the pterin core, the nutricophore is 4-hydroxy-2,5,6triaminopyrimidine. It is suggested that an electron donating effect of the 5 -amino group is of major importance for the antioxidant activity of 4-hydroxy-2,5,6-tria- 
minopyrimidine. A similar electron donating effect is probably important for the antioxidant activity of THF and 5-MTHF.

\section{Conclusions and implications}

In the studies on the four selected antioxidants their nutricophores were identified i.e. 4hydroxy $2,5,6$-triaminopyrimidine in FA, the dithiolane ring in LA and 2,6dihydroxyacetophenone in phloretin. In VEP the entire molecule contributes to its antioxidant activity. In a nutricophore the activity responsible for a health promoting effect of a specific nutrient resides. Knowledge on the nutricophore is essential for understanding the molecular mechanism of the health promoting effect.

For the impact of this knowledge, a comparison between drugs and diet can be made. The molecular mechanism of action of a compound provides the fundament for the desired health promoting effect and the rationale for the possible application of that compound, irrespective whether the compound is either a pharmacon or a specific nutrient. Identification of a nutricophore can also help to strengthen our therapeutic arsenal. It becomes possible to predict which ingredients of our diet are of potential interest and what kind of food should be consumed to increase the intake of these ingredients, when necessary. Aiternatively, it can be used to determine which biosynthetic pathways in food crops might be altered by genetic engineering to increase the dietary content of these valuable compounds. In these strategies Paracelsus' rule should be kept in mind and the optimal dose should be determined first.

Knowledge on the nutricophore is also indispensable for designing even more potent compounds. The new nutricophore and mechanism found in the study on VEP may lead to the development of a new class of antioxidants for the protection against free radical mediated disorders. The same applies for the nutricophore discovered in phloretin, which greatly differs from those previously reported in flavonoids. The disclosure of several nutricophores within the flavonoids shows the diversity of the molecular mechanism of action within a group of compounds often incorrectly lumped together. For the folates it was shown that the reduced metabolites display a superior antioxidant activity compared to the other forms of folate. This suggests that it is worthwhile to examine whether these reduced forms might be preferred instead of the oxidized form given at present as folate supplement.

The molecular mechanism disclosed for LA directly proves that antioxidant therapy has to be adjusted to the type of damage that occurs. LA only protects against a specific form of $\mathrm{ONOOH}$ damage. This underlines that in assessing the risk-benefit of applynig of antioxidants, the molecular mechanism has to be known. 


\section{Samenvatting}

In deze dissertatie worden de toxicologische aspecten van een aantal actuele antioxidanten onderzocht. De basis van de toxicologie is de "risk-benefit" analyse. Antioxidanten worden toegepast om schade van vrije radicalen, die ten grondslag ligt aan diverse pathologische aandoeningen, te voorkomen. Veel mensen slikken antioxidanten omdat ze geloven dat dit hun gezondheid bevordert. Antioxidanten kunnen echter ook negatieve effecten hebben op de gezondheid. Een frappant voorbeeld is de toename in het risico om longkanker te krijgen als rokers $\beta$-coroteen gaan gebruiken. Zowel de positieve als de negatieve gezondheidseffecten moeten worden vastgesteld en met elkaar in verband worden gebracht om een rationale voor het gebruik van een antioxidant vast te stellen. De studies in deze dissertatie focuseren zich op de gunstige effecten van de antioxidanten en geven de noodzaak aan om de moleculaire mechanismen van deze effecten te leren kennen.

In de algemene introductie wordt uiteengezet dat antioxidanten zeer viteenlopende biologische effecten kunnen hebben. Vaak is een antioxidant niet een cenduidig gedefinieerde verbinding. Zo bestaan van vitamine $\mathrm{E}$ wel 40 verschillende vitameren, terwijl meer dan 5000 verschillende tavonoiden zijn geidentificeerd. Daar komt bij dat antioxidanten in ons lichaarn worden omgezet tot metabolieten die op hun beurt kunnen bijdragen aan het biologische effect. Bovendien geven antioxidanten niet alleen verschillende antioxidant activiteiten, maar kumnen ze ook eigenschappen bezitten die niets te maken hebben met deze activiteit. In het onderzoek dat in deze dissertatie wordt beschreven, wordt het moleculaire mechamisme van een viertal toxicologisch relevante antioxidanten onderzocht. Het betreft: vitamine $\mathrm{E}$ fosfaat, phloretine, lipoïnezur en foliumzuur.

Vitamine $\mathrm{E}$ esters zouden alleen een antioxidant activiteit verkrijgen na hydrolyse tot vitamine E. In Hoofdstuk 2 wordt echter beschreven dat vitamine E fosfaat (VEP) zelf, dus zonder omgezet te worden in vitamine $\mathrm{E}$, ook een goed werkzame antioxidant is in de lipide peroxidatie assay met zowel verhitte als onverhitte lever microsomen van de rat. Bovendien werd geconstateerd dat VEP gedurende deze bescherming, in tegenstelling tot vitamine $\mathrm{E}$ zelf, niet werd verbruikt. Van de vitamine E esters veroorzaakte VEP de sterkste hemolyse van erythrocyten. EPR analyses waarbij 16-doxylstearinezuur als spinlabel werd gebruikt, lieten zien dat VEP, in tegenstelling tot vitamine E, de mombraan vloeibaarheid vermindert. Dit wijst erop dat VEP in het membraan wordt opgenomen en daardoor een barrière vormt voor het transport van radicalen van het ene meervoudigonverzadigdevetzuur naar het andere.

Naar analogie van vitamine E succinaat (VES) suggereert het oppervlakactieve karakter van VEP dat het een nieuw apoptotisch middel zou kunnen zijn. In Hooldstuk 3 werd daarom het effect van VEP op de osteosarcoma cellijn MG-63 onderzocht. VEP in- 
duceerde celdood, antiproliferatieve effecten en DNA degradatie die sterker was dan die met VES. Een verklaring voor het sterkere apoptotische effect van VEP t.o.v. dat van VES zou de starre struktuur van het VEP kunnen zijn. Een andere suggestie voor het biologische effect van VEP is de combinatie van membraan destabilisatie en de ontregeling wan de signaaltransductie. Deze effecten van VEP verdienen vooral aandacht, omdat VEP niet alleen in voedsel arnwezig blikt te zijn, maar ook in ons lichaam met spiegels die soms gelijk zijn aan of zelfs hoger zijn dan die van vitamine $\mathrm{E}$ zelf.

Het gunstige effect van flavonoiden op de gezondheid heeft veel aandacht gevraagd van zowel de consument als onderzoekers op het gebied van voeding. Zoals Chantal Beerens-Heijnen elegant laat zien in haar recent verschenen dissertatie (Universiteit Maastricht, 2004) is het moleculaire mechanisme van de ca. 5000 flavonoiden niet identiek. Twee verschillende nutricoforen konden worden geïdentificeerd binnen de flavonolen, een subgroep van de flawonoiden. Een nutricofoor is gedefinieerd als een struktuur element van een voedingsstof waar zich de biochemische activiteit bevindt, die verantwoordelijk is voor de bevordering van de gezondheid. Binnen de dihydrochalconen, cen andere subgroep van de flavonoiden met phloretine als belangrijke representant, werd een derde mutricofoor in de flavonoiden geidentificeerd (Hoofdstuk 4). Phloretine bleek een potente antioxidant bij het wegvangen van peroxynitriet en het beschermen tegen lipide peroxidatie. Substitutie van de 2-OH groep door glucose (waardoor de verbinding phloridzine ontstaal) verminderde de antlioxidant activiteit met een factor 18 t.o.v. phloretine. Vergelijking met struktureel verwante verbindingen wees erop dat de antioxidant pharmacofoor van phloretine het 2,6-dihydroxy-acetophenon is. De grote antioxidant activiteit van het 2,6-dihydroxyacetophenon kan worden verklaard door de tautomerisatie van het radicaal dat ontstaat na de eliminatie van waterstof. Het 2,6-dihydroxyacetophenon is dus een nieuwe antioxidant pharmacofoor die verschilt van de eerder ontdekte pharmacoforen in flavonoiden.

In Hooldstuk 5 wordt de antioxidant activiteit van lipoinezuur (LA) onderzocht. A fhankelijk van de target die beschermo moest worden, werd gevonden dat LA hetzij Een slechte dan wel en zeer goede scavenger van peroxynitriet was. LA is een slechte antioxidant bij het beschemen tegen de vorm van peroxymitriet (ONOOH) schade bij dihydrothodamine-123 oxidatie, maar bij de bescherming tegen de glutathion-Stransferase P1-1 (GST-PI-1) inactivatie door ONOOH was LA het meest actief van alle onderzochte zwavel-houdende antioxidanten. De betekenis van deze vinding is dat tegen het ene type schade dat door ONOOH wordt veroorzaakt LA kan beschermen, terwijl LA bij het andere type schade door ONOOH geen waarde heeft. Deze tegenstrijdigheid wordt verklaard met een moleculair mechanisme nl. dat de oriëntatie van de wee aan elkar grenzende zwavel atomen het antioxidant profiel van LA bepaalt. We veronderstellen dat beide zwavel atomen van het LA een cruciale rol spelen 
bij de reactie van een specifieke vorm van ONOOH met LA. De mogelijkheid van LA om GST-PI- $\|$ te beschermen tegen ONOOH schade kan van therapeutisch belang zijn. In het laatste hoofdstuk (Hoofdstuk 6) werd het antioxidant effect van foliumzunr(FA) bestudeerd. De metabolieten van FA die een prominente antioxidant activiteit bezaten werden geidentificeerd. Dit waren tetrahydrofolaat (THF) en 5-methyltetrahydrofolaat (5-MTHF), Van deze verbindingen werd ook de nutricofoor geïdentificeerd, nl. 4hydroxy-2,5,6-triaminopyrimidine. We veronderstellen dat het electronen donerende effect van de 5-amino groep van groot belang is voor de antioxidant werking van het 4hydroxy-2,5,6-triaminopyrimidine. Een vergelijkbaar electronen donerend effect is waarschijnlijk belangrijk voor de antioxidant werking van THF en 5-MTHF. 



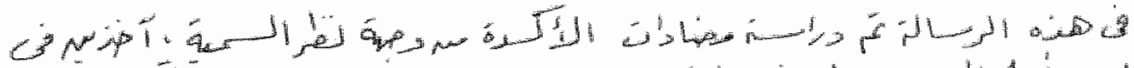

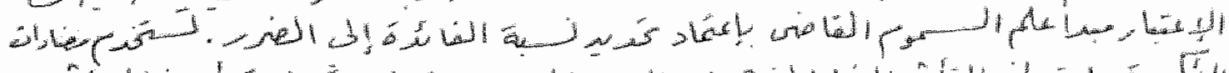

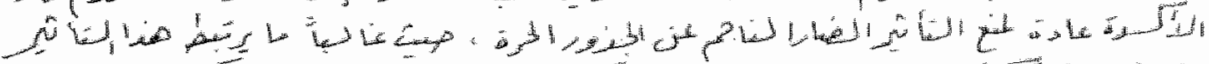

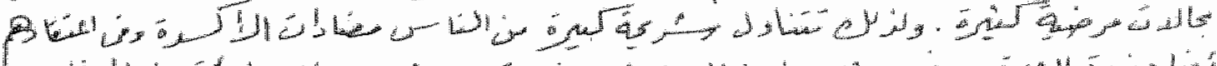

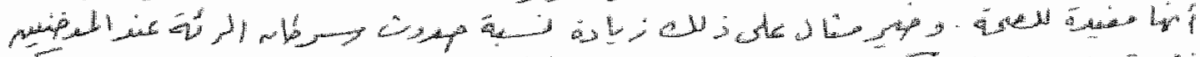

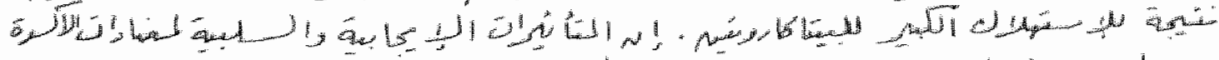

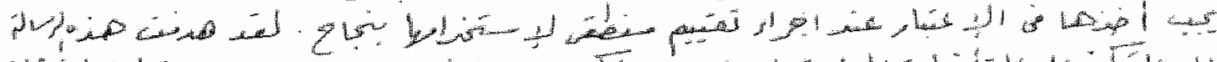
-

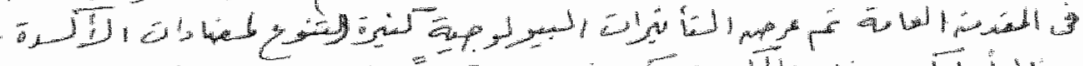
Lis

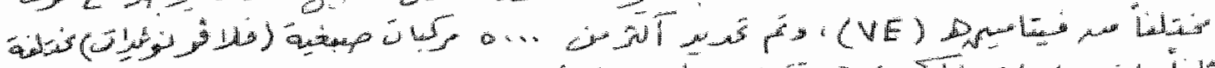

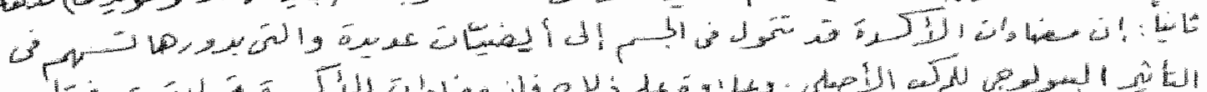

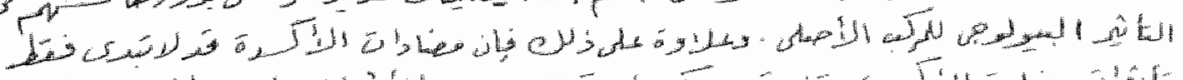

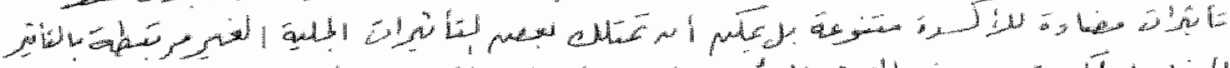

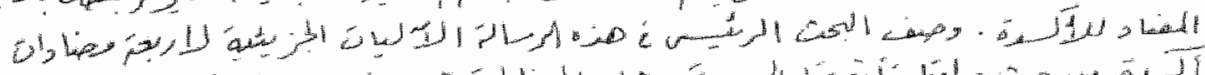

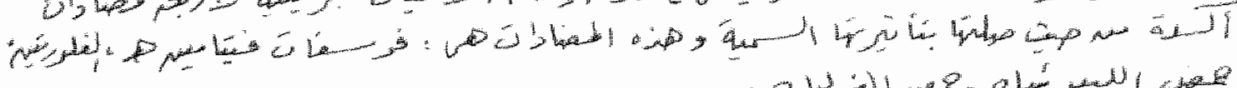

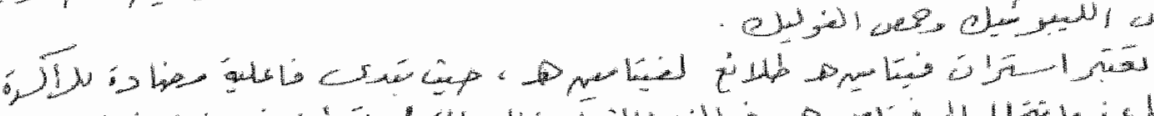

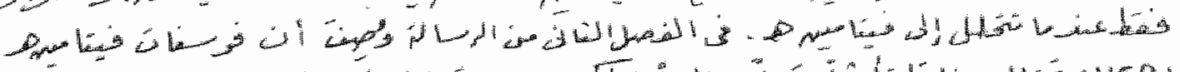

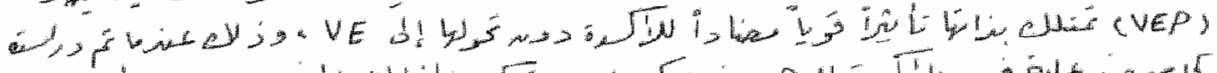

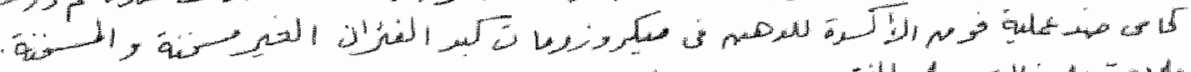

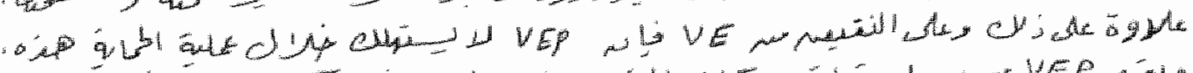

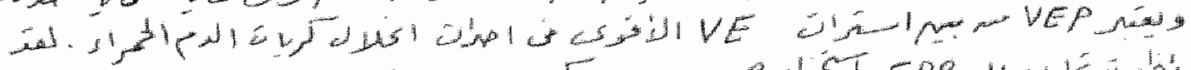
Q V. a d L

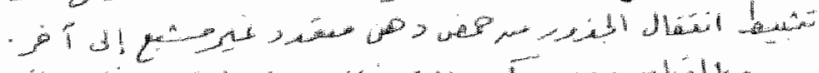
LabV VEP w

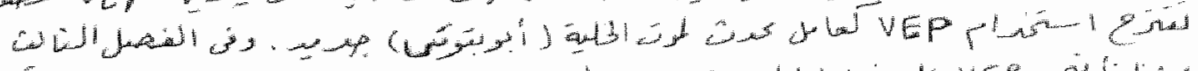
L VE 


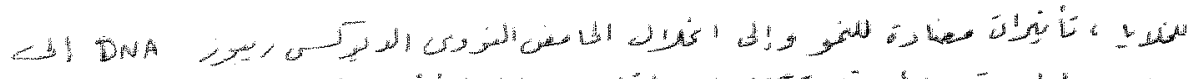

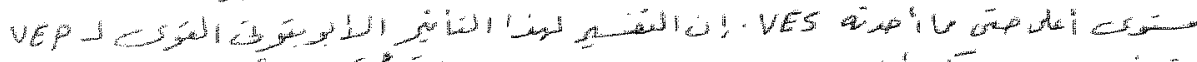
OP

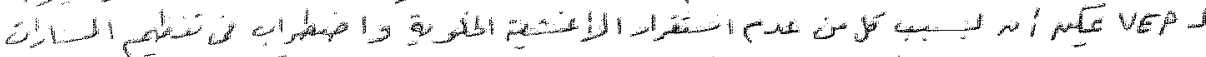
W VEF Cy

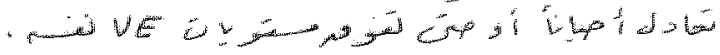

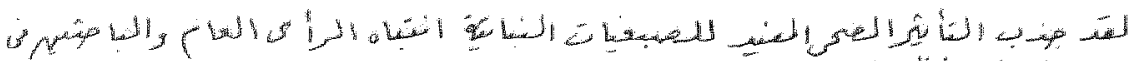

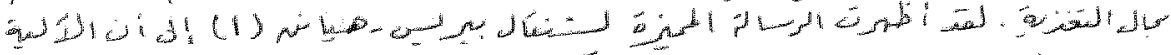

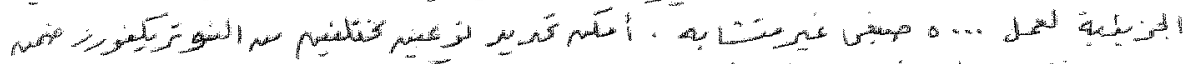

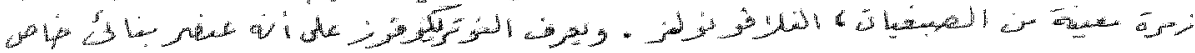

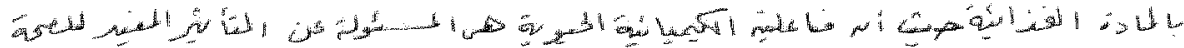

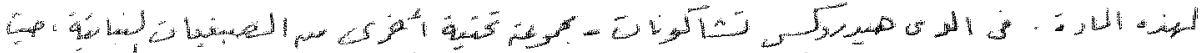
ن Sy

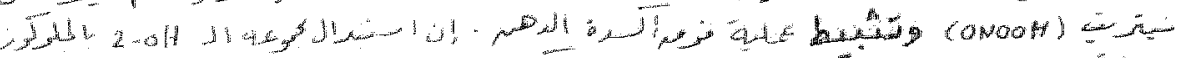

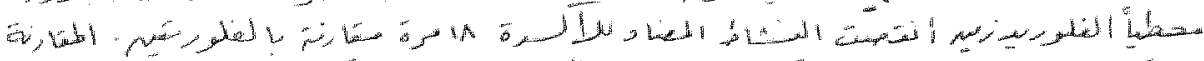

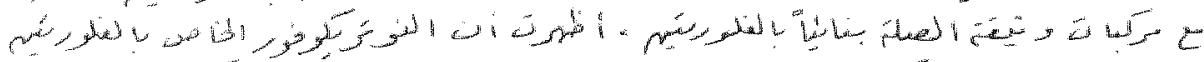
a

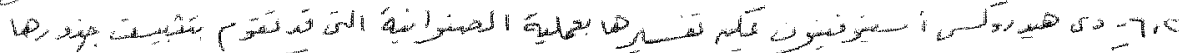

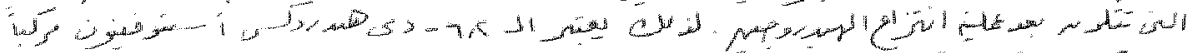

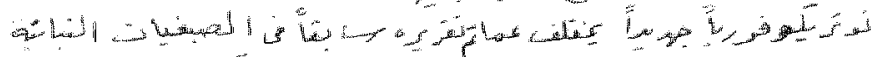

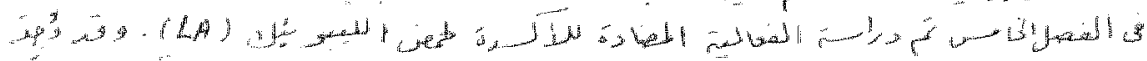

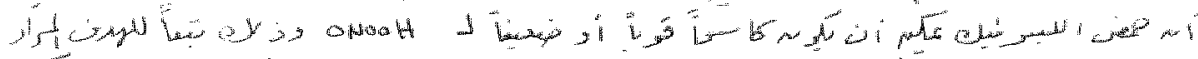

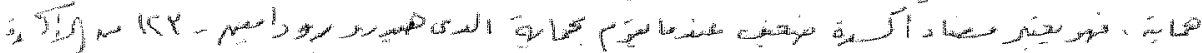
g.t.

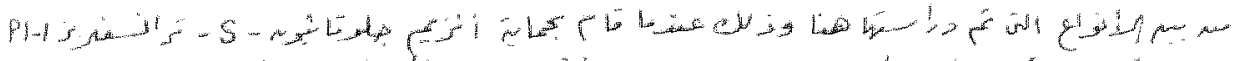

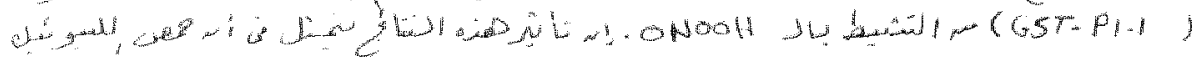

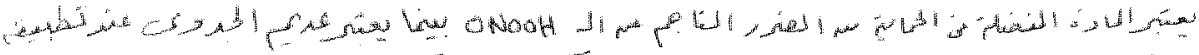

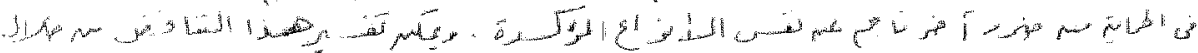

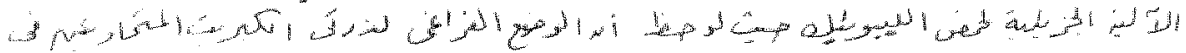




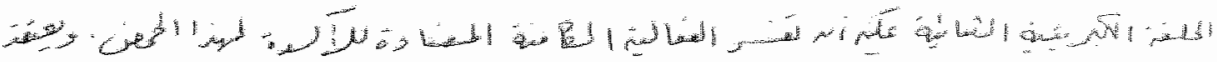

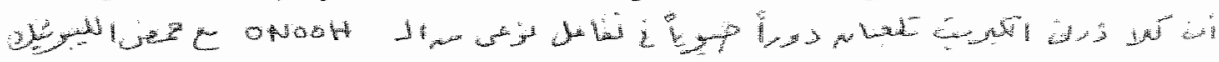

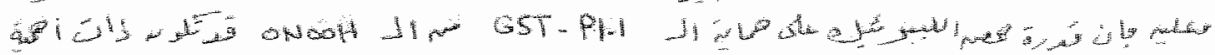
det

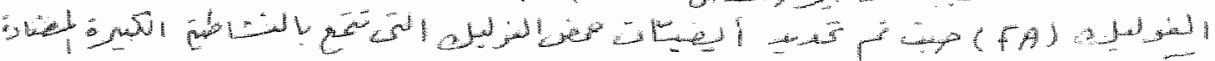
तथ

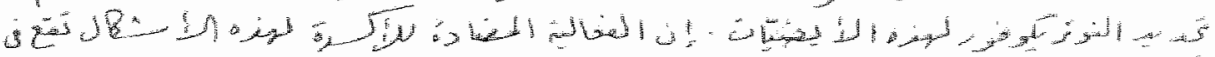

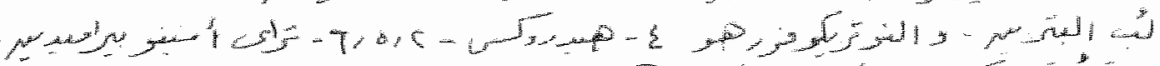

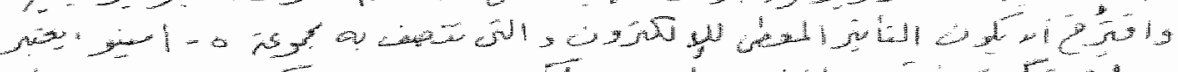

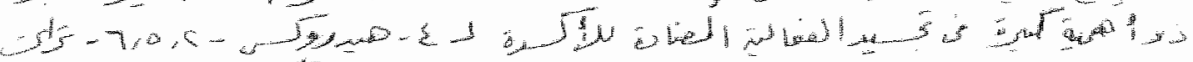
able

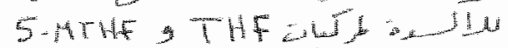

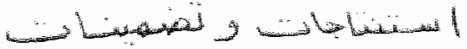

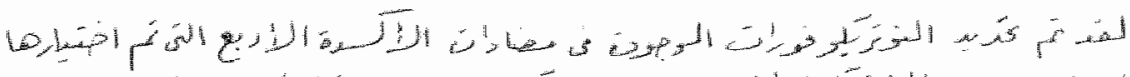

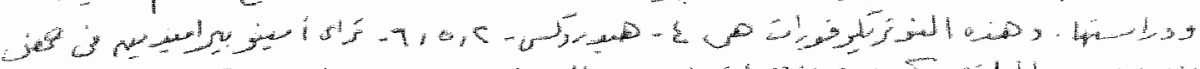

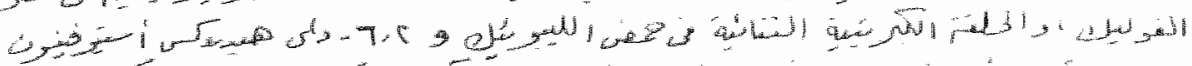

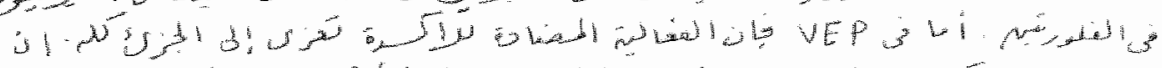

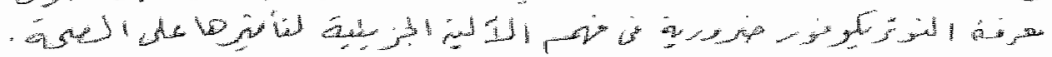

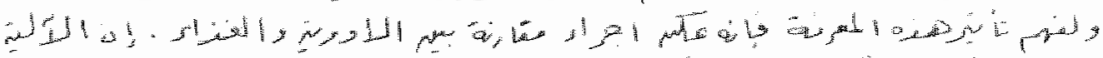

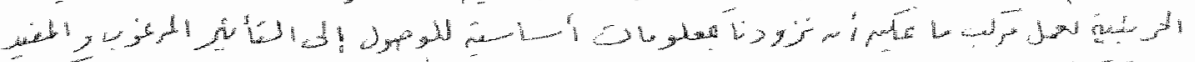

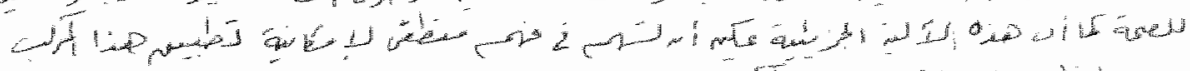

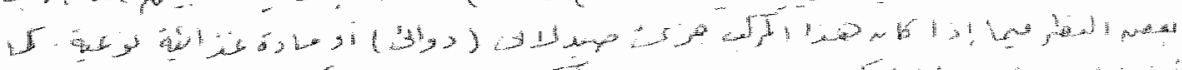

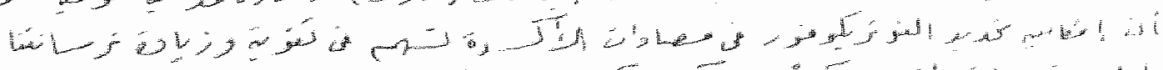
(b)

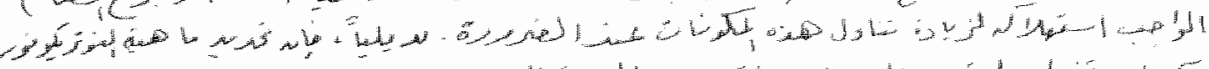

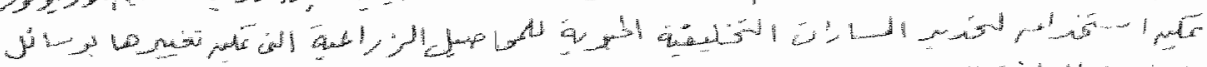

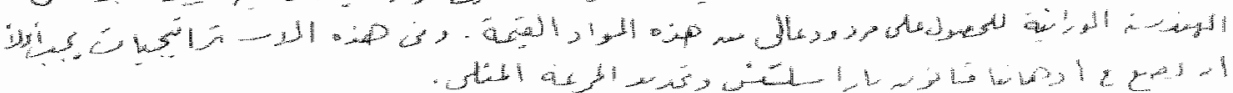


W

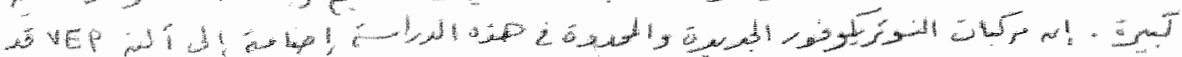

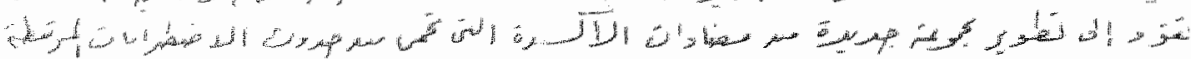

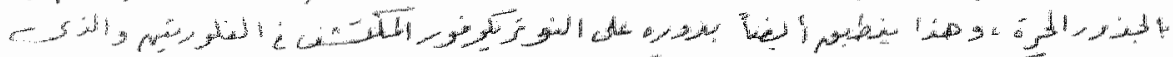

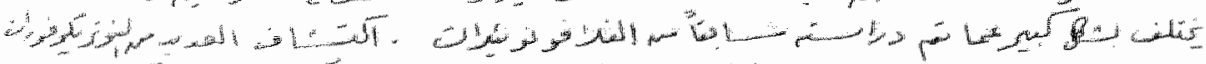

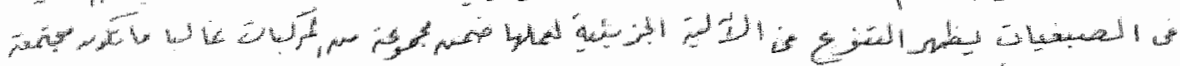

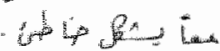

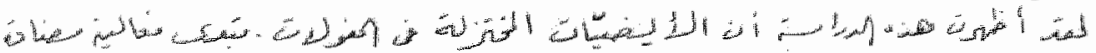

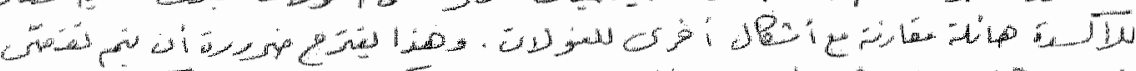

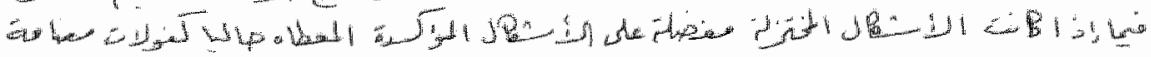

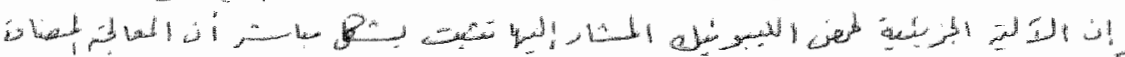

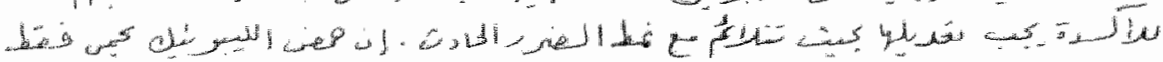

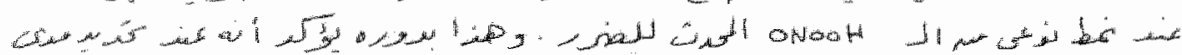
a Lill

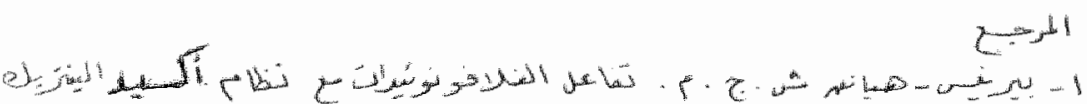
. 


\section{List of publications}

Sayed-Ahmed MM, Shouman SA, Rezk BM, Khalifa MH, Osman AM, El-Merzabani MM. Propionyl-L-carnitine as potential protective agent against adrianycin-induced impaiment of fatty acid beta-oxidation in isolated heart mitochondria. Phamacol Res. $2000 ; 4: 143-50$.

Rezk BM, Haenen GRMM, van der Vijgh WJF, Bast A. The antioxidant activity of phloretin: the disclosure of a new antioxidant pharmacophore in flavonoids. Biochem Biophys Res Commun. 2002; 295: 9-13.

Rezk BM, Haenen GRMM, van der Vijgh WJE, Bast A. Tetrahydrofolate and 5methyltetrahydrofolate are folates with high antioxidant activity. Identification of the antioxidant pharmacophore. FEBS Lett. 2003; 555; 601 -5.

Rezk BM, Haenen GRMM, van der Vijgh WJF, Bast A. Lipoic acid protects efficiently only against a specific form of peroxynitrite-induced damage. $J$ Biol Chem. 2004; 279 : 9693-7.

Rezk BM, Haenen GRMM, Van Der Vijgh WJF, Bast A. The extraordinary antioxidant activity of vitamin E phosphate. Biochim Biophys Acta. 2004; 1683: 16-21.

Rezk BM, Haenen GRMM, Van Der Vijgh WJF, Bast A. Vitamin E phosphate is a novel apoptotic agent. (Submitted)

Rezk BM, Haenen GRMM, Van Der Vijgh WJF, Bast A. Antioxidants and their metabolites: Some toxicological aspects. (Review, in preparation)

\section{Posters}

Rezk BM, Haenen GRMM, Van Der Vijgh WJF, Bast A. The extraordinary antioxidant activity of vitamin $\mathrm{E}$ phosphate. Proceedings of the annual meeting of the Cardiovascular Research Institute Maastricht (CARIM) (28 November 2001)

Rezk BM, Haenen GRMM, van der Vijgh WJF, Bast A. The antioxidant activity of phloretin: the disclosure of a new antioxidant phamacophore in flavonoids. Ist workshop, European Graduate School, Molecular Mechanisms of Food Toxicology (7-8 November 2002) 
Rezk BM, Haencn GRMM, van der Vijgh WJF, Bast A. Identification of the antioxidant pharmacophore in tetrahydrofolate and 5-methyltetrahydrofolate. Proceedings, 2nd Seminar, European Graduate School of Toxicology. 28 October 2003

Rezk BM, Haenen GRMM, van der Vijgh WJF, Bast A. Lipoic acid protects efficiently only against a specific form of peroxynitrite-induced damage. Proceedings of the Jubilee Annual Meeting of the Netherlands Society of Toxicology, 10-1.1 June 2004 


\section{Acknowledgements}

Praise is to Allah, who guided and supported me to do this thesis and bring it to light. Indeed, I would never have succeeded without the guidance and support of Allah.

First of all, my cordial thanks go out to my father and his colleagues, Mr. Fawzy Tawfieq, Mr. Rezk Kamal, Mr, Husain Hasanien and Shikh Abd El-Mohsen El-Feqy. Thoy did hard efforts to collect donations to build my primary school (Al-Sabria's school, ELBeheira, Egypt). This school is located in a small village that is very close to my hometown. The distance is about $0.5 \mathrm{~km}$ compared to $5 \mathrm{~km}$ of the nearest primary school that was available for us at that time. Of course, my primary education started at this school. Historically, this school began with four classrooms and four teachers including the chairman. Currenty, this school consists of 20 classrooms and more than 30 teachers and employees.

In this way my journey to get the PhD degree started at the Sabria primary school that will end at the Faculty of Medicine, Maastricht University. This journey included my education and graduation at the Dr. Taha Husain prep school, Damanhour secondary military school, Faculty of Science, Cairo University and National Cancer Institute, Cairo University. During this educational joumey, many teachers and professors played. very important roles in my life, especially, Mr. Fawzy Tawfeiq, Shikh Abd El-Maqsoud, Mr. Kamal Abd El-Nour, Mr. Ali Farahat, Prof. dr. Maher Khalifa, prof. dr. Tahany ElMamlouk, dr. Hafez Farouq dr. Rafaat El-Awady, prof. dr. Mohamed Sayed, prof. dr. Abd El-Hady Abd El-Wahab, prof. dr. Samia Shouman, prof. dr. Mohamed Moneer, prof. dr. Tareq Mansour, prof: dr. Abd El-Moneim Osman, prof. dr. Abd El-Baset ElAasar and prof. dr. Mahmoud El-Merzabani.

Special gratitude and appreciation to prof. dr. Aalt Bast for his kindness and parentally encouragement. He has given me an unlimited support during ny PhD project and my life in Maastricht. Prof. Aalt taught me how to think scientilically, how to apply these ideas practically and how to sell these data for publication. Importantly, he reared me under his eyes.

I am deeply grateful to prof. dr. Wim J.F. van der Vijgh for his tremendous advice and motivation that helped me to complete this thesis. He was a referec for my Master thesis and he introduced me as a PhD student to prof. Aalt Bast. Actually my dear friend dr. Mohamed Abou El-Hassan played an important role to help me in the process of travelling to Holland.

Special words of thanks are for dr. Guido R.M.M. Haenen, a pioneer supervisor, for his kindness, encouragement and critical reading of my book. The perfect and shrewd revisions of dr. Guido were not only scientific but were also a very nice symphony of arts. Many of his ideas form the basis of my thesis. 
My appreciations should be expressed to all the members of the department of Pharmacology and Toxicology, especially prof. dr. Harry Struijker-Boudier and prof. dr. Jos Smits for their hospitality during my research in the department. 1 am also much indebted to the secretaries of the department of Pharmacology and Toxicology, Mia Hogenboom, Els Geutts and Marielle Hensing-Beckers for their kind assistance. I would like to express my deep gratitude to Maud Senden in the Office of International Relations, Faculty of Medicine, for her nice assistance when I was in Egypt.

My sincere thanks go out to my colleagues of the laboratory of Toxicology, Agnes Boots, Mariken Arts, dr. Rachel van Haaften, Els Kosters, dr. Chantal Beerens-Heijnen, Liesbeth Geraets, Saskia Rietjens, Agon Vllasaliu, Marc Fischer, Marie-José Drittij, dr. Gertjan den Hartog, Els Swennen, for their kind and friendly relationships. Certainly, I will never forget how Gertjan and Leo Baars coached me in bicycling. Gertjan also helped me in preparing of the layout of this thesis. Really, I appreciate the helpfulness of Agnes, Mariken and Marc during my stay in Maastricht. I would also like to thank the colleagues of the department of Health Risk Analysis and Toxicology, Faculty of Health Sciences, especially, dr. Harald Moonen, dr. Marcel van Herwijnen, dr. Geja Hageman, Danitsja van Leeuwen, Ralph Gottschalk and Lou Maes for their kind help during my work in their laboratory. Of course, I will keep in mind the advice of Marcel on DNA!

I am grateful to Mr. Amr Khalled, originator of the programme 'Life Makers' on TV, for his inspiration, encouragement and enthusiasm. Amr Khaled has more than one million viewers. He has planted optimism and happiness in us. Importantly, I have been involved in the project of 'Life Makers'. My co-operation was on the development of scientific research in Egypt and other Arabic countries over almost 20 years. I hope that the Minister of the high education and the scientific research in Egypt, prof. dr. Amr Salama, will take a positive decision on my plan for this development.

I would also like to express my appreciation to Arabic and Islamic friends and their families in Maastricht, Mr. Fadel Burshan, dr. Malek El-Abbasi, dr. Abd El-Aziz ElKak, dr. Raed Al-Dieri, dr. Amr Ali, Mohamed Wahdan, Ayman Khedr, Mohamed E1Shahal, Yasser El-Tayeb, Muslataq Khan, Abd El-Qader Bennaghmouch, Fawzy Babiker, dr. Mohamed Mukhayer, dr. Khaled Habbani, dr. Adel Jbinouf, El-Shiekh Hassan, Mohamed El-Sajiad, Al-Bashir Al-Hebri, Sahal Ibrahim and Thab Abd El-Rahman, for their continuous encouragement. They created a familiar and harmonised amosphere for me, in which I never felt lonely.

Importantly, I an also indebted to my Egyptian friends, dr. Hassan Emara, dr. Zakaria Abd El-Ghaffar, Hamdy Abou Zaid, Shady Abd El-Rahman, Magid El-Qady, Rabea Sinhabi, Wael Yassin, Salah Shaban, Emad Hamdy, Ahmed Aaref, Ahmed Abd ElAziz, Ahmed Ramadan, Tareq El-Dieri, Wael Abd El-Moneim, Eed Ibrahim, Medhat Awad, Awad-Allah Mohye El-Dien, Ibrahim Abou Ashier, El-Sayed Anwar, Abd El- 
Hady Abd El-Sadiq, Khaled Mamdouh, Ahmed Hasanien, Sherief Autaian and Salah Tawfieq, for keeping in contact and their prayers during the last three years. 1 am also grateful to other brothers and sisters in Egypt I would like to mention, but the limited number of pages of the acknowledgement prevents me to do so. I leave my thankfulness to them to Allah.

Last but not least, words cannot express my feelings for my mother. She has sacrificed a lot for me. Her love and encouragement were the motor, which gave me the power to complete my journey to get the PhD degree. Likewise, my cordial thanks go out to my brothers and sisters, Gamal, Mohamed, Wagieh, Karem, Samia, Fatema and Mahmoud, for their support and love. Actually, I consider Fatema not only to be my sister but also my daughter. Finally, I am grateful to my big family (Abd El-Salam's family) and all other families in my village. 



\section{Curriculum Vitae}

Bashir Mahmoud Rezk was born in 1972 on January 23, at El-Beheira, Damanhour, Egypt. In May 1995, he acquired his B.Sc. degree from the Faculty of Science, Cairo University. He received a scholarship for the Master program of the Acadenry of Scicntific Research and Technology in the Pharmacology and Experimental Oncology Unit, National Cancer Insititute, Cancer Biology Department, Cairo University (1996-1999). He studied the effect of propionyl-L-carmitine on adriamycin-induced cardiotoxicity. This study was supervised by Assistant prof. dr. Mohamed M. Sayed-Ahmed, Prof. dr. Samia A. Shouman and prof. dr. Maher H. Khalifa. He successfully passed in the premaster courses in physiology, Faculty of Science, Cairo University (October, 1997). In 1998, he was awarded the Mowled Nabawy Prize which he received from Mr President Mohamed Hosny Mubarak, President of the Arab Republic of Egypt. In 1999, he lef his work as a joumalist in the Egyptian Press after almost 2 years. In July 2000 he obtained his master degree in comparative physiology, Cairo University. From 2000 till 2001 he was responsible for the project of Experimental Therapy in the unit of Pharmacology and Experimental Oncology, National Cancer Insititute. In May 2001, he obtained a scholarship for a Ph.D. program in the field of human toxicology from the Foundation on Prevention and Treatment of Chronic Diseases, in the Department of Ptharmacology and Toxicology, Faculty of Medicine, Maastricht University, The Natherlands. This work has resulted in the present Ph.D. thesis. The research described in the thesis was supervised by dr. Guido Haenen, prof. dr. Wim van der Vijgh and prof. dr. Aalt Bast. 



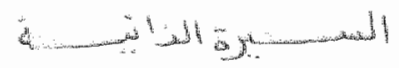

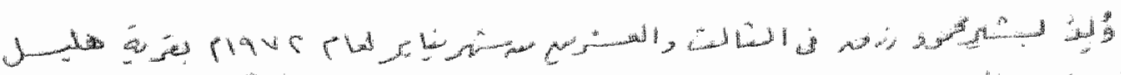

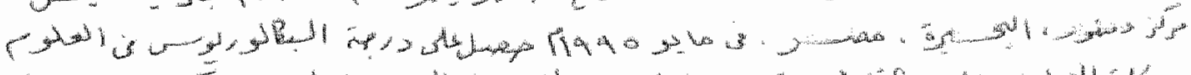

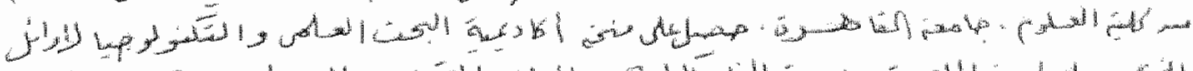

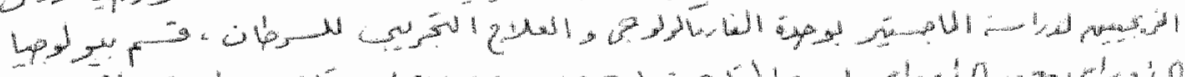

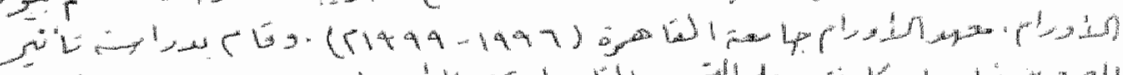
Ex

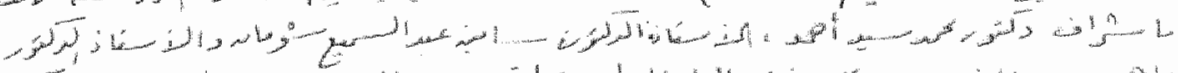
से

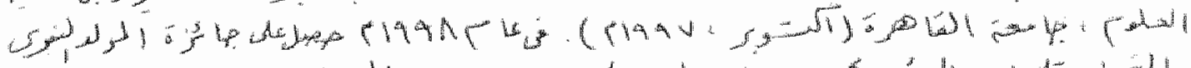
d)

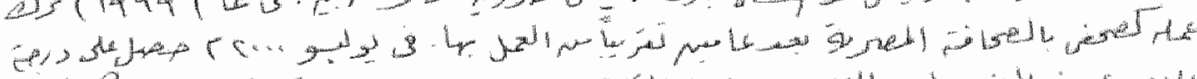

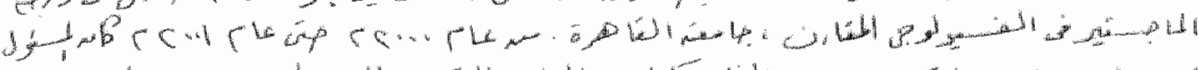

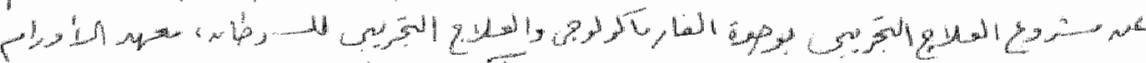

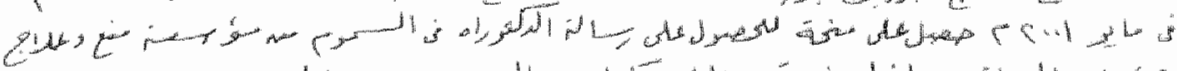

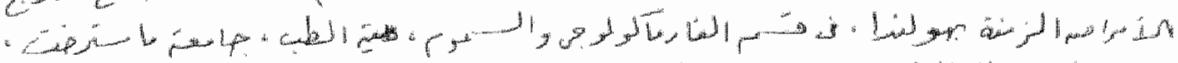

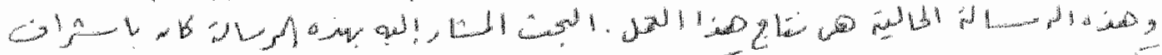
- 